\title{
Inhibition of ITK differentiates GVT and GVHD in allo-HSCT
}

Mahinbanu Mammadli1, Weishan Huang2,7, Rebecca Harris1, Aisha Sultana1, Ying Cheng3, Wei Tong3, Jeffery Pu4, Teresa Gentile4, Jessica Henty-Ridilla5, Shanti Dsouza6, Qi Yang6, Avery August7, Alaji Bah8, and Mobin Karimi1.*.

1Department of Microbiology and Immunology, SUNY Upstate Medical University, Syracuse, NY 13210.

${ }_{2}$ Department of Pathobiological Sciences, School of Veterinary Medicine, Louisiana State University, Baton Rouge, LA 70803.

3Division of Hematology, Children's Hospital of Philadelphia, Philadelphia, PA 19104.

4Department of Hematology, SUNY Upstate Medical University, Syracuse, NY 13210.

5Department of Cell \& Developmental Biology, SUNY Upstate Medical University, Syracuse, NY 13210.

6Department of Immunology and Microbial Disease, Albany Medical College, Albany, NY 12208.

7Department of Microbiology and Immunology, College of Veterinary Medicine, Cornell University, Ithaca, NY 14853.

8Department of Biochemistry and Molecular Biology, SUNY Upstate Medical University, Syracuse, NY 13210.

To whom correspondence should be addressed:

*Mobin Karimi

Assistant Professor of Immunology and Microbiology

SUNY Upstate Medical University,

766 Irving Ave Weiskotten Hall Suite 2281,

Syracuse, NY 13210

Office Phone: 315-464-2344

Laboratory Phone: 315-464-7652

Email: karimim@upstate.edu

Key Points:

- Inhibiting ITK by a novel peptide significantly reduces GVHD but retains GVT.

- ITK deficient donor T cells exhibit minimal GVHD, but maintain GVT activity.

- ITK deficient donor T cells exhibit significantly reduced production of inflammatory cytokines and migration to GVHD target organs.

- Eomes is required for GVT effect. 


\begin{abstract}
Allogeneic hematopoietic stem cell transplantation is a life-saving treatment for many malignant and nonmalignant diseases. Donor T cells contained within the graft prevent tumor recurrence via graft-versus-tumor (GVT) effects, however, also cause graft-versus-host disease (GVHD). Novel treatment strategies are therefore needed to allow maintenance of GVT while suppressing GVHD. Here we show using murine models, that targeting IL-2-inducible T cell kinase (ITK) in donor T cells reduces GVHD while preserving the beneficial GVT effects. Donor T cells from Itk-/- mice exhibit significantly reduced production of inflammatory cytokines and migration to GVHD target organs such as liver and small intestine, while maintaining GVT efficacy against primary B-ALL tumors. Itk-/ T cells exhibited reduced expression of IRF4 and decreased JAK/STAT signaling activity, but preserved cytotoxicity, which was accompanied by upregulation of Eomesodermin (Eomes), which was necessary for GVT function. A novel peptide inhibitor ITK signaling is also able to prevent GVHD. This novel peptide inhibitor also reduced cytokine production in mice and human T cells. Altogether, our data suggest that inhibiting ITK could be a therapeutic strategy to reduce GVHD while preserving the beneficial GVT effects following allo-HSCT treatment.
\end{abstract}




\section{Introduction}

Allo-reactive donor $\mathrm{T}$ cells present in the graft are required for donor stem cell engraftment and are essential for anti-tumor activity (graft-versus-tumor: GVT)1,2, but the same donor T cells also cause significant tissue damage to the host known as graft-versus-host disease (GVHD)3. This remains the most significant obstacle to the broader application of allogeneic hematopoietic stem cell transplantation (allo-HSCT), a life-saving treatment for many malignant and nonmalignant diseases. Standard immunosuppressive therapy for GVHD is often therapeutically sub-optimal and predisposes patients to opportunistic infections such as Cytomegalovirus (CMV) and relapse of the underlying malignancy4, 5. Thus, specific signaling pathways that can be targeted to allow the effects of GVT to occur while inhibiting GVHD need to be identified.

The Tec family nonreceptor tyrosine kinase, Interleukin-2-inducible T cell kinase (ITK), regulates activation of T cells downstream of $\mathrm{T}$ cell receptor (TCR) and has been shown to be involved in the activation of intracellular calcium signaling and MAPK pathways, and polarization of actin cytoskeleton, supporting an integral role for ITK in T cell activation and function6, 7. ITK regulates T cell signaling by participating in a multimolecular proximal signaling complex, which includes the adaptor SH2 domain-containing leukocyte protein of 76 $\mathrm{kDa}$ (SLP76)8, 9. In particular, ITK interacts with tyrosine residue 145 (Y145) of SLP76 when phosphorylated, and a Y145F mutation of SLP76 leads to defective TCR-mediated ITK activation10. Interaction between SLP76 and ITK not only influences signals leading to cytokineproduction by $\mathrm{T}$ cell populations, but also regulates the development of distinct innate type cytokine-producing $\mathrm{T}$ cell populations in the thymus11,12,13, referred to as innate memory phenotype (IMP) T cells. 
Since activation, expansion, cytokine production, and migration of alloreactive donor $\mathrm{T}$ cells to target organs are hallmarks of GVHD 14,15 , and ITK is involved in these T cell activities. Here we used several distinct but complementary models, including Itk-/- mice, SLP76 Y145F knock-in (SLP76 Y145FKI) mice, and a newly developed ITK-specific inhibitory peptide to investigate the therapeutic potential of targeting ITK signaling in donor T cells for the separation of GVHD and GVT. Using allo-HSCT models from C57Bl/6 mice to BALB/c mice to examine GVHD and GVT by T cells from Itk -/ or SLP76 Y145FKI mice6, 8, we found that both CD4+ and CD8+ T cells transplanted from ITK signaling deficient mice did not induce GVHD, but retained GVT function compared to T cells from wild type (WT) mice. WT bone marrow derived T cells exhibited GVT effect but eventually caused GVHD. Furthermore, while IMP T cells derived from Itk-/ bone marrow cells were able to clear the tumor without inducing GVHD, T cells from IL-4 receptor and ITK double knockout (Itk/Il4ra DKO) which lack this phenotype also did not induce GVHD, indicating that absence of ITK, and not IMP cells, is responsible for reduced GVHD in the absence of ITK. Itk-- T cells also exhibited increased expression of perforin and Eomes, which are necessary for tumor killing. In addition, T cells from Itk-/ mice showed significantly reduced expression of pro-inflammatory cytokines and decreased tissue damage during allo-HSCT. A novel and specific ITK inhibitory peptide that prevents the SH2 domain of ITK from docking onto SLP76 at tyrosine 145 position (SLP76pTYR), specifically inhibited the phosphorylation of ITK and downstream signaling molecules including PLC $\gamma$ and ERK, without affecting the phosphorylation mTOR, P13K or AKT. SLP76pTYR also enhanced the development of FoxP3+ Treg cells. SLP76pTYR also significantly reduces IFN- $\gamma$ and TNF$\alpha$ by T cells from human GVHD patients. Finally, this novel specific peptide significantly reduces GVHD pathophysiology but maintained GVT function in an allo-HSCT major mismatch 
bioRxiv preprint doi: https://doi.org/10.1101/2020.07.15.204693; this version posted July 15, 2020. The copyright holder for this preprint (which was not certified by peer review) is the author/funder. All rights reserved. No reuse allowed without permission.

model. Our studies therefore identify a specific and novel potential therapeutic target for separating GVHD and GVT after allo-HSCT, with potential in other T cell mediated diseases. 


\section{Results}

\section{Ablation of ITK retains GVT effect but avoids GVHD during allo-HSCT.}

To determine whether TCR-mediated activation of ITK impacts GVHD pathogenesis after alloHSCT, we examined the effects of ITK signaling on donor CD4+ and CD8+ T cells in allotransplant models, utilized C57Bl/6 mice (MHC haplotype b) as donors and BALB/c mice (MHC haplotype d) as recipients. To induce GVHD, we used MHC-mismatched donors and recipient, utilizing T cell-depleted bone marrow cells from B6.PL-Thyla/CyJ (Thy1.1) mice, along with T cells from C57BL/6 (B6) WT or Itk-/- mice injected into irradiated BALB/c mice along with BALL-luc cells. Lethally irradiated BALB/c mice were injected intravenously with $5 \times 106$ wildtype (WT) T cell-depleted donor BM cells along with 1×106 FACS-sorted donor T cells $(1 \times 106 \mathrm{CD} 8+$ and $1 \times 106 \mathrm{CD} 4+)$, followed by intravenous challenge with $2 \times 105$ luciferaseexpressing primary tumor cells B-ALL-luc blast cells as described16. Recipient BALB/c mice were monitored for tumor growth using IVIS for over 60 days (Fig. 1A). While tumor growth was observed in T cell-depleted BM-transplanted mice without T cells, tumor growth was not seen in mice transplanted with T cells from either WT or Itk-/ mice. As expected, mice transplanted with WT T cells cleared the tumor but suffered significantly from GVHD. By contrast, mice transplanted with $I t k$-/ T cells cleared the tumor and displayed minimal signs of GVHD. Most animals transplanted with Itk-/ T cells survived for more than 65 days post-alloHSCT (Fig. 1B), with significantly reduced weight loss and clinical scores compared to those transplanted with WT T cells (scored based on weight, posture, activity, fur texture, and skin integrity as previously described17, Fig. 1C-D). BALB/c mice transplanted with WT T cells suffered from GVHD, while mice transplanted with Itk-/ T cells survived for $>65$ days postHSCT and tumor challenge with minimal signs of GVHD (Fig. 1E). 
Donor CD8+ T cells are more potent than CD4+ $\mathrm{T}$ cells in mediating GVT effects, but both CD4+ and CD8+ T cells mediate severe GVHD in mice and humans 18, 19. To determine whether CD4+ T cell-intrinsic ITK signaling might be sufficient to induce GVHD, we repeated the same experiments using purified CD4+ T cells from either WT or Itk-/ mice in the MHC-mismatch mouse model of allo-HSCT (B6 $\rightarrow$ BALB/c) (Sup. Fig. 1A-C). Recipients of WT CD4+ T cells exhibited greater weight loss and mortality compared to mice receiving T cell-depleted bone marrow (TCDBM) cells alone (Sup. Fig. 1B). In contrast, recipients of TCDBM mixed with Itk-/CD4+ T cells had limited signs of GVHD, with greatly reduced mortality and clinical scores, indicating that CD4+ T cell-intrinsic ITK signaling can contribute to the severity of GVHD (Sup. Fig. 1B-C). Our results indicate that ITK signaling is dispensable for anti-tumor immunity, but required for GVHD. Given the role of SLP76 in regulating ITK signaling, we next tested whether the GVT effect described above would remain intact when allo-HSCT was performed with T cells from SLP76 Y145FKI mice, which have a disrupted ITK signaling8. We used CD8+ T cells, and CD4+ T cells mixed at 1:1 ratio as donors as shown in Figure 1. Lethally irradiated $\mathrm{BALB} / \mathrm{c}$ mice were transplanted with T cell-depleted BM (TсDBM) alone, or together with FACS-sorted CD8+ T cells from either C57B1/6 WT or SLP76 Y145FKI mice, and challenged intravenously with B-ALL-luc tumor cells. While tumor growth was observed in TCDBMtransplanted mice without T cells, tumor growth was not seen in mice transplanted with either WT or SLP76 Y145FKI T cells. Notably, mice transplanted with WT T cells suffered from GVHD, while mice transplanted with SLP76 Y145FKI T cells survived for $>65$ days postHSCT and tumor challenge with minimal signs of GVHD and (Sup. Fig. 2A-E). To determine whether tumor clearance by SLP76 Y145FKI CD8+ T cells was limited to B-All-luc cells, we performed a similar experiment using intravenously injected luciferase-expressing A20 luc cells 
20, 21. A20 luc cells failed to grow in mice that were transplanted with either WT or SLP76

Y145FKI CD8+T cells (Sup. Fig. 2). Next, we tested purified Itk-/- or SLP76 Y145FKI CD4+ T cells in the same model (Sup. Fig. 1D-F). When we used SLP76 Y145FKI CD4+ T cells, only 2 out of 10 mice developed GVHD, while all animals that received WT T cells had to be euthanized due to GVHD. Mice transplanted with SLP76 Y145FKI CD4+ T cells also exhibited reduced weight loss and clinical symptoms of GVHD (Sup. Fig. 1D-F).

\section{The regulatory function of ITK in GVHD is T cell-intrinsic}

The innate memory phenotype (IMP: CD44hiCD122hi) of Itk-/ CD8+ T cells arises in the thymus during development, as opposed to memory CD8+ T cells that are also CD44hi, but largely arise in the periphery of WT mice in response to foreign antigens or due to homeostatic proliferation 13, 22. We examined pre-transplanted CD8+ T cells for CD44 expression, and observed that Itk-/CD8+ T cells expressed substantially higher levels of CD44 compared to CD8+ T cells from WT mice (Fig. 2A). We sought to understand whether the emergence of IMP is sufficient to separate GVHD from GVT. To test this, we generated WT IMP T cells using a mixed-bone marrow approach in which T cell-depleted BM from WT and Itk-/- mice were mixed at a 3:1 (WT: Itk-/-) ratio23. The irradiated syngeneic (B6) Thy 1.1 hosts were reconstituted with this mixture of T cell-depleted CD45.2+ WT and CD45.1+Itk-/ BM cells, along with a control group receiving mixed CD45.2+ WT and CD45.1+ WT BM cells (Fig. 2B). WT BM-derived CD8+ thymocytes that develop in such mixed BM chimera acquire an IMP phenotype due to their development in the same thymus as the Itk-/ T cells23, which we also observed in our experiments (Fig. 2B)13, 22. After reconstitution of the T cell compartment 10 weeks later, T cells derived from WT (CD45.2+Thy1.1-) and Itk-/ (CD45.1+) donor cells were sorted from the bone marrow chimeras. 
These sorted T cells were transplanted into irradiated BALB/c mice along with TCDBM in the allo-HSCT model as described above, and tested for their function in GVHD and GVT. Analysis of the BALB/c recipients of these different IMP CD8+ T cells indicates that WT IMP cells were not able to separate GVT from GVHD effects (Fig. 2C-G). Thus, the appearance of IMP is not sufficient to separate GVHD from GVT; other mechanisms are also essential for the protective effects of ITK deficient T cells.

\section{Eomes expression but not innate memory phenotype $\mathbf{T}$ cells is required for GVT effect.}

Itk-/ CD8+ T cells exhibit attenuated TCR signaling and an innate memory phenotype (IMP)23, as indicated by expression of high levels of CD44, CD122, and a key transcription factor Eomes

(Fig. 3A). To examine how these IMP T cells from Itk-/- mice mount GVT responses, we utilized the MHC-mismatch mouse model of allo-HSCT (WT, Itk-/ $\rightarrow$ BALB/c, i.e., H2 $\mathrm{Kb}_{\mathrm{b}+} \rightarrow \mathrm{H} 2 \mathrm{~K}_{\mathrm{d}+}$ ). We then sorted B6 $\left(\mathrm{H} 2 \mathrm{~K}_{b+}\right)$ T cells from recipient mice and determined their cytotoxicity against BALL-luc cells. We found that these cells effectively killed primary tumor cells in vitro, even in the absence of ITK (Fig. 3B). Moreover, we observed significantly increased expression of perforin in CD8+ T cells from Itk-/ mice compared to T cells from WT mice in the absence of activation (Fig. 3C). Our findings demonstrate that CD8+ T cells from Itk-/ mice have enhanced activation markers, and exert cytotoxicity against primary tumor cells.

IL-4 is known to upregulate Eomes13, 24, which we verified by comparing T cells from WT and Itk/Il4ra double KO (DKO) mice. Removing IL-4 signaling from the Itk-/ mice led to decreased expression of Eomes compared to T cells from WT mice (Fig. 3D). Next we used the allo-HSCT model, where T cells from WT or Itk/Il4ra DKO were transplanted into irradiated BALB/c mice. 7 days post transplantation, WT or Itk/Il4ra DKO T cells were then sorted from 
the $\mathrm{BALB} / \mathrm{c}$ recipient mice and Eomes expression by these donor $\mathrm{T}$ cells determined. We observed that upon allo-activation, the donor WT or Itk/Il4ra T cells still show increased Eomes expression (Fig. 3D) (Sup. Fig. 3). Next, we tested the function of Itk/Il4ra DKO T cells in long term allo-HSCT model. WT or Itk/Il4ra DKO BM were transplanted into irradiated BALB/c for GVHD and GVT studies. We observed that donor T cells from Itk/Il4ra DKO mice did not induce GVHD, and most of the animals survived compared to recipient mice that received donor T cells from WT mice (Fig. 3E). BALB/c transplanted with Itk/Il4ra donor T cells also had much less weight loss and significantly better clinical scores compared to BALB/c mice transplanted with WT donor T cells (Fig. 3F-G). Furthermore Itk/Il4ra DKO donor T cells cleared tumor without inducing GVHD (Fig. 3H). This data demonstrated that IMP CD8+ cells may not be important for GVHD, but that the loss of ITK is essential for GVHD and GVT.

To further investigate the role of Eomes in tumor clearance and in the cytotoxic function we crossed SLP76Y145FKI mice with Eomesflox/flox and crossed these mice with CD4cre to delete the Eomes specifically in T cells10,25. To obtain ex vivo activated cells, we performed similar allo-HSCT experiments as described above, and additionally used T cells from WT or SLP76Y145FKI mice with or without Eomes. 7 days post-transplant, donor T cells were sorted as described by $\mathrm{H} 2 \mathrm{~Kb}$ positivity, and in vitro cytotoxicity assays were performed at 40:1 ratios. We observed that donor T cells lacking Eomes were unable to kill tumor targets (Fig. 3I). Next, we examined the role of Eomes in the allo-HSCT model. Lethally irradiated BALB/c mice were injected intravenously with $5 \times 106$ WT T cell-depleted BM cells along with $1 \times 106$ FACS-sorted CD8+ and CD4+ from either WT mice or SLP76Y145FKI Eomesflox/flox with or without CD4cre, followed by intravenous challenge with $2 \times 105$ luciferase-expressing primary tumor cells BALL-luc blast cells as described 16. Recipient animals transplanted with WT T cells cleared the 
tumors cells but developed acute GVHD (Fig. 3J). Recipient animals transplanted with T cells from SLP76Y145FKI Eomesflox/flox without CD4cre mice, however, cleared the tumors without showing signs of GVHD (Fig. 3L) and (Sup. Fig. 3B).. Notably, recipient animals transplanted with T cells from SLP76Y145FKI Eomesflox/flox with CD4cre mice were unable to clear the tumor and all died from tumor burden. This data provided further evidence that Eomes is required for the GVT effects (Fig. 3M).

\section{ITK deficiency results in reduced cytokine production.}

It is known that the conditioning regimen for allo-HSCT elicits an increase in the production of inflammatory cytokines by donor T cells, known as a "cytokine storm", and is considered one of the hallmarks of GVHD pathogenesis26. We obtained blood samples from GVHD patients and examined the levels of serum inflammatory cytokines such as IL-33, IL- $1 \alpha$, IFN- $\gamma$, TNF- $\alpha$ and IL-17A compared to healthy donors. We observed that patients with GVHD have significantly higher level of serum proinflammatory cytokines compared to healthy control (Fig. 4A). Next we assessed cytokine production by $I t k-$ - T cells in our allo-HSCT model (B6 $\rightarrow$ BALB/c), examining the levels of serum inflammatory cytokines such as IL-33, IL- $1 \alpha$, IFN- $\gamma$, TNF- $\alpha$ and IL-17A on day 7 post allo-transplantation (Fig. 4B). We found that serum IFN- $\gamma$ and TNF- $\alpha$ were significantly reduced in recipients that received $I t k-/ \mathrm{CD} 8+\mathrm{T}$ cells mice compared to those that received WT CD8+ T cells (Fig. 4B). Thus, we confirmed that the findings in our preclinical model correlated with human GVHD samples. We also isolated Itk-/- donor T cells from the secondary lymphoid organs of recipients using anti-H2 $\mathrm{Kb}$ antibodies (expressed by donor C57Bl/6 cells) and stimulated them with anti-CD3/CD28 (Fig. 4C), or PMA/ionomycin (to bypass the proximal signaling defect, (Sup. Fig. 4) in the presence of Brefeldin A, or left them 
unstimulated for 6 hours, followed by analysis of IFN- $\gamma$ and TNF- $\alpha$ cytokine production.

Compared to WT T cells, Itk-/ T cells were capable of producing IFN- $\gamma$ and TNF- $\alpha$ when T cell signaling was bypassed by re-stimulation with PMA and ionomycin (Sup. Fig. 4), however, they produced significantly less inflammatory cytokines when stimulated via TCR/CD28 (Fig. 4C, D). Next, we determined whether the reduction of cytokine production by Itk-/- donor T cells was due to cell-intrinsic or extrinsic factors. We mixed purified Itk-/ CD8+ T cells with purified WT CD8+ T cells at a 1:1 ratio and transplanted the mixed cells into irradiated BALB/c as described above. On day 7, donor $\mathrm{T}$ cells were isolated from recipient mice using $\mathrm{H} 2 \mathrm{~Kb}+$ and examined for IFN- $\gamma$ and TNF- $\alpha$ expression as described above. We found that WT donor CD8+ T cells produced higher levels of inflammatory cytokines than Itk-/ donor CD8+ T cells, suggesting that the reduced cytokine production observed by Itk-/ donor T cells is T cell-intrinsic (Fig. $\mathbf{4 E}$ ).

We next examined donor T cell proliferation using a BrdU incorporation assay. 7 days post allo-transplantation as described above, transplanted $\mathrm{T}$ cells were examined for proliferation by BrdU incorporation. Donor T cells from Itk-/ mice showed reduced proliferation compared to donor T cells from WT mice (Fig. 4F). To determine if the reduced proliferation of Itk-/- donor T cells was due to cell-intrinsic mechanisms, we mixed sort purified Itk-/- CD8+ T cells with purified WT CD8+ T cells at a 1:1 ratio, followed by transplantation as described above. Interestingly, no difference was observed in BrdU incorporation between WT and Itk-- donor T cells in the mixed transplant models, indicating that the reduced proliferation of donor Itk-/ T cells proliferation was due to cell-extrinsic effects (Fig. 4G). Thus, both cell intrinsic and extrinsic mechanisms regulate the behavior of Itk-- CD8+ donor T cells.

The transcription factor IRF4 has been shown to play critical roles in modulating TCR signaling, including TCR signal strength such as those regulated by ITK27, 28. The JAK/STAT 
signaling pathway is also critical for the response of $\mathrm{T}$ cells to cytokines29, 30, 31. To examine whether there was a differential signaling between WT and Itk-/ donor T cells in the GVHD and GVT model as determined by expression of IRF4 and JAK/STAT, we examined expression of IRF4, JAK1, JAK2 and STAT3 by purified T cells from spleen. Our data showed that Itk-/- donor T cells expressed significantly less IRF4, JAK1, JAK2, and STAT3 as well as phosphorylated forms of JAK1, JAK2 and STAT3 (Fig. 4H, I). Our data suggest that the lack of ITK expression affects the expression of IRF4, and the amount of cytokine signals the cells received. These data may explain the reduced cytokine production and proliferation in Itk-/ T cells observed above.

\section{ITK/SPL76-Y145 signaling axis is required for T cell migration to the GVHD target tissues.}

GVHD involves early migration of alloreactive $\mathrm{T}$ cells into the target organs, followed by $\mathrm{T}$ cell expansion and tissue destruction. Modulation of alloreactive T cell trafficking has been suggested to play a significant role in ameliorating experimental GVHD 32. Therefore, we examined the trafficking of donor T cells to GVHD target tissues as previously described 32. Irradiated BALB/c recipient mice were injected with CD8+ T cells from Itk-/ (CD45.2+) and WT C57B1/6 (CD45.1+) mice mixed at a 1:1 ratio (Fig. 5A), and 7 days post transplantation, recipient mice were examined for the presence of donor $\mathrm{T}$ cells in the spleen, lymph nodes, liver and the small intestines. While the WT: Itk-^ T cell ratio remained $\sim 1: 1$ in the spleen and lymph nodes (Fig. 5B), this ratio in the liver and small intestine was significantly elevated suggesting that Itk-/ T cells were defective in migration to and/or expansion in those tissues. Using histological staining for H\&E, we also observed significant leukocyte infiltration into GVHD target organs, liver skin and small intestine (SI)33, in WT T cell recipients but not in Itk-/- T cell recipients (Fig. 5C). As an alternative approach, we tracked $\mathrm{T}$ cells in allo-BMT mice by using donor CD8+ T cells from WT and Itk-/- mice that also express luciferase, which could be monitored by 
bioluminescence 27. We observed that donor T cells from Itk-/ had significantly impaired residency in GVHD target organs, including the liver and small intestine (SI), compared to WT, despite no differences in spleen and lymph nodes (Fig. 5D)33. We next examined donor T cell proliferation as described above. 7 days post allo-transplantation as described above, transplanted donor T cells in liver and small intestine of recipients were examined for proliferation by BrdU incorporation. Donor T cells from Itk-/ mice showed reduced proliferation compared to donor T cells in GVHD target organs from WT mice (Fig. 5E). In the mixed T cell transfer model, we had determined that Itk-/ T cell proliferation was comparable to that of WT cells; therefore, it is very likely that the reduced numbers of Itk-/ T cells in the liver and small intestine was due to impaired T cell trafficking. Pro-inflammatory conditioning treatment may promote T cell migration into GVHD target tissues 34,35. Indeed, in the same mixed T cell transfer model, we found that chemokine and chemokine receptor expression (Aplnr, Cxcr5, Accr2, CCL12, CCL2, CCL5, Ccr9, Ackr4, and Cmtm4) was also significantly reduced in Itk-/CD8+ T cells at day 7 post-transfer (Fig. 5F). These data suggest that $1 t k-/$ CD8+ T cells display attenuated chemokine receptor expression, which correlates with defective migration to GVHD target organs and target organ pathology.

Given that $I t k$-/ T cells exhibit defective migration to target organs of GVHD, we predicted that although Itk-/ T cells can clear tumor cells in the blood and secondary lymphoid organs, they would not be able to kill tumors that reside in tissues. To test this possibility, lethally irradiated BALB/c mice were BM-transplanted together with FACS-sorted WT or Itk-/CD8+ T cells, and challenged with subcutaneously injected B-All luc cells. Although Itk-/ CD8+ T cells did not cause GVHD, the subcutaneously injected tumors were cleared in mice transplanted with WT CD8+ T cells but not with Itk-/ CD8+ T cells (Fig. 5G-K). Together, these 
data suggest that the ITK signaling in T cells can separate GVHD from GVT effects, but only for tumors that reside in the circulation and in secondary lymphoid organs (such as hematologic malignancies).

\section{ITK differentially regulates gene expression in T cells during GVHD.}

As an unbiased approach to further explore differences between WT and Itk-/ CD8+ T cells, we employed RNA sequencing analysis to examine the differences in gene expression between WT and Itk-/ CD8+ T cells following allo-HSCT. We sort purified donor WT and Itk-^ CD8+ T cells (using $\mathrm{H}-2 \mathrm{~K}_{\mathrm{b}}$ antigen expressed by donor T cells) before and 7 days after they were transferred into irradiated BALB/c recipients, for RNA sequencing. Although WT and Itk-/ CD8+ T cells are distinct prior to transplantation due to the enhanced IMP in the absence of ITK, WT and Itk-/cells homed to the spleen post transplantation are similar as revealed by the fact that they clustered within a close proximity in the Principal Component Analyses (PCA) (Fig. 6A). We were unable to collect enough cells from the intestine of the Itk-/ T cell recipients, since they are deficient in homing to the intestine (Fig. 5E), however the WT T cells that home to the intestine (referred to as "Gut") exhibited significantly different transcriptomic profiles compared to Itk-/as revealed by the PCA (Fig. 6A). To further determine the differentially expressed genes that are unique in WT cells associated with their ability to home to the GVHD target organ (intestine or "Gut"), we compared the lists of genes that were up- or down- regulated after the cells were transferred into the recipients and homed to different organs. We found that genes that are up- or down-regulated in Itk-/- T cells isolated from the spleens of the recipients (Itk-/-Spl), as compared to $I t k$-/ pre-transplanted cells (Itk-/-Pre), have minimal overlap with those that are differentially expressed in WT cells homed to the gut (normalized to WT-Pre) (Fig. 6B\&C). Genes that are 
differentially expressed in WT T cells that were able to home to the GVHD target organ may reveal signals that are deficient due to the absence of ITK. We therefore extracted the list of genes that are up- or down-regulated in only WT T cells isolated from the gut of the recipients post transplantation (Fig. 6D shows 23 up-regulated and Fig. 6E shows 27 down-regulated genes). The differentially expressed genes between WT and Itk-/- donor T cells were enriched for transcripts encoding lymphocyte homing molecules such as adhesion molecules and chemokine signaling proteins, which might contribute to the defective homing capability of $I t k-$ - donor T cells (Fig. 6F). The results of critical gene that were differentially expressed were confirmed by q-RT-PCR (Fig. 6G). Using pathway enrichment analyses, our data also revealed a critical role for ITK in regulating genes involved in T cell cytokine/cytokine receptor interaction, cell adhesion, graft-versus-host disease, allograft rejection, and chemokine signaling pathways (Fig. 5F). These data suggest that ITK regulates the expression of signature genes associated with the homing of the transplanted cells into the GVHD targeted organs, while it does not have an apparent effect in $\mathrm{T}$ cell homing in the spleen. This may, in part, explain the ability of Itk-/ T cells to maintain GVT effects while being unable to home to the GVHD target organs and participate in GVHD.

\section{Novel peptide SLP76pTYR inhibitor specifically targets ITK signaling and enhances Treg}

cell development. Since Itk-/ T cells can separate GVHD from GVT, as can SLP76 Y145FKI T cells, we sought to disrupt ITK signaling with pharmacological agents. When we used several commercially available small molecule inhibitors, including 10n 36,37 and commercially available CTA056 38 and GSK2250665A39, we observed that these small molecules also inhibit several other kinases including mTOR and AKT, suggesting that these molecules were not specific 
(Sup. Fig. 5). We thus sought to design a novel inhibitor that specifically targets ITK signaling by preventing the SH2 domain of ITK from docking onto SLP76 at tyrosine 145 position. In our quest to generate a potent inhibitor of the ITK-SH2 domain:SLP76-pY145 interaction, we analyzed the physico-chemical and structural properties of the interface of the SH2 domain and SLP76-pY145 (Fig. 7A,B), since evolution usually selects for residues at specific protein: protein interfaces for certain properties40. To design a short peptide that can inhibit ITK via competitive bidding, we examined SLP76-Y145 region of SLP76 in our initial peptide inhibitor design. In addition, to avoid the unintended non-specific binding of our peptide to the more than hundred other SH2 domains (and/or to other unexpected targets) in vivo41. we incorporated as many distinctive features of the SLP76 region around the pY145 as possible, using as a guide, atomic resolution NMR spectroscopy structures of the SH2 domain of ITK, free and in complex with a short peptide containing a pTyr residue 40 (Fig. 7A). The SH2 domain of ITK contains complementary electrostatic surface, because the phosphotyrosine binding pocket as well as the surrounding surface groove are highly positively charged, suggesting that electrostatics most likely will play a key role in this interaction. We thus designed a novel SLP76145pTYR peptide to bind to the ITK SH2 domain in order to prevent ITK from docking onto SLP76 at tyrosine at 145 position. BLASTing 42 the peptide sequence of our novel peptide SLP76145pTYR peptide against the non-redundant human proteome also shows minimal identity with other proteins, suggesting that SLP76145pTYR and the SH2 domain interaction is unique, and most likely will be specific towards ITK signalling. To test this, we cultured T cells with FITC-conjugated SLP76pTYR, (FITC Dye) -132NEEEEAPVEDDADpYEPPPSNDEEA155(GRKKRRQRRRPQ) vehicle or nonspecific peptide (FITC Dye) 
using microscopy and flow cytometry. We observed that significant numbers of cells were positive for FITC (Fig. 7B, D-G). Next we examined whether the FITC label was localized in specific locations in the cell. We imaged the cells in a single focal plane near the cover glass, and observed that FITC was clustered in specific locations of the cell (Fig. 7E). ITK deficiency is known to enhance the development of regulatory $\mathrm{T}$ cells 43,44 , and we tested the peptide inhibitor to determine whether inhibition of ITK with SLP76pTYR would induce Tregs. Total mouse T cells were stimulated with anti-CD345 and in the presence of either SLP76pTYR or nonspecific peptide for 24 to 48 hours, and cells were harvested and examined for the presence of Tregs (CD4+CD25+FoxP3+). We observed significantly enhanced differentiation of Treg cells in T cell cultures treated with SLP76pTYR peptide compared to vehicle alone or nonspecific peptide (Fig. 8A-B). Next, we examined the signaling molecules that are specifically activated upon activation of ITK, including the phosphorylation of ITK, PLC $\gamma 1$, and ERK, and we observed significant reduction in the phosphorylation of these molecules compared to either vehicle alone or scramble peptide (Fig. 8C-D). Next we investigated the effects of SLP76pTYR peptide on human PBMC samples from GVHD patients and normal donors. T cells from these patients were stimulated with anti-CD3 (OKT3) for 24 hours in the presence of SLP76pTYR or nonspecific peptide. We observed there was significant reduction in the phosphorylation of PLC $\gamma 1$, slight reduction in pERK but no effect on pAKT and pMTOR (Fig. 8E-F), providing evidence that SLP76pTYR peptide has effects on both mouse and human T cells. Notably, SLP76pTYR peptide exhibited minimal off-target effects against other kinases including the mTOR, PI3K, and AKT (Fig. 8CF). Next we investigated the effects of SLP76pTYR peptide on the ability of human PBMC to produce proinflammatory cytokines. T cells from normal donors were stimulated with anti-CD3 (OKT3) and CD28 in the presence of SLP76pTYR or vehicle alone. We also examined T cells 
incubated with SLP76pTYR or vehicle alone in the presence of PMA+I in the presence of Brefeldin A. Our data shows that T cells stmulated with anti-CD3/CD28 show significantly reduced IFN- $\gamma$ and TNF- $\alpha$ when incubated in the presence of SLP76pTYR compared to those in the presence of vehicle alone (Fig. 8G). The cells also did not exhibit signs of apoptosis after 48 hours incubation with SLP76pTYR peptide, suggesting that this peptide does not induce general toxicity in the cells (Sup. Fig. 6).

\section{Inhibition of T cells by peptide SLP76pTYR allows tumor clearance without inducing}

GVHD. Next we evaluated the potential for peptide inhibitor of SLP76pTYR in modulating Itk in vivo $\mathrm{n}$ GVT vs GVHD as proof of principle for the approach. WT T cells CD8+ $\mathrm{T}$ and CD4+ $\mathrm{T}$ cells were mixed at 1:1 ratio transduced with retrovirus carrying SLP76pTYR or empty vector. Lethally irradiated BALB/c mice were transplanted with T cell-depleted BM (TCDBM) alone, or together with SLP76pTYR (or vector) transduced WT CD8+ and CD4+ T cells, and challenged intravenously with B-ALL-luc tumor cells. While tumor growth was observed in TCDBMtransplanted mice without T cells, tumor growth was not seen in mice transplanted with either untransduced T cells or T cells transduced with either empty viruses or SLP76pTYR. Notably, mice transplanted with untransduced $\mathrm{T}$ cells or $\mathrm{T}$ cells transduced with empty viruses suffered from GVHD, while mice transplanted with SLP76pTYR transduced T cells survived for $>40$ days post-HSCT and tumor challenge with minimal signs of GVHD and (Fig. 9A-E).

Altogether this data demonstrated that ITK signaling can separate GVHD from GVT. Inhibition of ITK by SLP76, specifically targeted ITK signaling, allows tumor clearance and minimizes development of GVHD. Finally, our novel peptide inhibitor of ITK is specific and has the potential to be used in a clinical setting for $\mathrm{T}$ cell-mediated disorders. 


\section{Discussion}

In this report, we demonstrate that the absence of the TCR-regulated kinase ITK significantly suppresses GVHD pathogenesis, while maintaining GVT in models of allo-HSCT. This is due to the effect of the ITK signaling pathway on regulation of Eomes, a critical transcription factor required for T cell cytotoxic function. Loss of ITK also altered expression of IRF4, and the JAK/STAT pathway components JAK1, JAK2 and STAT, which play critical roles in controlling cytokine expression46, 47. Transcriptome analysis by RNA sequencing also revealed that ITK signaling controls chemokine receptor expression during this process, which in turn affects the ability of donor T cells to migrate to GVHD target organs. Taken together, these data suggest that ITK could represent a potential target for the separation of GVHD and GVT responses after allo-HSCT.

The adaptor protein SLP76 plays an important role regulating T cell activation downstream of TCR by assembling a multimolecular signaling complex that includes ITK. The phosphorylation of SLP76 at Y145 leads to the activation and recruitment of ITK, which phosphorylates PLC $\gamma 1$, leading to its activation, mobilization of calcium, and activation of the NFAT transcription factor48. Hence, T cells that carry a Y145F mutation of SLP76 fail to phosphorylate and activate PLC $\gamma 1$ in response to TCR stimulation10. Although T cells expressing the SLP76 Y145F mutant exhibit signaling defects downstream of TCR stimulation, not all T cell functions are lost when ITK recruitment and activation is defective. For example, both Itk-/and SLP76 Y145FKI T cells can clear acute LCMV infection49, 50, 51. The similarity in the ability of Itk-/ T cells, and the SLP76 Y145FKI T cells in being able to induce GVT without GVHD indicates that the SLP76/ITK pathway controls these functions. Both Itk-/ and SLP76 Y145FKI CD8+ T cells develop into IMP cells (CD122+ CD44hi phenotype) in the thymus, and it is 
possible that such cells are responsible for the GVHD and GVT effects we observe. However, in experiments where WT T cells are able to develop into IMPs, we find that they retained the capacity to induce acute GVHD as well as clear tumor in GVT, suggesting a T cell-intrinsic function of ITK in promoting GVHD during allo-HSCT.

IMP cells express significantly higher Eomes expression compared to their WT non-IMP counterparts. However, we found that IMP CD8+ T cells are not responsible for distinguishing GVHD and GVT. Similarly, the cytotoxicity of Itk-/ CD8+ T cells is not dependent on the IMP. However, we found that expression of the transcription factor Eomes is required for the in vitro cytolytic function of CD8+ T cells that lack ITK/SLP76 signaling. Similarly, in vivo, Eomes is required for the GVT effects of T cells that lack ITK/SLP76 signaling in the allo-HSCT model. We did note that to our surprise, Itk-/ CD8+ T cells exhibit similar or higher in vitro cytotoxicity compared to WT CD8+ T cells. This may be due to the higher levels of perforin expressed by Itk/. T cells compared to WT T cells. However, SLP76Y145FKI CD8+ T cells show slightly reduced cytotoxicity compared to WT cells. There may also be subtle differences in signaling between cell lacking Itk T cells, or carrying the SLP76Y145F mutant, that explains these differences.

Our data showed that Itk-/- donor CD8+ T cells exhibited reduced expression of chemokine receptors compared to WT counterparts. Moreover, the migration of Itk-/ donor T cells to target organs was also severely defective, reflecting the reduced expression of key chemokine receptors. The defective migration of $I t k-/-\mathrm{CD} 8+\mathrm{T}$ cells likely contributes to the attenuation of GVHD, since these T cells could still display GVT effects against tumor cells that were injected intravenously and reside in secondary lymphoid organs. By contrast, WT but not It $k$ - $\mathrm{CD} 8+\mathrm{T}$ cells were able to inhibit tumor growth when the tumor cells were injected 
subcutaneously. The compartmentalization of T cells to secondary lymphoid organs can be an effective strategy for preventing GVHD, while leaving GVT effects against hematologic malignancies intact. For example, the retention of T cells to secondary lymphoid organs by FTY720-mediated inhibition of S1P1 ameliorates GVHD while maintaining GVT effects52, 53. Similarly, inhibition of T cell migration to GVHD target organs by targeting the chemokine receptors CCR2 or CCR5 protects against GVHD-induced pathology54, 55, 56, which at least with CCR2 deficiency was shown to preserve the GVT effect. Importantly, in a clinical study, CCR5 blockade by a small molecule antagonist led to a reduction in GVHD with no significant difference in relapse rates, suggesting that blocking $\mathrm{T}$ cell migration to target tissues could reduce GVHD severity without compromising the beneficial GVT effect. In addition, the inhibition of CXCR3 ameliorates GVHD in allo-HSCT mice57, 58, 59, 60. Activated allo-reactive CD8+ T cells upregulate the expression of CX3CR1 and CXCR6 after allo-HSCT61, 62, and these receptors are important for the homing of CD8+ T cells to the liver and intestines. Thus, CXCR6 deficiency or blockade of the CXCR3 and CXCR6 ligands attenuates GVHD60, and importantly, the GVT effect is still maintained under these conditions62. Thus, blocking T cell migration by chemokine receptor blockade could be beneficial in the treatment of GVHD after allo-HSCT. Since activated $I t k-/$ CD8+ T cells displayed significantly reduced expression of chemokine receptors, the compartmentalization of $\mathrm{CD} 8+\mathrm{T}$ cells to secondary lymphoid organs likely contributes to the preservation of GVT effects while severely attenuating GVHD.

Although suppression of TCR signaling can prevent GVHD, the complete suppression of T cell responses negates the beneficial GVT effect that is also provided by the same donor $\mathrm{T}$ cells after allo-HSCT63, 64. Thus, the fact that mice transplanted with Itk-/ T cells are able to mount GVT responses is an exciting feature. The preservation of the GVT response could have 
occurred for several reasons. First, the proliferation and cytotoxicity activity of $I t k-$ - CD8+ T cells is preserved compared to pro-inflammatory cytokine production. The manifestations and severity of GVHD are highly influenced by local cytokines, which, in turn, activate transcription factors and drive development toward cytokine storm. In addition, proinflammatory cytokines exert direct effects on GVHD target tissues65, 66, 67. Indeed, the presence of cytokine storm is considered one of the hallmarks of GVHD pathogenesis26, 68, and our data showed cytokine production was significantly reduced in mice that received Itk-/- or SLP76 Y145FKI T cells. We also confirmed that cytokine production is T cell-intrinsic while proliferation is $\mathrm{T}$ cell-extrinsic.

To explore the potential mechanism of this observed difference in cytokine and chemokine receptor expression between WT and $I t k$-/ donor T cells, we analyzed key transcription factors and pathways that may be involved in these processes. We found significant differences in expression of the transcription factor IRF4 and the JAK/STAT signaling pathways, which regulate the expression of key molecules required for the maintenance of $\mathrm{T}$ cell effector function, cytokine production, and chemokine receptor upregulation. Since IRF4 has been shown to play critical roles in modulating TCR signal strength and T cell function11,28, 69, 70, it is likely that reduction in the activation of IRF4, and of the JAK/STAT pathway contribute to reduced cytokine expression, thus alleviating the cytokine storm in GVHD. In addition, the inability to migrate to target organs may also affect this process, and thus explain the inability of the Itk-/donor T cells to induce GVHD.

We have also demonstrated proof of concept that specific targeting of the SLP76/ITK interactions can be achieved to potentially differentially modulate GVT and GVHD by pharmacological agents. Rather than directly inhibiting the activity of the kinase domain of ITK, which could result in complete blockage of all ITK kinase activity in T cells (and potentially 
non-specifically affect other tyrosine kinases), we developed a strategy to specifically disrupt the SLP76-pY145-mediated activation of ITK function in T cells. This strategy takes advantage of the SP76 pY145-mediated docking of ITK through its SH2 domain, given our findings that, like Itk-/ T cells, SLP76-Y145FKI mutant T cells can mediate tumor clearance through GVT, without inducing the unwanted GVHD effects. ITK interacts with SLP76 via its SH3 and SH2 domains onto the poly-proline motif and pY145 of SLP76 respectively. Thus, converting Y145 to F145 in SLP76 or preventing SH2 docking by our novel SLP76145pTYR peptide does not completely abolish the interaction between SLP76 and ITK, but significantly affects ITK kinase activity and results in severe defects in specific downstream signaling pathways71, 72. Therefore, we decided to target this specific interaction, which would retain signaling pathways that maintain GVT effects, but ameliorate GVHD. When we utilized SLP76145pTYR peptide to specifically target ITK signaling, we observed that this inhibitor is very specific in only inhibiting ITK signaling, without having significant effects on other tyrosine kinases nor apparent toxicity as determined by cell viability compared to nonspecific peptide or vehicle alone. Furthermore, SLP76145pTYR inhibition of ITK signaling also enhances Tregs in vitro, confirming its ability to affect ITK signaling on $\mathrm{T}$ cell effector function. Our data demonstrated that TCR stimulation of primary human T cells isolated from PBMC in the presence of SLP76pTYR led to significantly reduced IFN- $\gamma$ and TNF- $\alpha$ production, which was not observed when they were stimulated with PMA+Ionomycin in the presence of SLP76pTYR. Finally, donor T cells treated with SLP76pTYR, resulted in tumor clearance without inducing GVHD. Future combinatorial therapies involving our novel SLP76145pTYR peptide inhibitor and small molecule inhibitors, such as the BTK/ITK dual antagonist, Ibrutinib, can potentially be an effective strategy for enhancing GVT while avoiding GVHD. Ibrutinib is FDA-approved for the treatment of chronic 
lymphocytic leukemia73, and although its effects on GVT outcome has not been reported, Ibrutinib has recently been shown to protect against acute and chronic GVHD in mouse models of allogeneic BMT74, 75. Thus, combining more selective ITK inhibition using our SLP76Y145 peptide with Ibrutinib could be beneficial in the treatment of GVHD, while maintaining GVT effects after allo-HSCT. 


\section{Materials and Methods}

Mice

SLP76 Y145FKI and SLP76 Y145FKI Eomesflox/flox mice were generated as previously described and were a kind gift of Dr. Martha S. Jordan (University of Pennsylvania)25 Itk-/- mice as were described previously76. C57BL/6, C57BL/6.SJL (B6-SJL), ROSA26-pCAGGs-LSLLuciferase, Thy1.1 (B6.PL-Thy1a/CyJ), CD45.1 (B6.SJL-Ptprca Pepcb/BoyJ) and BALB/c mice were purchased from the Charles River or Jackson Laboratory. Mice expressing Cre driven by the CMV promoter (CMV-Cre) were purchased from the Jackson Laboratory and crossed to ROSA26-pCAGGs-LSL-Luciferase mice (B6-luc). B6-luc mice were bred with SLP76Y145FKI or Itk-/- mice to create Y145F-luc mice and Itk-/luc. Itk-/- and Il4ra/- double knockout mice have been described13. Mice aged 8-12 weeks were used, and all experiments were performed with age and sex-matched mice. Animal maintenance and experimentation were performed in accordance with the rules and guidance set by the institutional animal care and use committees at SUNY Upstate Medical University and Cornell University.

\section{Reagents, cell lines, flow cytometry.}

Monoclonal antibodies were purchased from eBiosciences (San Diego, CA) or BD Biosciences (San Diego, CA). Antibodies used included anti-CD3, anti-CD28, anti-CD3-FITC, anti-CD8FITC, anti-BrdU-APC, anti-IFN- $\gamma$-APC, anti-TNF- $\alpha$-PE, anti-CD45.1-PerCPCy5.5, anti-CD122APC, anti-CD44-Violet H, anti-Eomes-Blue A, anti-CD25-Violet H, anti-FoxP3-APC, anti-Tbet-Violet $\mathrm{H}$, anti-CD4-Violet A, anti-CD45.1-Pacific Blue, anti-H-2Kd-Pacific Blue. We used multiplex ELISA from Biolegend LEGEND plex and some kits were custom ordered to detect both mouse and human cytokines. Luciferin was purchased from Perkin Elmer (Waltham, MA) 
and Gold Bio (St Louis MO). Dead cells were excluded from analysis with LIVE/DEAD Fixable Aqua Dead Cell staining. Flow cytometry was performed by BD LSR-II or

BD LSR Fortessa (BD Biosciences). Data were analyzed with FlowJo software (Tree Star, Ashland, OR).

For cell sorting, T cells were purified with either anti-CD8 or anti-CD4 magnetic beads using MACS columns (Miltenyi Biotec, Auburn, CA) prior to cell surface staining. FACS sorting was performed with a FACS Aria cell sorter (BD Biosciences). FACS-sorted populations were typically of $>95 \%$ purity. Antibodies against ITK, PLC $\gamma 1$, ERK, IRF4, STAT3, JAK2, JAK1, GAPDH, $\beta$-Actin total and/or phospho proteins were purchased from Cell Signaling Technology (Danvers, MA). All cell culture reagents and chemicals were purchased from Invitrogen (Grand Island, NY) and Sigma-Aldrich (St. Louis, MO), unless otherwise specified. The A20 cell lines (American Type Culture Collection; Manassas, VA), and primary mice BALL blasts a primary cells 16 were transduced with luciferase, and cultured as described previously 77.

Statistics. All numerical data reported as means with standard deviation. Data are analyzed for significance with GraphPad Prism. Differences are determined using one-way or two-way ANOVA and Tukey's multiple comparisons tests, or with a student's t-test when necessary. Pvalues less than or equal to 0.05 are considered significant. All transplant experiments are done with $\mathrm{N}=5$ mice per group, and repeated at least twice, according to power analyses. Mice are sexmatched, and age-matched as closely as possible.

\section{Allo-HSCT and GVT studies}


Lethally irradiated BALB/c mice (800 cGy) were injected intravenously with $5 \times 106$ T celldepleted bone marrow (TCDBM) cells with or without either 1×106 FACS-sorted CD8+, CD4+ T cells, or CD8/CD4 cells mixed at a 1:1 ratio. FACS-sorted total CD8+, total CD4+, or mixed CD8+ and CD8+ T cells from WT (C57B1/6), Itk-/, SLP76 Y145FKI or SLP76 Y145FKI Eomesflox/flox mice either crossed with or without CD4cre were used. For GVT experiments, BALL primary blasts 16 transduced with luciferase were cultured as described previously77 and $2 \times 105$ luciferase-expressing primary B-ALL blasts were used. Mice were evaluated twice a week from the time of tumor injection for 70 days by bioluminescence imaging using the IVIS 200 Imaging System (Xenogen) as previously described78. Clinical presentation of the mice was assessed 2-3 times per week by a scoring system that sums changes in 5 clinical parameters: weight loss, posture, activity, fur texture, and skin integrity17. Mice were euthanized when they lost $\geq 30 \%$ of their initial body weight. Bone marrow cells from Itk-/ (CD45.1+) or C57B1/6 (CD45.2+) mice were mixed at different ratios 1:1 (Itk-/:WT), 1:2, 1:3, 1:4, and transplanted into lethally irradiated Thy1.1 mice. In some experiments, we used Itk-/- on a CD45.2 background and WT on a CD45.1 as indicated in the figure legends. Mice were bled through tail vein after 9 weeks to determine the presence of Itk-/- and WT cells. In some experiments, Itk-/- (CD45.1+) and WT (CD45.2) cells T cells were FACS-sorted from Thy1.1 hosts and then transplanted to irradiated BALB/c mice carrying tumor cells, along with T cell-depleted bone marrow as described above. This was followed by analysis of GVHD and GVT. In some experiments FACS-sorted CD8+ T cells from WT, SLP76 Y145FKI or Itk-/ B6 mice were mixed at a 1:1 ratio and injected into BALB/c mice $(2 \times 106 \mathrm{CD} 8+\mathrm{T}$ cells total). For tissue imaging experiments, alloHSCT was performed with $5 \times 106$ WT T cell-depleted BM cells and $1 \times 106$ FACS-sorted CD8+ T cells (from B6-luc, SLP76 Y145F-luc mice or Itk--luc mice) and bioluminescence imaging of 
tissues was performed as previously described 79. Briefly, 5 minutes after injection with luciferin $(10 \mu \mathrm{g} / \mathrm{g}$ body weight), selected tissues were prepared and imaged for 5 minutes. Imaging data were analyzed and quantified with Living Image Software (Xenogen) and Igor (Wave Metrics, Lake Oswego, OR).

\section{Cytokine production, cytotoxicity, and BrdU incorporation assays}

On Day 7 post BM transplantation, serum and single cell suspensions of spleens were obtained.

Serum IL33, IL-1 $\alpha$, IFN- $\gamma$, TNF- $\alpha$ and IL-17A content were determined by multiplex cytokine assays (Biolegend LEGEND plex). T cells were stimulated with anti-CD3/CD28 for 4-6 hours in the presence of brefeldin $\mathrm{A}(10 \mu \mathrm{M})$ and stained intracellularly for cytokines (IFN- $\gamma$ and TNF- $\alpha$ ). Control cells were stimulated with PMA and ionomycin in the presence of brefeldin A. For detection of BrdU, mice were administered BrdU with an initial bolus of BrdU (2 mg per $200 \mu \mathrm{l}$ intraperitoneally) and given drinking water containing BrdU ( $1 \mathrm{mg} / \mathrm{ml})$ for 2 days. Spleen cells from these mice were resuspended in freezing media (90\% FCS, 10\% DMSO) and stored overnight at $-80^{\circ} \mathrm{C}$. Cells were subsequently thawed at room temperature and stained for BrdU.

For cytotoxicity assays, luciferase-expressing A20 cells were seeded in 96-well flat bottom plates at a concentration of $3 \times 105$ cells $/ \mathrm{ml}$. D-firefly luciferin potassium salt $(75 \mu \mathrm{g} / \mathrm{ml}$; Caliper Hopkinton, MA) was added to each well and bioluminescence was measured with IVIS 200 Imaging System. Subsequently, ex vivo effector cells (MACS-sorted or FACS-sorted CD8+ T cells from bone marrow-transplanted mice) were added at 40:1, 30:1,20:1, 10:1, and 5:1 effector-to-target (E:T) ratios and incubated at $37^{\circ} \mathrm{C}$ for 4 hours. Bioluminescence in relative luciferase units (RLU) was then measured for 1 minute. Cells treated with $1 \%$ Nonidet P-40 was used as a measure of maximal killing. Target cells incubated without effector cells were used to 
measure spontaneous death. Triplicate wells were averaged and percent lysis was calculated from the data using the following equation: $\%$ specific lysis $=100 \times$ (spontaneous death RLUtest RLU)/(spontaneous death RLU- maximal killing RLU).

\section{Migration assays}

Lethally irradiated BALB/c mice were injected intravenously with 5×106 WT T cell-depleted bone marrow (TCDBM) from B6.PL-Thyla/CyJ and FACS-sorted CD8+ T cells from B6.SJL and Itk-/ or SLP76 Y145FKI mice mixed at a 1:1 ratio. Seven days post transplantation, the mice were sacrificed and lymphocytes from the liver, small intestine, spleen, and skin-draining lymph nodes were isolated. Livers were perfused with PBS, dissociated, and filtered with a 70 $\mu \mathrm{m}$ filter. The small intestines were washed in media, shaken in strip buffer at $37^{\circ} \mathrm{C}$ for 30 minutes to remove the epithelial cells, and then washed, before digesting with collagenase D (100 mg/ml) and DNase $(1 \mathrm{mg} / \mathrm{ml})$ for 30 minutes in $37^{\circ} \mathrm{C}$, and followed by filtering with a $70 \mu \mathrm{m}$ filter. Lymphocytes from the liver and intestines were further enriched using a 40\% Percoll gradient. The cells were analyzed for $\mathrm{H} 2 \mathrm{~K} b, \mathrm{CD} 45.1+$ and CD45.2+ CD8+ T cells by flow cytometry, but we excluded any bone marrow-derived T cells (Thy1.1+).

\section{RNA sequencing}

CD8+ T cells from WT C5Bl/6 or Itk-/- mice were MACS purified and FACS sorted, and $2 \times 106$

FACS sorted CD8+ T cells were transplanted into BALB/c mice, along with TCDBM as described above. Seven days post transplantation, donor cells were purified from spleen (Spl) and small intestine (Gut). Samples were submitted to SUNY Upstate Medical University Sequencing core facility for RNA sequencing. We were unable to sort enough donor T cells from small intestine 
of the recipient mice that received Itk-/ T cells. Therefore, we generated RNA sequencing data from five groups: WT-Pre and Itk-/--Pre cells prior to transplantation; and WT-Gut, WT-Spleen, and $I t k$ - $/$-Spleen using cells isolated from 7 days post transplantation. Copy numbers were further analyzed in Gene Spring for normalization, quality control, correlation, principal component analysis and gene differential expression. The sequencing data is deposited in (https://www.ncbi.nlm.nih.gov/geo/)

\section{Western blotting}

Cells were lysed in freshly prepared lysis buffer (10 mM Tris, $\mathrm{pH} 8,150 \mathrm{mM} \mathrm{NaCl}, 1 \mathrm{mM}$ EDTA, 1\% Nonidet-P40, 0.5\% Deoxycholate, 0.1\% SDS, complete Protease Inhibitor Cocktail [Roche, Palo Alto, CA], and $500 \mu \mathrm{M}$ PMSF) and centrifuged for 10 minutes at $4^{\circ} \mathrm{C}$. Aliquots containing $70 \mu \mathrm{g}$ protein were separated on an $12-18 \%$ denaturing polyacrylamide gel and transferred to nitrocellulose membranes for immunoblot analysis using Abs specific to IRF4, JAK1, JAK2, ERK, PLC $\gamma 1$, ITK, mTOR, AKT, P13K and STAT3 total and/or phospho proteins.

\section{qPCR assay}

To confirm the differences observed in RNA sequencing, pre- and post-transplanted donor T cells were FACS sorted from recipient mice on $\mathrm{H} 2 \mathrm{~K}_{\mathrm{b}}$ markers, and total RNA was isolated from T cells using the RNeasy kit Qiagen (Germantown, MD). cDNA was made from total RNA using cDNA synthesis kit (Invitrogen). qRT-PCR assay was performed with a premade customized plate (Fisher Scientific, Hampton, NH).

\section{SLP76145pTYR Peptide}


To generate a molecule that specifically inhibist the interaction between pY145 of SLP76 and the SH2 domain of ITK, we designed a peptide based on the amino acid sequence of SLP76 from N132 to A155, which contains a phosphorylated tyrosine residue at Y145 (Fig. 8). To ensure that our peptide easily enters cells and that its cellular localization can be monitored, we incorporated a C-terminal TAT-peptide and an N-terminal fluorescent FITC dye respectively and named it SLP76145pTYR peptide (Fig. 8). Both SLP76145pTYR peptide (FITC Dye) 132NEEEEAPVEDDADpYEPPPSNDEEA155-(GRKKRRQRRRPQ) and non-specific (FITC Dye)-IIMTTTTNNKKSSRRVVVVAAAADD-(GRKKRRQRRRPQ) control peptide, were synthesized by Genscript Inc (Piscataway, NJ), and initially dissolved in 3\% ammonia water to a final concentration of $10 \mu \mathrm{g} / \mu \mathrm{L}$ and then further diluted into PBS media to a final concentration of $1 \mu \mathrm{g} / \mu \mathrm{L}$. Fresh splenocytes were isolated from WT mice, and T cells were generated from splenocytes as previously described80. Briefly, T cells were isolated from splenocytes using Miltenyi beads, then cultured in complete RPMI media $(3 \times 106$ cells $/ \mathrm{mL})$ plated on anti-CD3 (145-2C11; BD Pharmingen, San Diego, CA) antibody-coated tissue culture plates. T cells were incubated with SLP76145pTYR peptide or vehicle alone at different concentrations ranging from $10 \mathrm{ng} / \mathrm{ml}$ to $1 \mu \mathrm{g} / \mathrm{ml}$ in the presence of $4 \mu \mathrm{g} / \mathrm{ml}$ of polybrene (Sigma-Aldridge, St. Louis, MO). Cells were spun for 60 minutes at 200 RPM and cultured for 24-48 hours 24 to 48 hours. Cells were examined for the presence of FITC by microscopy using a Leica DMi8 microscope equipped with an infinity total internal reflection fluorescence (TIRF) and DIC modules, a Lumencor SOLA SE II light box, a 150 mW 488 (GFP) laser and filter cube, a 100x/1.47 NA objective, and an Andor iXon Life 897 EMCCD camera. FITC expression was confirmed by flow cytometry as well Cells were lysed and used in Western blots. 


\section{Toxicity assay}

Yac1 and B-ALL cells line were transduced with luciferase as described 81. Luciferaseexpressing tumor cells were placed in 96-well round bottom plates at a concentration of $3 \times 105$ cells/ml in triplicates, given D-firefly luciferin potassium salt $(75 \mu \mathrm{g} / \mathrm{ml}$; Caliper Hopkinton, MA), and luciferase activity measured with a luminometer. This was done to establish the Bioluminescence Imaging (BLI) baseline readings before the occurrence of any cell death and to ensure equal distribution of target cells among wells. Subsequently, SLP76pTYR or vehicle were added at $1 \mu \mathrm{g} / \mathrm{well}$ in $100 \mu \mathrm{l}$ of media and serial dilutions performed, followed by incubation at $37^{\circ} \mathrm{C}$. BLI was then measured for 60 seconds with a luminometer (Packard Fusion Universal Microplate Analyzer, Model A153600) as relative light units (RLU). Triplicate wells were averaged and data presented as photons per second per well.

\section{Human Patient Samples}

T cells were isolated from Peripheral Blood Mononuclear Cells (PBMC) of GVHD patients or normal healthy donors as previously described 82. Briefly, mononuclear cells were isolated from GVHD patient samples by Ficoll-Hypaque density centrifugation and separated by positive selection with CD8 and CD4 MACS Microbeads. The final product was resuspended at $2 \times 106$ cells/ml in media and stimulated with OKT-3 (1 $\mu \mathrm{g} / \mathrm{ml}$; Ortho Bio Tech), anti-human CD28, in the presence SLP76pTYR or vehicle for 24 hours. T cell lysates were used in western blot analysis. We also isolated plasma from GVHD patients and healthy donors and performed cytokine ELISAs on these plasma samples using multiplex ELISA kits (Biolegend, San Diego, CA). 
Transducing primary T cells with SLP76pTYR: To generate viruses that specifically express SLP76pTYR. SLP76pTYR was cloned as fusion protein with pCherry ordered through 14

Integrated DNA Technology (IDT). The insert was cloned into pQCX-I-X retroviral vector between MLU1 and Xho1 restriction sites, and the expression of insert confirmed by digestion and sequencing. To produce retroviral supernatants, Phoenix packaging cells were plated in $175 \mathrm{~cm} 2$ flasks, and transfected with $20 \mu \mathrm{g}$ of vector using Lipofectamine 2000 reagent (Invitrogen, Carlsbad, CA), according to the manufacturer's protocol. The medium was changed after 8-12 hours, and viral supernatants were harvested after 24-36 hours. Concentrated viral supernatants were re-suspended in IMDM media (Invitrogen) and used to transduce primary T cells in the presence of polybrene (10 $\mu \mathrm{g} / \mathrm{ml})$ and protamine sulfate $(10 \mu \mathrm{g} / \mathrm{ml})$ to enhance transduction efficiency. T cells transduced with viruses containing either SLP76pTYR or empty plasmid were injected into mice. 
Acknowledgements: We thank all members of the Karimi and August laboratories for helpful discussions. This research was funded in part by a grant from the National Blood Foundation Scholar Award to (MK) and the National Institutes of Health (NIH LRP \#L6 MD0010106 and AI130182 to MK, AI120701 and AI126814 to AA, R35ES028244 to AA and Gary Perdew, AI129422 to AA and WH, and AI146226 and GM130555-sub6610 to WH).

Author contributions: MM, WH, AS, QY, SD, JR, AB and MK performed experiments; WT, YC, JP and TG provided valuable reagents; RH assisted with data analysis, experimental design, and scientific discussion; and WH, QY, AA, AB and MK designed experiments, analyzed the data, and wrote the manuscript.

Conflict of Interest: AA receives research support from 3M Corporation. WH receives research support from Mega Robo Technologies. The other authors declare no conflicts of interest. 


\section{References}

1. Breems, D.A. \& Lowenberg, B. Autologous stem cell transplantation in the treatment of adults with acute myeloid leukaemia. Br J Haematol 130, 825-833 (2005).

2. Tugues, S. et al. Graft-versus-host disease, but not graft-versus-leukemia immunity, is mediated by GM-CSF-licensed myeloid cells. Sci Transl Med 10 (2018).

3. Bastien, J.P., Roy, J. \& Roy, D.C. Selective T-cell depletion for haplotype-mismatched allogeneic stem cell transplantation. Semin Oncol 39, 674-682 (2012).

4. Bleakley, M., Turtle, C.J. \& Riddell, S.R. Augmentation of anti-tumor immunity by adoptive T-cell transfer after allogeneic hematopoietic stem cell transplantation. Expert Rev Hematol 5, 409-425 (2012).

5. Ferrara, J.L. Blood and Marrow Transplant Clinical Trials Network: Progress since the State of the Science Symposium 2007. Biol Blood Marrow Transplant 20, 149-153 (2014).

6. August, A., Sadra, A., Dupont, B. \& Hanafusa, H. Src-induced activation of inducible T cell kinase (ITK) requires phosphatidylinositol 3-kinase activity and the Pleckstrin homology domain of inducible T cell kinase. Proc Natl Acad Sci U S A 94, 11227-11232 (1997).

7. Qi, Q., Sahu, N. \& August, A. Tec kinase Itk forms membrane clusters specifically in the vicinity of recruiting receptors. J Biol Chem 281, 38529-38534 (2006).

8. Koretzky, G.A., Abtahian, F. \& Silverman, M.A. SLP76 and SLP65: complex regulation of signalling in lymphocytes and beyond. Nat Rev Immunol 6, 67-78 (2006).

9. Kambayashi, T., Larosa, D.F., Silverman, M.A. \& Koretzky, G.A. Cooperation of adapter molecules in proximal signaling cascades during allergic inflammation. Immunol Rev 232, 99-114 (2009).

10. Jordan, M.S. et al. Functional hierarchy of the N-terminal tyrosines of SLP-76. J Immunol 176, 2430-2438 (2006).

11. Atherly, L.O. et al. The Tec family tyrosine kinases Itk and Rlk regulate the development of conventional CD8+ T cells. Immunity 25, 79-91 (2006).

12. Hu, J., Sahu, N., Walsh, E. \& August, A. Memory phenotype CD8+ T cells with innate function selectively develop in the absence of active Itk. Eur J Immunol 37, 2892-2899 (2007).

13. Huang, W., Huang, F., Kannan, A.K., Hu, J. \& August, A. ITK tunes IL-4-induced development of innate memory CD8+ T cells in a gammadelta $\mathrm{T}$ and invariant NKT cellindependent manner. J Leukoc Biol 96, 55-63 (2014). 
14. Henden, A.S. \& Hill, G.R. Cytokines in Graft-versus-Host Disease. J Immunol 194, 4604$4612(2015)$.

15. Lynch Kelly, D., Lyon, D.E., Ameringer, S.A. \& Elswick, R.K. Symptoms, Cytokines, and Quality of Life in Patients Diagnosed with Chronic Graft-Versus-Host Disease Following Allogeneic Hematopoietic Stem Cell Transplantation. Oncol Nurs Forum 42, 265-275 (2015).

16. Cheng, Y. et al. LNK/SH2B3 regulates IL-7 receptor signaling in normal and malignant B-progenitors. J Clin Invest 126, 1267-1281 (2016).

17. Cooke, K.R. et al. An experimental model of idiopathic pneumonia syndrome after bone marrow transplantation: I. The roles of minor H antigens and endotoxin. Blood 88, 32303239 (1996).

18. Martin, P.J. Donor CD8 cells prevent allogeneic marrow graft rejection in mice: potential implications for marrow transplantation in humans. J Exp Med 178, 703-712 (1993).

19. Gallardo, D. et al. Low-dose donor CD8+ cells in the CD4-depleted graft prevent allogeneic marrow graft rejection and severe graft-versus-host disease for chronic myeloid leukemia patients in first chronic phase. Bone Marrow Transplant 20, 945-952 (1997).

20. Kang, C.W. et al. Apoptosis of tumor infiltrating effector TIM-3+CD8+ T cells in colon cancer. Sci Rep 5, 15659 (2015).

21. Cheng, L. et al. Hyper-IL-15 suppresses metastatic and autochthonous liver cancer by promoting tumour-specific CD8+ T cell responses. J Hepatol 61, 1297-1303 (2014).

22. Weinreich, M.A., Odumade, O.A., Jameson, S.C. \& Hogquist, K.A. T cells expressing the transcription factor PLZF regulate the development of memory-like CD8+ T cells. Nat Immunol 11, 709-716 (2010).

23. Huang, W., Hu, J. \& August, A. Cutting edge: innate memory CD8+ T cells are distinct from homeostatic expanded CD8+ T cells and rapidly respond to primary antigenic stimuli. J Immunol 190, 2490-2494 (2013).

24. Carty, S.A., Koretzky, G.A. \& Jordan, M.S. Interleukin-4 regulates eomesodermin in CD8+ T cell development and differentiation. PLoS One 9, e106659 (2014).

25. Jordan, M.S. et al. Complementation in trans of altered thymocyte development in mice expressing mutant forms of the adaptor molecule SLP76. Immunity 28, 359-369 (2008).

26. D'Aveni, M. et al. G-CSF mobilizes CD34+ regulatory monocytes that inhibit graft-versushost disease. Science Translational Medicine 7, 281 ra242 (2015). 
27. Negrin, R.S. \& Contag, C.H. In vivo imaging using bioluminescence: a tool for probing graft-versus-host disease. Nat Rev Immunol 6, 484-490 (2006).

28. Biswas, P.S. et al. Phosphorylation of IRF4 by ROCK2 regulates IL-17 and IL-21 production and the development of autoimmunity in mice. J Clin Invest 120, 3280-3295 (2010).

29. Yi, J. et al. IL-27 Promotes Human Placenta-Derived Mesenchymal Stromal Cell Ability To Induce the Generation of CD4(+)IL-10(+)IFN-gamma(+) T Cells via the JAK/STAT Pathway in the Treatment of Experimental Graft-versus-Host Disease. J Immunol 202, 1124-1136 (2019).

30. O'Shea, J.J., Gadina, M. \& Schreiber, R.D. Cytokine signaling in 2002: new surprises in the Jak/Stat pathway. Cell 109 Suppl, S121-131 (2002).

31. Morris, R., Kershaw, N.J. \& Babon, J.J. The molecular details of cytokine signaling via the JAK/STAT pathway. Protein Sci 27, 1984-2009 (2018).

32. Lu, S.X. et al. Absence of P-selectin in recipients of allogeneic bone marrow transplantation ameliorates experimental graft-versus-host disease. J Immunol 185, 19121919 (2010).

33. Cho, H.S. et al. CD8(+) T Cells Require ITK-Mediated TCR Signaling for Migration to the Intestine. Immunohorizons 4, 57-71 (2020).

34. Wysocki, C.A. et al. Differential roles for CCR5 expression on donor T cells during graftversus-host disease based on pretransplant conditioning. J Immunol 173, 845-854 (2004).

35. Wysocki, C.A., Panoskaltsis-Mortari, A., Blazar, B.R. \& Serody, J.S. Leukocyte migration and graft-versus-host disease. Blood 105, 4191-4199 (2005).

36. Carson, C.C. et al. IL2 Inducible T-cell Kinase, a Novel Therapeutic Target in Melanoma. Clin Cancer Res 21, 2167-2176 (2015).

37. Riether, D. et al. 5-Aminomethylbenzimidazoles as potent ITK antagonists. Bioorg Med Chem Lett 19, 1588-1591 (2009).

38. Guo, W. et al. Molecular characteristics of CTA056, a novel interleukin-2-inducible T-cell kinase inhibitor that selectively targets malignant $\mathrm{T}$ cells and modulates oncomirs. Mol Pharmacol 82, 938-947 (2012).

39. Alder, C.M. et al. Identification of a Novel and Selective Series of Itk Inhibitors via a Template-Hopping Strategy. ACS Med Chem Lett 4, 948-952 (2013). 
40. Pletneva, E.V., Sundd, M., Fulton, D.B. \& Andreotti, A.H. Molecular details of Itk activation by prolyl isomerization and phospholigand binding: the NMR structure of the Itk SH2 domain bound to a phosphopeptide. J Mol Biol 357, 550-561 (2006).

41. Andersen, T.C.B. et al. The SH3 domains of the protein kinases ITK and LCK compete for adjacent sites on T cell-specific adapter protein. J Biol Chem 294, 15480-15494 (2019).

42. Altschul, S.F., Gish, W., Miller, W., Myers, E.W. \& Lipman, D.J. Basic local alignment search tool. J Mol Biol 215, 403-410 (1990).

43. Owen, D.L. et al. Thymic regulatory T cells arise via two distinct developmental programs. Nat Immunol 20, 195-205 (2019).

44. $\quad$ Elmore, J.P. et al. Tuning T helper cell differentiation by ITK. Biochem Soc Trans 48, 179185 (2020).

45. Sugie, K., Jeon, M.S. \& Grey, H.M. Activation of naive CD4 T cells by anti-CD3 reveals an important role for Fyn in Lck-mediated signaling. Proc Natl Acad Sci U S A 101, 1485914864 (2004).

46. Seif, F. et al. The role of JAK-STAT signaling pathway and its regulators in the fate of T helper cells. Cell Commun Signal 15, 23 (2017).

47. Malemud, C.J. The role of the JAK/STAT signal pathway in rheumatoid arthritis. Ther Adv Musculoskelet Dis 10, 117-127 (2018).

48. Sahu, N. \& August, A. ITK inhibitors in inflammation and immune-mediated disorders. Curr Top Med Chem 9, 690-703 (2009).

49. Smith-Garvin, J.E. et al. T-cell receptor signals direct the composition and function of the memory CD8+ T-cell pool. Blood 116, 5548-5559 (2010).

50. Bachmann, M.F., Littman, D.R. \& Liao, X.C. Antiviral immune responses in Itk-deficient mice. J Virol 71, 7253-7257 (1997).

51. Lee, A. et al. IL-4 Induced Innate CD8+ T Cells Control Persistent Viral Infection. PLoS Pathog 11, e1005193 (2015).

52. Hashimoto, D. et al. FTY720 enhances the activation-induced apoptosis of donor T cells and modulates graft-versus-host disease. Eur J Immunol 37, 271-281 (2007).

53. Kim, Y.M., Sachs, T., Asavaroengchai, W., Bronson, R. \& Sykes, M. Graft-versus-host disease can be separated from graft-versus-lymphoma effects by control of lymphocyte trafficking with FTY720. J Clin Invest 111, 659-669 (2003). 
54. Murai, M. et al. Active participation of $\mathrm{CCR} 5(+) \mathrm{CD} 8(+) \mathrm{T}$ lymphocytes in the pathogenesis of liver injury in graft-versus-host disease. J Clin Invest 104, 49-57 (1999).

55. Murai, M. et al. Peyer's patch is the essential site in initiating murine acute and lethal graftversus-host reaction. Nat Immunol 4, 154-160 (2003).

56. Terwey, T.H. et al. CCR2 is required for CD8-induced graft-versus-host disease. Blood 106, 3322-3330 (2005).

57. He, S. et al. A new approach to the blocking of alloreactive T cell-mediated graft-versushost disease by in vivo administration of anti-CXCR3 neutralizing antibody. J Immunol 181, 7581-7592 (2008).

58. Villarroel, V.A., Okiyama, N., Tsuji, G., Linton, J.T. \& Katz, S.I. CXCR3-mediated skin homing of autoreactive CD8 $\mathrm{T}$ cells is a key determinant in murine graft-versus-host disease. J Invest Dermatol 134, 1552-1560 (2014).

59. Liu, W. et al. Bortezomib regulates the chemotactic characteristics of $\mathrm{T}$ cells through downregulation of CXCR3/CXCL9 expression and induction of apoptosis. Int J Hematol 96, 764-772 (2012).

60. Duffner, U. et al. Role of CXCR3-induced donor T-cell migration in acute GVHD. Exp Hematol 31, 897-902 (2003).

61. Barrett, A.J. A new checkpoint in the path to GVHD? How bedside-to-bench stem cell transplant studies can inform human GVHD biology. J Leukoc Biol 97, 213-215 (2015).

62. Sato, T. et al. Role for CXCR6 in recruitment of activated CD8+ lymphocytes to inflamed liver. J Immunol 174, 277-283 (2005).

63. Vadakekolathu, J. \& Rutella, S. T-Cell Manipulation Strategies to Prevent Graft-VersusHost Disease in Haploidentical Stem Cell Transplantation. Biomedicines 5 (2017).

64. Vaeth, M. et al. Selective NFAT targeting in T cells ameliorates GvHD while maintaining antitumor activity. Proc Natl Acad Sci US A 112, 1125-1130 (2015).

65. Hill, G.R. et al. Total body irradiation and acute graft-versus-host disease: the role of gastrointestinal damage and inflammatory cytokines. Blood 90, 3204-3213 (1997).

66. Mohty, M. et al. Inflammatory cytokines and acute graft-versus-host disease after reducedintensity conditioning allogeneic stem cell transplantation. Blood 106, 4407-4411 (2005).

67. Ju, X.P. et al. Cytokine expression during acute graft-versus-host disease after allogeneic peripheral stem cell transplantation. Bone Marrow Transplant 35, 1179-1186 (2005). 
68. Holler, E. Cytokines, viruses, and graft-versus-host disease. Curr Opin Hematol 9, 479484 (2002).

69. Biswas, P.S. et al. Dual regulation of IRF4 function in T and B cells is required for the coordination of T-B cell interactions and the prevention of autoimmunity. J Exp Med 209, 581-596 (2012).

70. Mudter, J. et al. IRF4 selectively controls cytokine gene expression in chronic intestinal inflammation. Arch Immunol Ther Exp (Warsz) 57, 369-376 (2009).

71. Shim, E.K., Jung, S.H. \& Lee, J.R. Role of two adaptor molecules SLP-76 and LAT in the PI3K signaling pathway in activated T cells. J Immunol 186, 2926-2935 (2011).

72. Smith-Garvin, J.E. et al. T-cell receptor signals direct the composition and function of the memory CD8+ T-cell pool. Blood 116, 5548-5559.

73. Maddocks, K. \& Jones, J.A. Bruton tyrosine kinase inhibition in chronic lymphocytic leukemia. Semin Oncol 43, 251-259 (2016).

74. Dubovsky, J.A. et al. Ibrutinib treatment ameliorates murine chronic graft-versus-host disease. J Clin Invest 124, 4867-4876 (2014).

75. Schutt, S.D. et al. Inhibition of BTK and ITK with Ibrutinib Is Effective in the Prevention of Chronic Graft-versus-Host Disease in Mice. PLoS One 10, e0137641 (2015).

76. Liao, X.C. \& Littman, D.R. Altered T cell receptor signaling and disrupted T cell development in mice lacking Itk. Immunity 3, 757-769 (1995).

77. Edinger, M. et al. CD4+CD25+ regulatory $\mathrm{T}$ cells preserve graft-versus-tumor activity while inhibiting graft-versus-host disease after bone marrow transplantation. Nat Med $\mathbf{9}$, 1144-1150 (2003).

78. Contag, C.H. \& Bachmann, M.H. Advances in in vivo bioluminescence imaging of gene expression. Annu Rev Biomed Eng 4, 235-260 (2002).

79. Beilhack, A. et al. In vivo analyses of early events in acute graft-versus-host disease reveal sequential infiltration of T-cell subsets. Blood 106, 1113-1122 (2005).

80. Baker, J., Verneris, M.R., Ito, M., Shizuru, J.A. \& Negrin, R.S. Expansion of cytolytic $\mathrm{CD} 8(+)$ natural killer T cells with limited capacity for graft-versus-host disease induction due to interferon gamma production. Blood 97, 2923-2931 (2001).

81. Karimi, M.A. et al. Measuring cytotoxicity by bioluminescence imaging outperforms the standard chromium-51 release assay. PLoS One 9, e89357 (2014). 
bioRxiv preprint doi: https://doi.org/10.1101/2020.07.15.204693; this version posted July 15, 2020. The copyright holder for this preprint (which was not certified by peer review) is the author/funder. All rights reserved. No reuse allowed without permission.

82. Karimi, M. et al. Silencing human NKG2D, DAP10, and DAP12 reduces cytotoxicity of activated CD8+ T cells and NK cells. J Immunol 175, 7819-7828 (2005). 


\section{Figure Legends}

\section{Figure 1. Absence of ITK retains GVT effect but avoids GVHD during allo-HSCT.}

1X106 purified WT or Itk-/ CD8+ T cells and 1X106 purified CD4+ T cells were mixed at a 1:1 ratio, and transplanted along with $2 \mathrm{X} 105 \mathrm{~B}-\mathrm{ALL}-l u c$ cells into irradiated BALB/c mice. Host BALB/c mice were imaged using IVIS 3 times a week. Group 1 received T cell depleted bone marrow only (labeled as TCDBM). Group 2 received $\mathrm{T}$ cell depleted bone marrow along with 1X105 B-ALL-luc cells (TCDBM+B-ALL luct), Group 3 was transplanted with 1 X106 purified WT CD8+ and 1 X106 CD4+ T cells (1:1 ratio) along with 2X105 B-ALL$l u c+$ cells (TCDBM+B-ALL ${ }_{l u c}+$ WT CD8+CD4). Group 4 received 1X106 purified Itk-CD8+ and 1 X106 CD4+ T cells (1:1 ratio) along with 2X105 B-ALL-luc+ cells (TCDBM+BALLluct Itk-/ CD8+CD4). (A) Recipient BALB/c mice were imaged using IVIS 3 times a week. (B) The mice were monitored for survival, (C) changes in body weight, and (D) clinical score for 65 days post BMT. (E) Quantitated luciferase bioluminescence of tumor growth. Statistical analysis for survival and clinical score was performed using log-rank test and two-way ANOVA, respectively. For weight changes and clinical score, one representative of 2 independent experiments is shown $(n=3$ mice/group for BM alone; $n=5$ experimental mice/group for all three groups. Survival is a combination of 2 experiments. $\mathrm{P}$ values presented with each group. Two-way ANOVA and students t-test were used for statistical analysis. Note: Control mouse is naïve mice used negative control for BLI.

\section{Figure 2. The regulatory function of ITK in GVHD is T cell-intrinsic. (A) Purified WT} and Itk-/ CD8+ T cells were examined for expression of CD44 prior to transplantation. (B) Whole bone marrow cells isolated from C57B1/6 WT (CD45.2) and Itk-/ (CD45.1) mice 
were mixed, and transplanted into irradiated Thy1.1 C57Bl/6 mice. 9-10 weeks later CD8+ T cells were sorted by CD45.2 and CD45.1 expression (donor T cells) and exclusion of Thy 1.1 positive (host T cells). Isolated sorted T cells were examined for expression of CD44, and transplanted into irradiated BALB/c mice. This experiment were repeated three times. (C) Irradiated BALB/c mice were divided in four different groups and transplanted with the sorted T cells described in (B) as follows: Group one was transplanted with 10X106TCDBM alone (тсDBM). Group two was transplanted with 10X106тсDBM and 2X105 B-ALL-luc, (TCDBM+B-ALLluc). Group three were transplanted with 10X106 TCDBM along with 1X106 purified WT 1X106 CD8+ T cells and 2X105 B-ALL-luc (тсDBM+B-ALLluc+WT CD45.2). The fourth group were transplanted 10X106 TCDBM along with and 1X106 purified Itk-/CD8+ T cells and 2X105 B-ALL-luc (TCDBM+B-ALLluc+Itk-/ CD45.1). These mice were monitored for tumor growth using IVIS system. (D) The mice were monitored for survival, (E) changes in body weight, and (G) clinical score for 47 days post BMT. For body weight changes and clinical score, one representative of 2 independent experiments is shown $(n=3$ mice/group for BM alone; $\mathrm{n}=5$ experimental mice/group for all three groups). (G) Quantitated luciferase bioluminescence of luciferase expressing B-ALL-luc cells. Statistical analysis for survival and clinical score was performed using log-rank test and two-way ANOVA, respectively. One representative experiment out of 2. Survival is combination of 2 experiments, 3 mice per group of control T cells depleted bone marrow, and 5 mice per group for all the experimental group. $\mathrm{P}$ value presented with each figure. Note: Control mouse is naïve mice used negative control for BLI. 
Figure 3. Eomes expression, but not innate memory phenotype $\mathbf{T}$ cells, is required for

GVT effect. (A) Purified WT and Itk-/ T cells were examined for expression of CD44, CD122, and Eomes by flow cytometry. (B) Purified WT or Itk-^ T cells were transplanted into irradiated BALB/c mice, at day 7 purified $\mathrm{T}$ cells were sorted by $\mathrm{H} 2 \mathrm{~K}_{\mathrm{d}}, \mathrm{CD} 45.1$ and CD45.2 expression. Ex vivo purified T cells were used in cytotoxicity assay against primary tumor target B-ALLluc+ cells at 40:1, 20:1, 5:1 ratio. (C) Purified T cells were examined for perforin by western blot. Quantitative analysis of four experiments of perforin expression by western blot data normalized against $\beta$ Actin. (D) Itk/Il4ra DKO T cells were examined for Eomes expression pre- and post-transplantation. (E) $1 \mathrm{X} 106$ purified WT and Itk/Il4ra DKO CD8+ T and 1X106 purified CD4+ T cells were mixed and transplanted along with 2X105 primary B-ALL-luc+ cells into irradiated BALB/c mice. Host BALB/c mice were imaged using IVIS 3 times a week. Group one received T cell depleted bone marrow alone (TCDBM). Group two received T cell depleted bone marrow along with 1X105 B-ALL-luc cells $(\mathrm{TCDBM}+\mathrm{B}-\mathrm{ALL} / u c)$. Group three was transplanted with $1 \mathrm{X} 106$ purified WT $\mathrm{T}$ cells and 2X105 B-ALL-luc cells (TCDBM+B-ALL luc +WT CD8+CD4). Group four received 1X106 purified T cells from Itk/Il4ra DKO along with 2X105 B-ALL-luc cells (TCDBM+B-ALLluc+ Itk/Il4ra DKO CD8+CD4). Recipient animals were monitored for survival, (F) changes in weight, and (G) clinical score. (H) Tumor burden was monitored as in figure 1. One representative of 2 independent experiments is shown $(n=3$ mice/group for BM alone; $n=5$ experimental mice/group for all three groups. The survival group were combinations of all experiments). (I) Purified donor T cells from either WT or SLP76 Y145FKI Eomesflox/flox mice with or without CD4cre were transplanted into irradiated BALB/c mice. On day 7 donor T cells were purified as described and used in ex vivo cytotoxicity assay against B- 
ALLluc-cells at 40:1 ratios. (J) 1X106 purified WT SLP76 Y145FKI Eomesflox/flox with or without CD4cre CD8+ T cells and 1 X106 purified CD4+ T cells were mixed and transplanted along with 2X105 B-ALL-luc cells into irradiated BALB/c mice. Host BALB/c mice were imaged using IVIS 3 times a week. Group one received T cell depleted bone marrow alone as (тсDBM). Group two received T cell depleted bone marrow along with 2X105 B-ALL-luc cells (тсDBM+B-ALLluc). Group three were transplanted with 1X106 purified WT T cells 2X105 B-ALL-luc cells (тсDBM+B-ALLluc+WT CD8). Group four received 1X106 purified T cells from SLP76 Y145FKI Eomesflox/flox cross with CD4+cre along with 2X105 B-ALL$l u c$ cells (TCDBM+B ALLluc+SLP75Y145FKI EomesFF+CD4cre CD8). Group five received 1X106 purified SLP76 Y145FKI Eomesflox/flox without CD4cre T cells along with 2X105 BALL-luc cells (TCDBM+B-ALLluc+SLP75Y145FKI EomesFF+CD4cre- CD8). The mice were monitored for survival, (K) body weight changes, and (L) clinical score for 50 days post BMT. For weight changes and clinical score, one representative of 2 independent experiments is shown $(\mathrm{n}=3$ mice/group for BM alone; $\mathrm{n}=5$ experimental mice/group for all three group. The survival group were a combination of all experiments. (M) Quantitated luciferase bioluminescence of tumor growth. Statistical analysis for survival and clinical score was performed using log- Two-way ANOVA were used for statistical analysis confirming by students $t$ test, $\mathrm{p}$ values are presented. Note: Control mouse is nä̈ve mice used negative control for BLI.

Figure 4. ITK deficiency results in reduced cytokine production. (A) Serum from Several GVHD patients were Isolated and examine for inflammatory cytokines production (IL-33, IL1 $\alpha$, IFN- $\gamma$ and TNF- $\alpha$ and IL-17A) determined by ELISA (B) 1X106 purified WT or Itk-/ CD8+ T 
cells were transplanted with into irradiated BALB/c mice. (B) At day 7 the post allo-HSCT, recipient BALB/c were euthanized and serum cytokines (IL-33, IL1 $\alpha$, IFN- $\gamma$ and TNF- $\alpha$ and IL17A) determined by ELISA. (C, D) Intracellular IFN- $\gamma$ and TNF- $\alpha$ expression by donor CD8+ T cells after stimulation with anti-CD3/anti-CD28 as determined by flow cytometry. Combined data from 3 independent experiments is shown for (C). (E) Flow cytometry analysis of purified WT and $I t k-/$ T cells that were mixed at a 1:1 ratio for transplantation into irradiated BALB/c mice. At day 7 donor T cells were gated for expression of $\mathrm{H}-2 \mathrm{~Kb}, \mathrm{CD} 45.1$, and CD45.2 and analyzed intracellular expression of IFN- $\gamma$ and TNF- $\alpha$ by flow cytometry after stimulation with anti-CD3/anti-CD28. Combined data from 4 independent experiments is shown, and the $\mathrm{p}$ values for each experiment is shown. (F) Purified WT or Itk-/- donor T cells were transplanted into irradiated BALB/c. At day 7 donor cells were analyzed for donor T cells proliferation by examining BrDU incorporation by flow cytometry. (G) Purified WT and Itk-/- donor T cells were mixed 1:1 ratio and transplanted into irradiated BALB/c, at day 7 donor $T$ cells were gated for the expression of $\mathrm{H}-2 \mathrm{~Kb}, \mathrm{CD} 45.1$, and CD45.2 and analyzed for BrDU incorporation. (H) Purified WT and Itk-/T cells were examined for the expression and phosphorylation of IRF4, JAK1/2 and STAT3 by western blot. (I) Quantitative analysis from western blots using ImageJ to normalize to $\beta$ Actin, data from 3 independent experiments. For statistical analysis we used two-way ANOVA and student's $t$ test, p values are presented.

\section{Figure 5. ITK/SLP76-Y145 signaling axis is required for $T$ cell migration to the GVHD}

target tissues. (A) Irradiated BALB/c mice were allo-HSCT-transplanted and injected with FACS-sorted WT and Itk-/ CD8+ T cells mixed at a 1:1 ratio. FACS analysis of sorted T cells pre-transplant shown. (B) At day 7 post-BMT, the spleen, liver, and small intestine (SI) 
were examined for donor WT and Itk-/ T cells. The ratio of WT: Itk-/ CD8+ T cells in the organs was determined. (C) At day 7 post-allo-HSCT, small intestines were examined by H\&E staining. (D) Irradiated BALB/c mice were BM-transplanted and injected with CD8+ T cells from luciferase-expressing WT or Itk-/ mice. Total bioluminescence from the spleen, pLN, liver, and SI, and representative bioluminescence images are shown on day 7 postHSCT, and quantified bioluminescence. (E) Purified WT or Itk-/- donor T cells were transplanted into irradiated BALB/c. At day 7 donor cells were analyzed for donor T cell proliferation in recipient liver and small intestine (SI) by examining BrDU incorporation by flow cytometry. (F) On Day 7 post-allo-HSCT, donor CD8+ T cells were isolated and examined for the expression of Aplnr, Cxcr5, Accr2, CCL12, CCL2, CCL5, CCr9, Ackr4, and Cmtm4 using q-RTPCR. p values were calculated using 2-way ANOVA and Student's $t$ test, p values are listed. (G) Irradiated BALB/c mice were transplanted with C57B1/6derived BM and FACS-sorted WT or Itk-/ CD8+ T cells, and challenged subcutaneously with luciferase-expressing B-All luc cells. Recipient animals were monitored for weight changes. Group one of recipient mice were transplanted T cells depleted bone marrow (TCD $\mathrm{BM})$. The second group of recipient mice were transplanted $\mathrm{T}$ cells depleted bone marrow and primary B-ALL luciferase $(\mathrm{TCDBM}+\mathrm{B}-\mathrm{ALL}$ luc $)$. The third group of recipient mice were transplanted WT T cells along 2X10s primary tumor cells B-ALL-luc (тсDBM+BALLluc + WT CD8). The fourth group of recipient mice were transplanted with T cell depleted bone marrow and primary B-ALL-luc, along with Itk-/- T cells (TCDBM+B-ALLluct Itk-/CD8). Representative bioluminescence images of tumor-bearing mice on days 9, 16, 30, 38, and 47 are shown. Note: Control mouse is naïve mice used negative control for BLI. 
(H) Animals were monitored for survival over 47 days. (I) Changes in weight loss. (J) Animals were monitored for clinical score. (K) Recipient mice were monitored for tumor growth using the IVIS imaging system and quantified. For weight changes and tumor burden, one representative of 2 independent experiments is shown ( $n=3$ mice/group) for control and $n=5$ mice for WT and n=5 mice for Itk-^. Survival group was combined from both experiments. P values were calculated using two-way ANOVA and Student's $t$ test, p values are listed.

Figure 6. ITK differentially regulates gene expression in T cells during GVHD. WT and Itk-/CD8+ T cells were FACS sorted then transplanted into irradiated BALB/c mice. At day 7 posttransplant, donor T cells were sort isolated (based on FACS expression of $\mathrm{H}-2 \mathrm{~Kb}, \mathrm{CD} 3$ and CD8) from host spleen and small intestine (Gut). Sorted donor T cells were subjected to RNA sequencing. (A) Principal component analysis of genes with $\geq 2$-fold change in any pairs of group combinations, with false discovery rate $(\mathrm{FDR}) \leq 0.05$. WT-Pre and Itk-/-Pre-denote cells prior to transfer, and WT-Spl, WT-Gut, and Itk-/-Spl denote cells isolated from the spleen (Spl) or small intestine (Gut) of the recipients post transfer. (B\&C) Venn diagram of genes that are $\geq$ 2-fold up- or down- regulated in the indicated comparisons, with FDR $(P) \leq 0.05$. (D-E) Heat map of 23 genes that are up-regulated in WT-Gut only. (F) Differentially expressed genes were enriched for pathway analysis comparing WT and Itk-/.. (G) WT and Itk-/. CD8+ T cells were FACS sorted then transplanted into irradiated BALB/c mice. At day 7 post-transplant, donor T cells were sort isolated (based FACS expression of H-2Kb, CD3 and CD8) from host spleen and small intestine (Gut). Total RNA was isolated from sorted donor T cells were and qPCR performed. 


\section{Figure 7. Development of a peptide that disrupts the interaction between SLP76 and ITK.}

(A) NMR Spectroscopy structures of murine ITK SH2 domain showing its complex with SLP76pTYR peptide containing a pTyr residue. The SH2 domain is rendered in surface representation (wheat), while the peptide with sequence (ADpYEPP) is shown in stick model (PDB code:2ETZ40), and (B) Electrostatic profile shown, calculated using the APBS plugin in Pymol. (C) Top: Organization of the domain architecture of ITK, and amino acid 132-152 of SLP76 adapter protein respectively. Bottom: Design of the novel peptide, SLP76pTYR, that inhibits the SLP76-mediated ITK signaling. (D). T cells were examined for percentage FITC positive by fluorescence microscopy. (E) A single cell in focal plane near the cover glass, was imaged. (F) Primary cells cultured with SLP76pTYR or scrambled peptide were washed and examined for FITC expression by flow cytometry. (G) Quantification of the expression in (F). For statistical analysis two-way ANOVA and confirmation by Student's $t$ test were performed.

Figure 8. Novel peptide SLP76pTYR specifically targets ITK signaling and enhances Treg cell development. (A) Total T cells stimulated in the presence of SLP76pTYR or vehicle alone were examined for CD4+ and FoxP3+. n=3 one representative experiment shown. (B) Quantification of three experiments as in (A). (C) Cell lysates from T cells stimulated in the presence of SLP76pTYR or vehicle alone were examined for phosphorylation of ITK, PLC $\gamma 1$ and ERK. Lysates were also examined for phosphorylation of PI3K, mTOR, P13K, and AKT. $\mathrm{n}=3$ one representative experiment shown. (D) Western blots were normalized to $\beta$-Actin and quantitative data from 3 independent experiments presented. (E) Human GVHD patients' samples were cells stimulated in the presence of SLP76pTYR or vehicle only. T cell lysates were used in western blots for analysis of pPLC $\gamma, \mathrm{pERK}, \mathrm{pAKT}, \mathrm{pMTOR}$, and $(\mathbf{H})$ three experiments 
were quantitated and normalized to $\beta$-Actin. $n=3$, one representative experiment shown. (G) Primary human T cells purified from PBMC were stimulated with CD3 and CD28 for 5 hours in the presence of vehicle alone or SLP76pTYR in the presence BFA. Intracellular IFN- $\gamma$ and TNF$\alpha$ expression by CD8+ and CD4+ T cells was determined by flow cytometry. For statistical analysis we used two-way ANOVA and Student's $t$ test. $\mathrm{P}$ values are presented.

\section{Inhibition of T cells by peptide SLP76pTYR allows tumor clearance without inducing}

GVHD. Purified WT CD8+ and CD4+ T cells were mixed (1X106 each) at a 1:1 ratio, and transduced with viruses containing SLP76pTYR or empty vector, then transplanted along with 1X105 B-ALL-luc cells into irradiated BALB/c mice. Host BALB/c mice were imaged using IVIS 3 times a week. (A) Group one received T cell depleted bone marrow alone (TCDBM). Group two received T cell depleted bone marrow along with 2X105 B-ALL-luc cells, $(\mathrm{TCDBM}+\mathrm{B}-\mathrm{ALL} l u c)$. The third group was transplanted with a 1:1 ratio of purified WT CD8+and CD4+ T cells (1X106 each) along with 2X105 B-ALL-luc cells (TCDBM+B-ALLluc+WT CD8+CD4). Group four received a 1:1 ratio of purified CD8+ and CD4+ T cells (1X106 each) transduced with control viruses along with 2X105 B-ALL-luc cells (TCDBM+B-ALLluc +Control CD8+CD4). Group four received a 1:1 ratio of purified CD8+ and CD4+ T cells (1X106 each) transduced with SLP76pTYR viruses along with 2X105 B-ALL-luc cells (TCDBM+BALLluc + Control CD8+CD4) (B) The mice were monitored for survival, (C) body weight changes, and (D) clinical score for 40 days post BMT. For weight changes and clinical score, one representative of 2 independent experiments is shown ( $\mathrm{n}=3$ mice/group for BM alone; $\mathrm{n}=5$ experimental mice/group for all three group). (E) Quantitated luciferase bioluminescence of 
bioRxiv preprint doi: https://doi.org/10.1101/2020.07.15.204693; this version posted July 15, 2020. The copyright holder for this preprint (which was not certified by peer review) is the author/funder. All rights reserved. No reuse allowed without permission.

tumor growth. Statistical analysis for survival and clinical score was performed using log-rank test and two-way ANOVA, respectively. 


\section{Supplementary Figure Legends}

Supplementary Figure 1. CD4+ T cells from Itk-/- and SLP76 Y145F mice exhibit attenuated induction of GVHD compared to WT T cells. (A, D) 1X106 purified WT or Itk-/ CD4+ T cells (A) or WT or SLP76 Y154FKI CD4+ T cells (D) were transplanted into irradiated BALB/c mice. The mice were monitored for survival, $(\mathbf{B}, \mathbf{E})$ changes in body weight, $(\mathbf{C}, \mathbf{F})$ clinical score for 70 days post BMT. For weight changes and clinical score, one representative of 2 independent experiments is shown $(\mathrm{n}=3$ mice/group for $\mathrm{BM}$ alone; $\mathrm{n}=5$ experimental mice/group for all three groups). The and $\mathrm{p}$ vales are presented. Two-way ANOVA and Student's $t$ test were used for statistical analysis.

\section{Supplementary Figure 2. Disruption of ITK $\rightarrow$ SLP76 Y145 signaling allows tumor clearance without inducing GVHD. 1X106 purified WT or SLP76 Y145FKI CD8+ T cells,} and $1 \mathrm{X} 106$ purified CD4+ $\mathrm{T}$ cells were mixed at a 1:1 ratio, and transplanted along with 2X105 A20-luc cells transplanted into irradiated BALB/c mice. Host BALB/c mice were imaged using IVIS 3 times a week. (A) Group one received T cell depleted bone marrow alone (тсDBM). Group two received T cell depleted bone marrow along with 2X105 A20-luc cells, (TCDBM+B-ALLluc). The third group was transplanted with 1 X106 purified WT CD8+ and 1 X106 CD4+ T cells (1:1 ratio) along with 2X105 A20-luc cells (TCDBM+B-ALLluc+WT CD8+CD4). Group four received 1X106 purified SLP76 Y145FKI CD8+ and 1X106 CD4+T cells (1:1 ratio) along with 2X105 B-ALL-luc cells (TCDBM+A20luc+Itk-/- CD8+CD4). (B) The mice were monitored for survival, $(\mathbf{C})$ body weight changes, and (D) clinical score for 65 days post BMT. For weight changes and clinical score, one representative of 2 independent experiments is shown $(\mathrm{n}=3$ mice/group for BM alone; $\mathrm{n}=5$ experimental 
mice/group for all three group). (E) Quantitated luciferase bioluminescence of tumor growth. Statistical analysis for survival and clinical score was performed using log-rank test and two-way ANOVA, respectively. Note: Control mouse is nä̈ve mice used negative control for BLI.

\section{Supplementary Figure 4. Eomes expression in T cells from Itk/Il4ra DKO and SLP76} Y145FKI Eomesflox/flox mice. (A) Purified T cells from WT and Itk/Il4ra DKO mice were isolated and transplanted into irradiated BALB/c mice. At day 7 donor T cells were gated for expression of $\mathrm{H}-2 \mathrm{~Kb}$ and $\mathrm{CD} 45.2$, and intracellular expression of Eomes pre and posttransplantation was analyzed. (B, C) Purified T cells from SLP76 Y145FKI Eomesflox/flox mice with or without CD4cre were transplanted into irradiated BALB/c mice. Pre- (B) and 7 days post-transplantation (C) of T cells from WT or SLP76 Y145FKI Eomesflox/flox mice with or without CD4cre, T cells were examined for Eomes expression.

\section{Supplementary Figure 4. T cells from Itk-/- mice are capable of cytokine production.}

Purified WT and Itk-/. T cells were transplanted into irradiated BALB/c mice. At day 7 donor T cells were gated for expression of $\mathrm{H}-2 \mathrm{~K}$, and CD45.2 and analyzed for intracellular expression of IFN $\gamma$ and TNF- $\alpha$ following ex vivo stimulation with PMA/ionomycin. Data from several experiments were combined and statistical analysis performed using two-way ANOVA and Student's $t$ test, with p values presented 


\section{Supplementary Figure 5. 10n and CTA056 ITK inhibitors are not specific.}

(A) WT T cells were cultured with either 10n or vehicle, then lysed post incubation and lysates were western blotted for pITK, pPLC $\gamma 1$ and pERK, pAKT, and pMTOR. (B) Western blots from three experiments were quantitated and normalized to $\beta$ Actin. (C) WT T cells were cultured with commercially available ITK inhibitor CTA056 or vehicle, and western blotted for pITK, pPLC $\gamma 1$ and pERK, pAKT, and pMTOR. (D) Western blots from three experiments were quantitated and normalized to $\beta$ Actin. (E) T cells from primary human PBMCs were isolated and cultured with either 10n or vehicle, the cells were lysed post incubation and lysates were western blotted for pPLC $\gamma 1$ pAKT, pMTOR and pERK. (F) Western blots from three experiments were quantitated and normalized to $\beta$ Actin. Two-way ANOVA and Student's $t$ test were using for statistical analysis.

Supplementary Figure 6. SLP76pTYR peptide is not toxic to cells. Yac1 and B-ALL-luc cells were cultured in 96 well plates in 3 replicates in the presence of vehicle only or increasing concentrations of SLP76pTYR as indicated. Cell were examined at 0 hrs., 2 hrs., 4 hrs. and 6 hrs. Two-way ANOVA and Student's $t$ test were used for statistical analysis. 
A

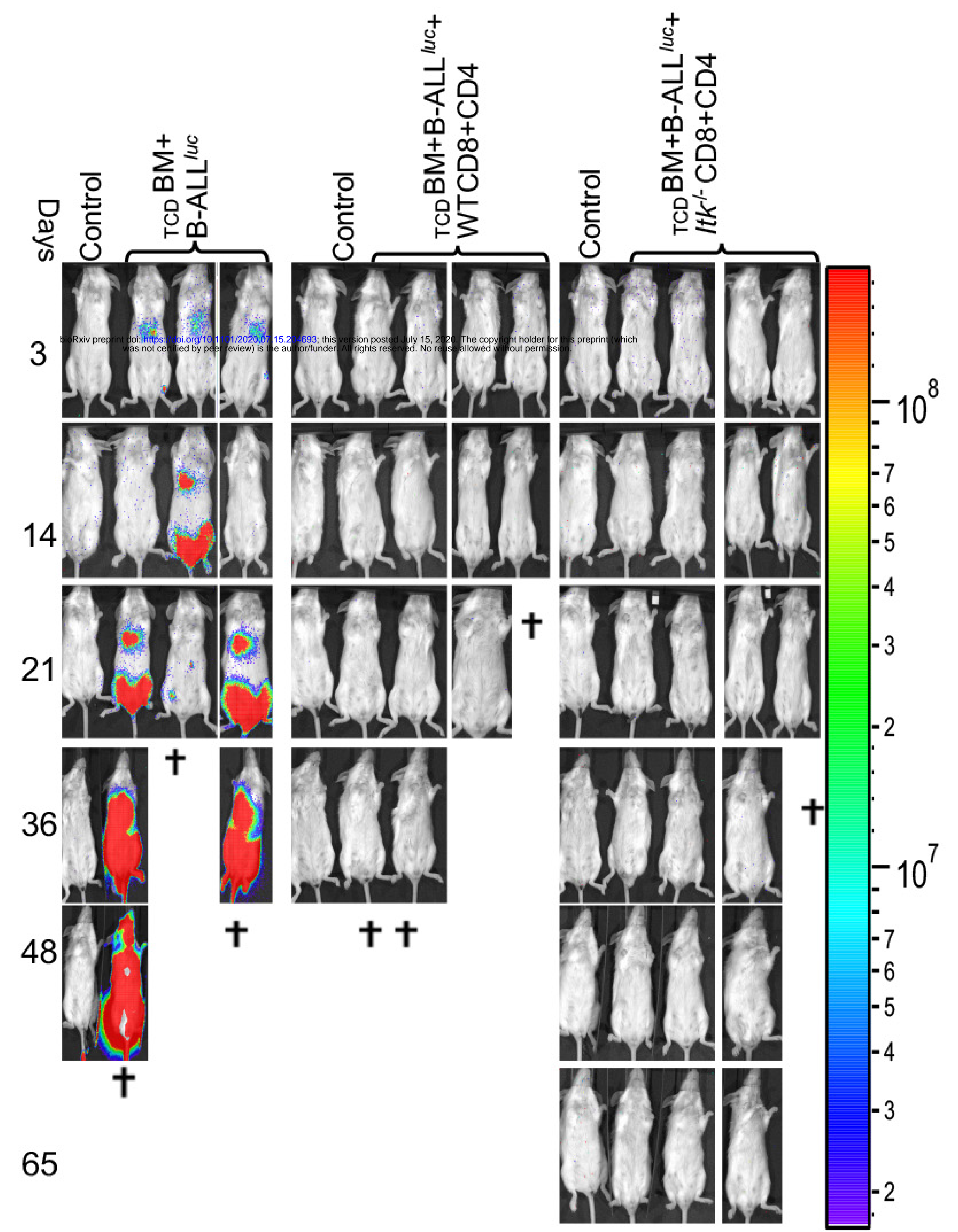

B

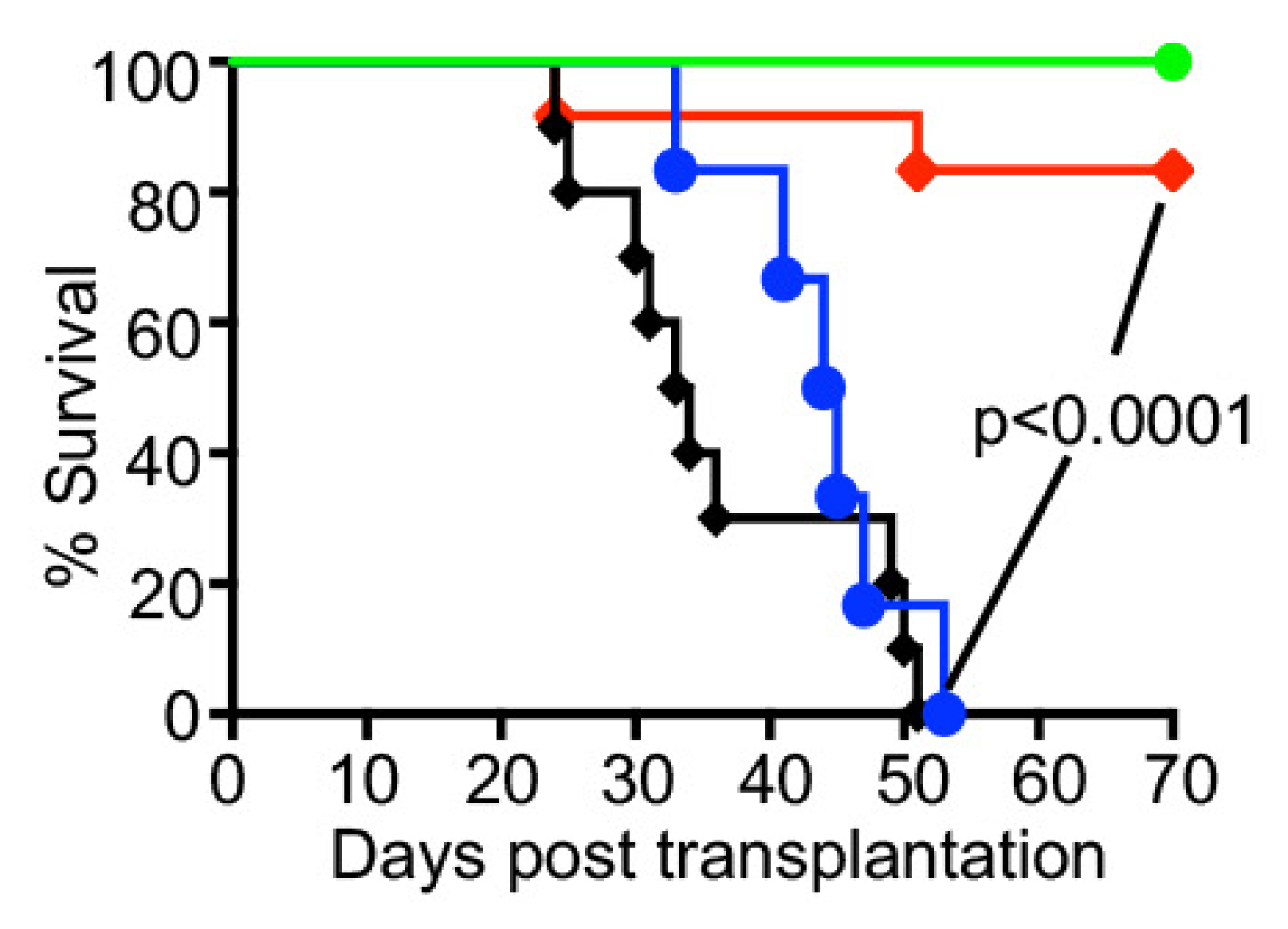

D

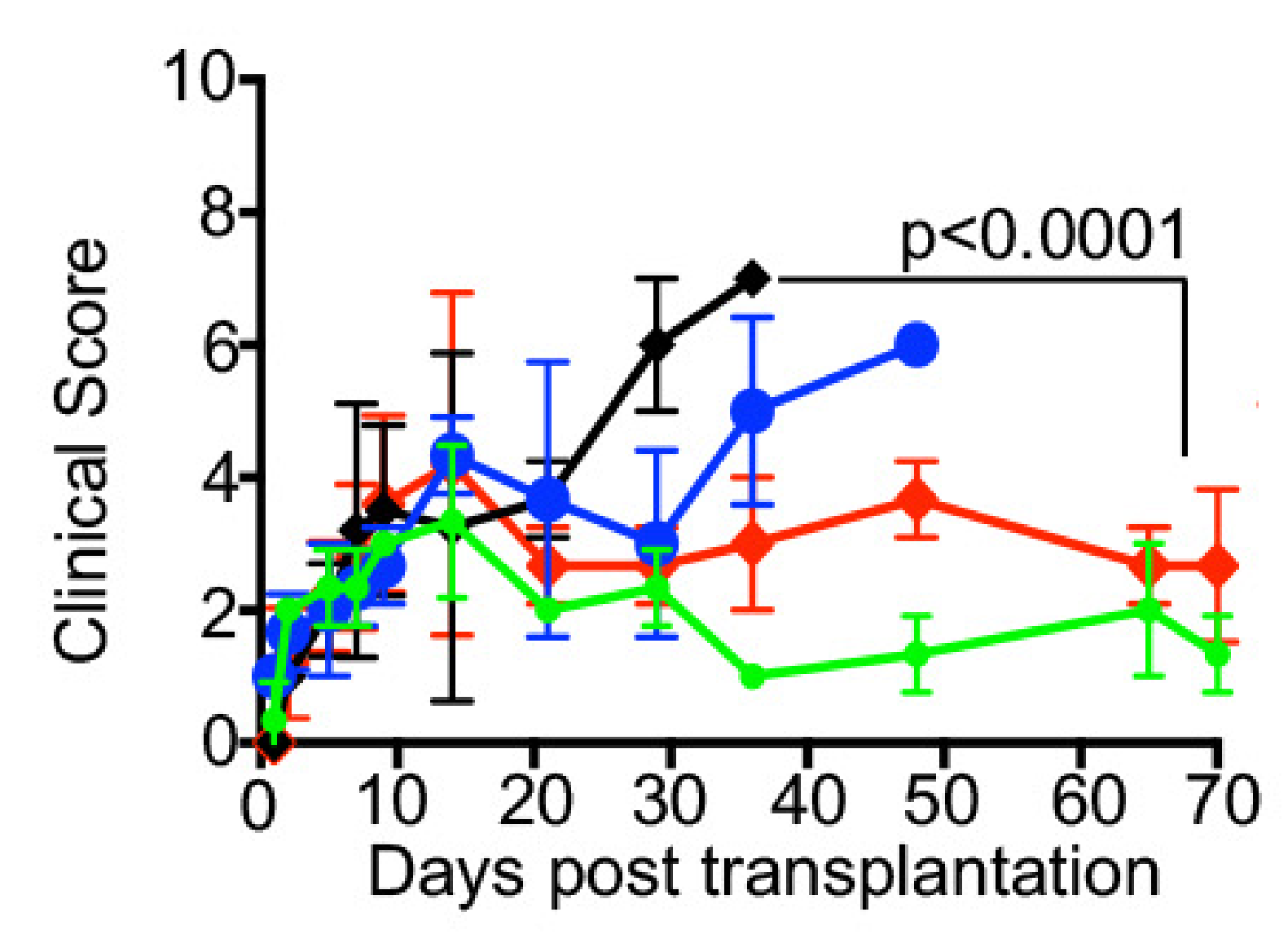

C

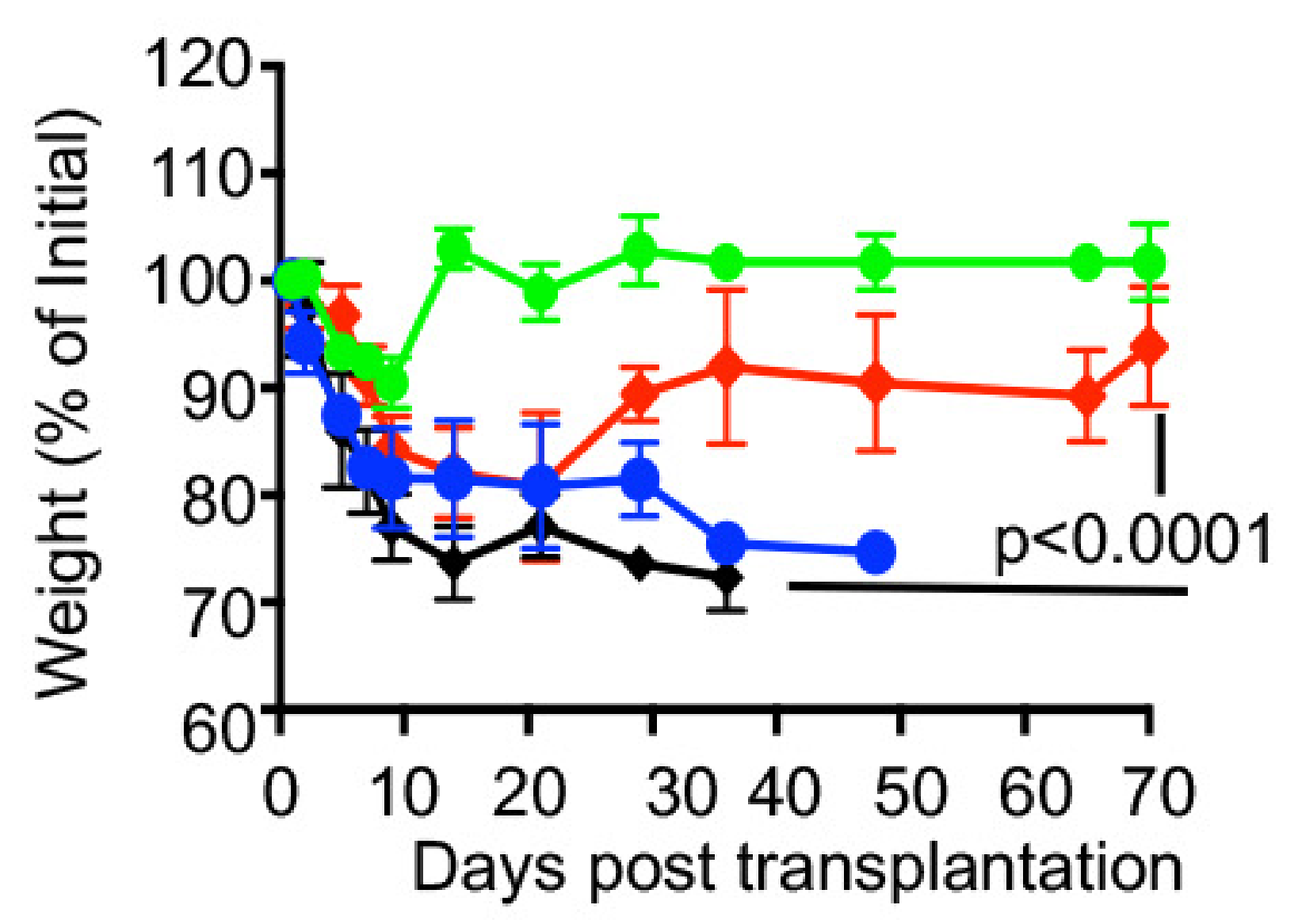

-TCD BM

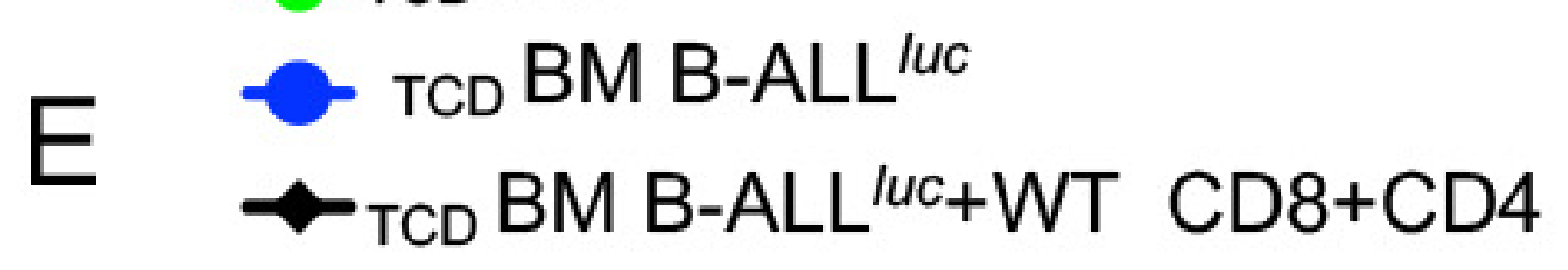

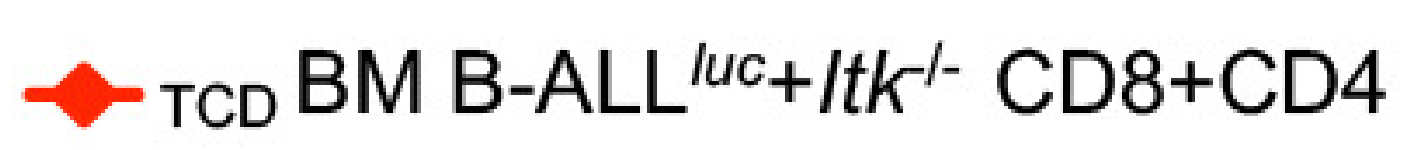

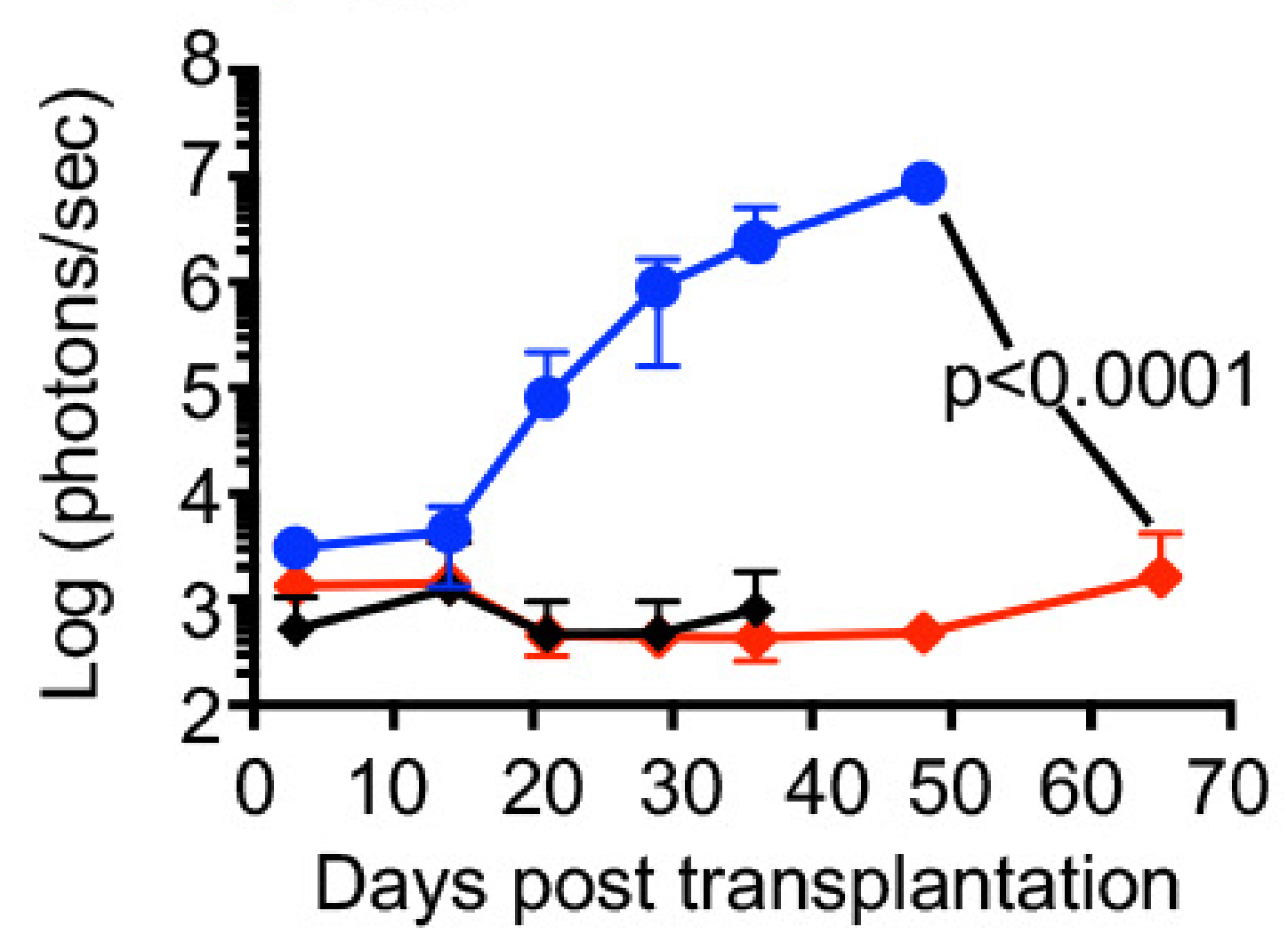




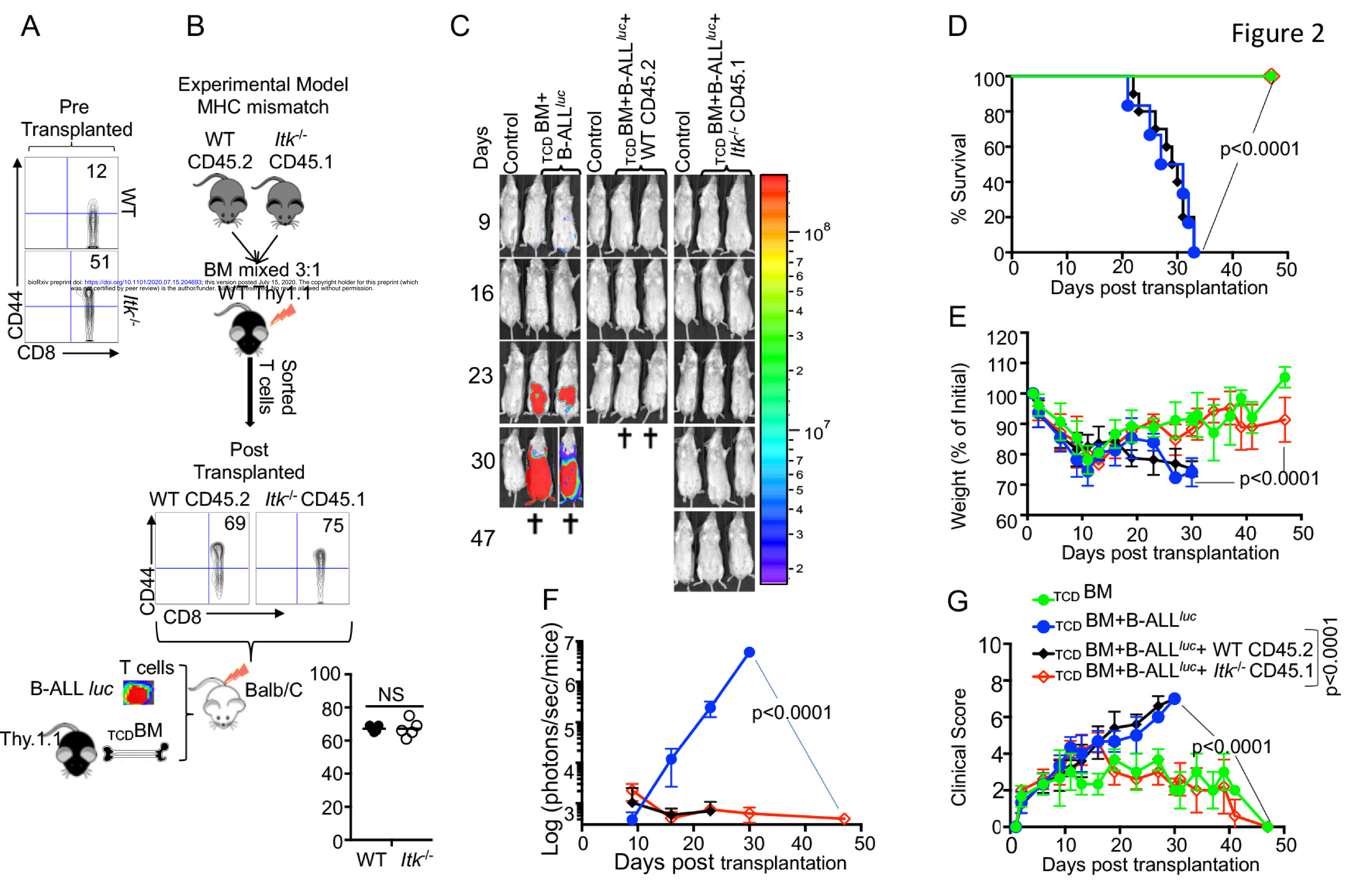




\section{A}

Pre transplant

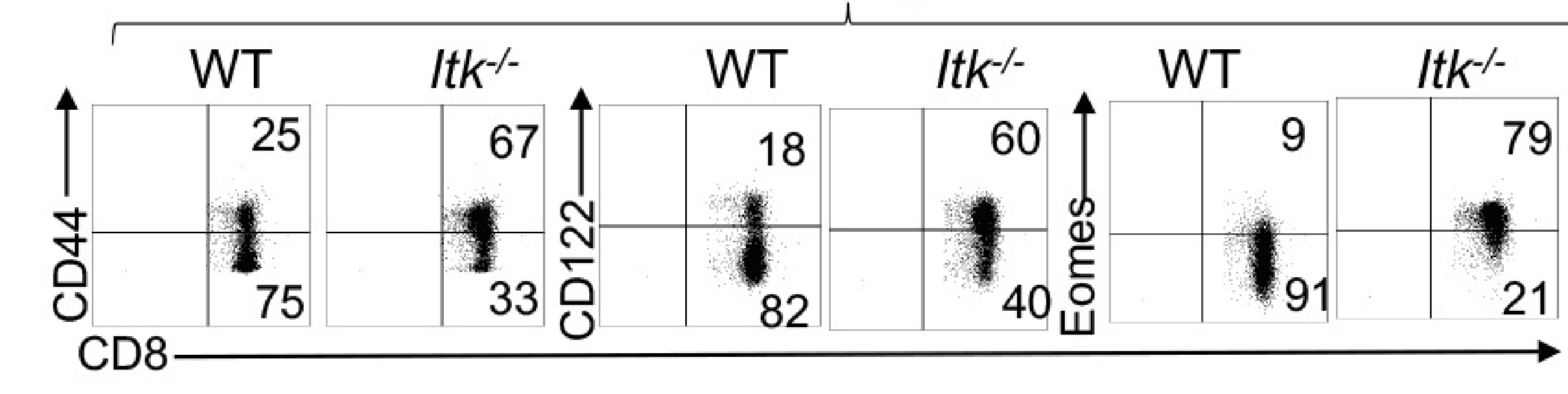

E
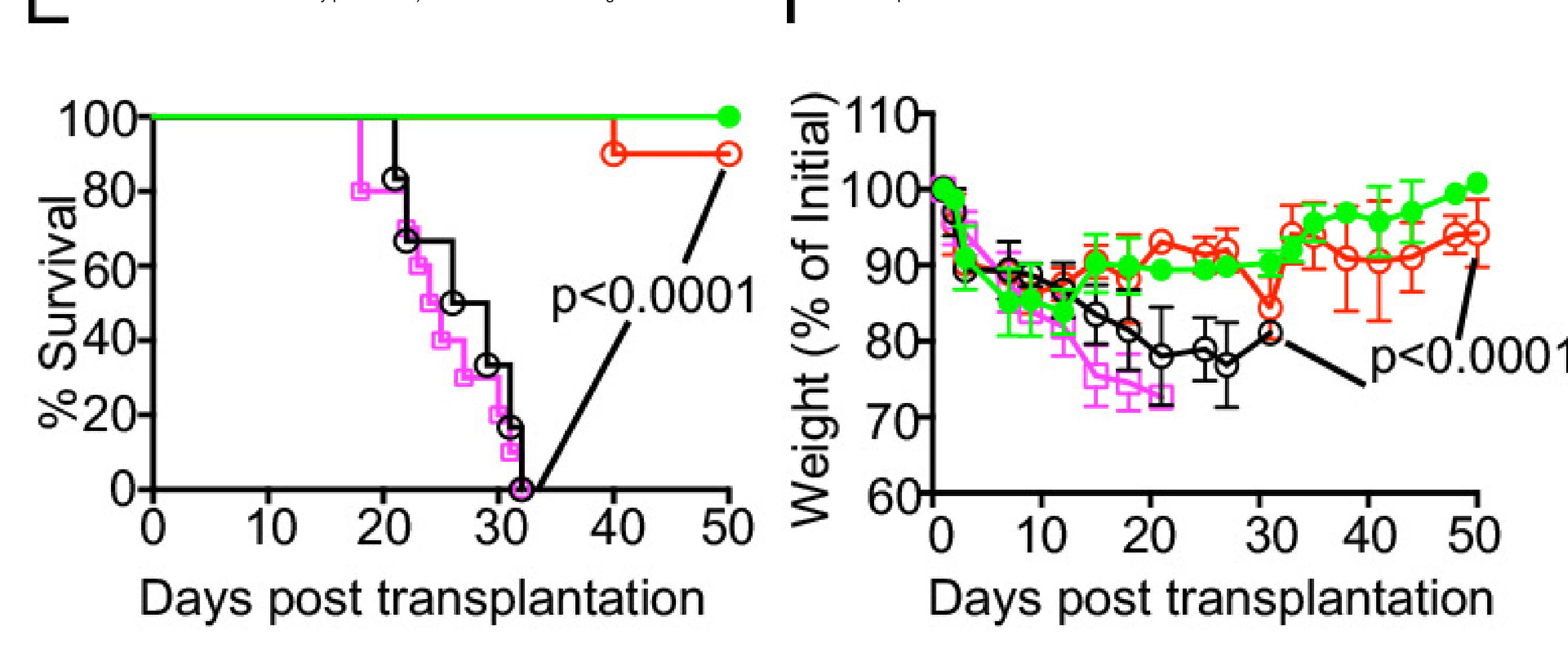

B

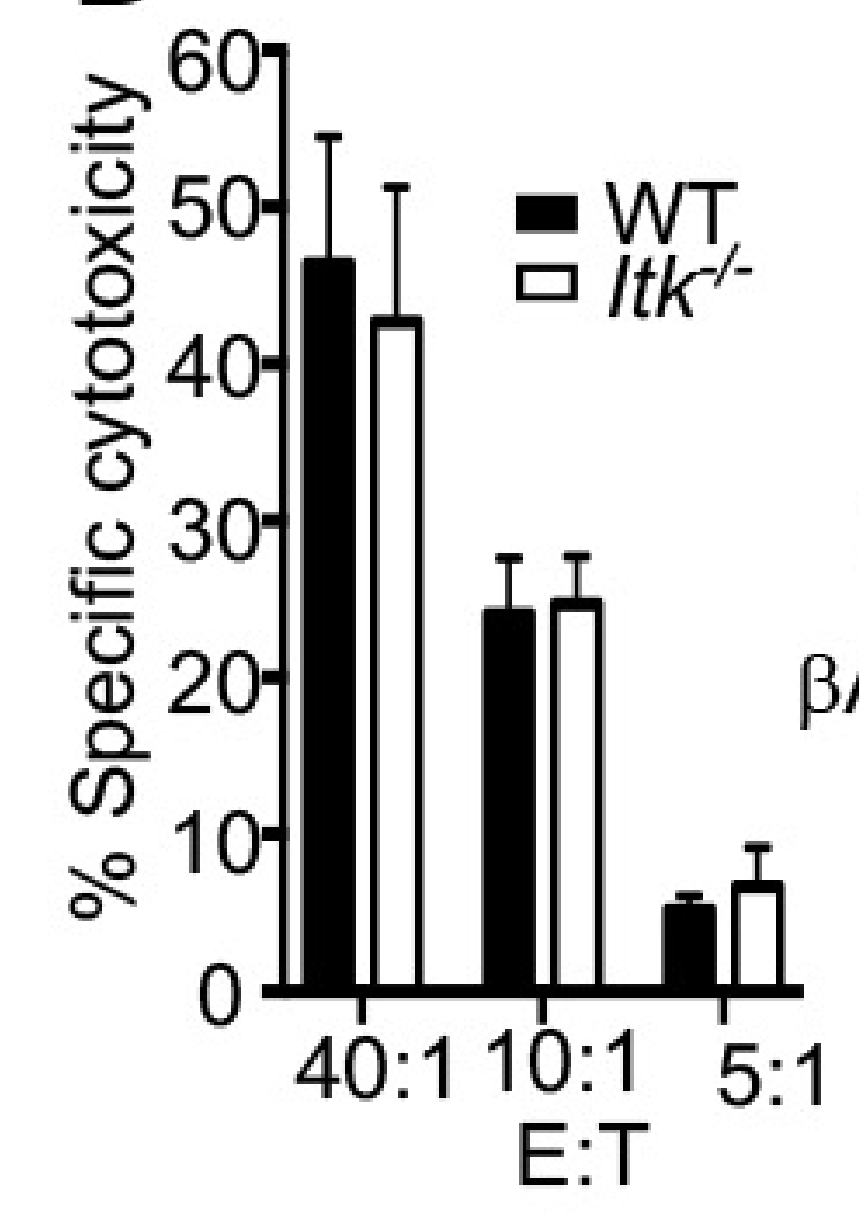

G

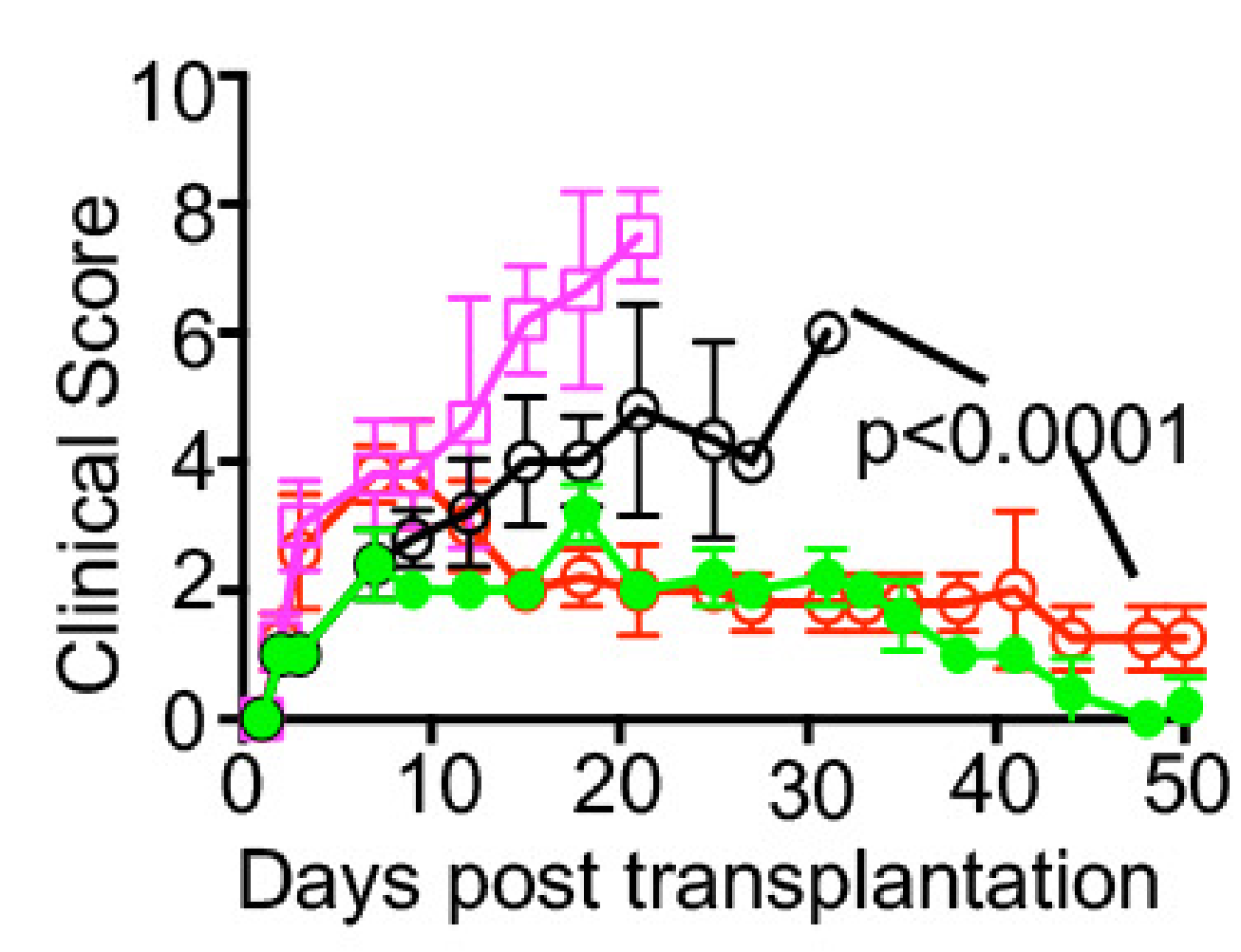

C

D

Figure 3

\begin{tabular}{l}
1 \\
3 \\
\hline 0 \\
$\bar{x}$
\end{tabular}

1

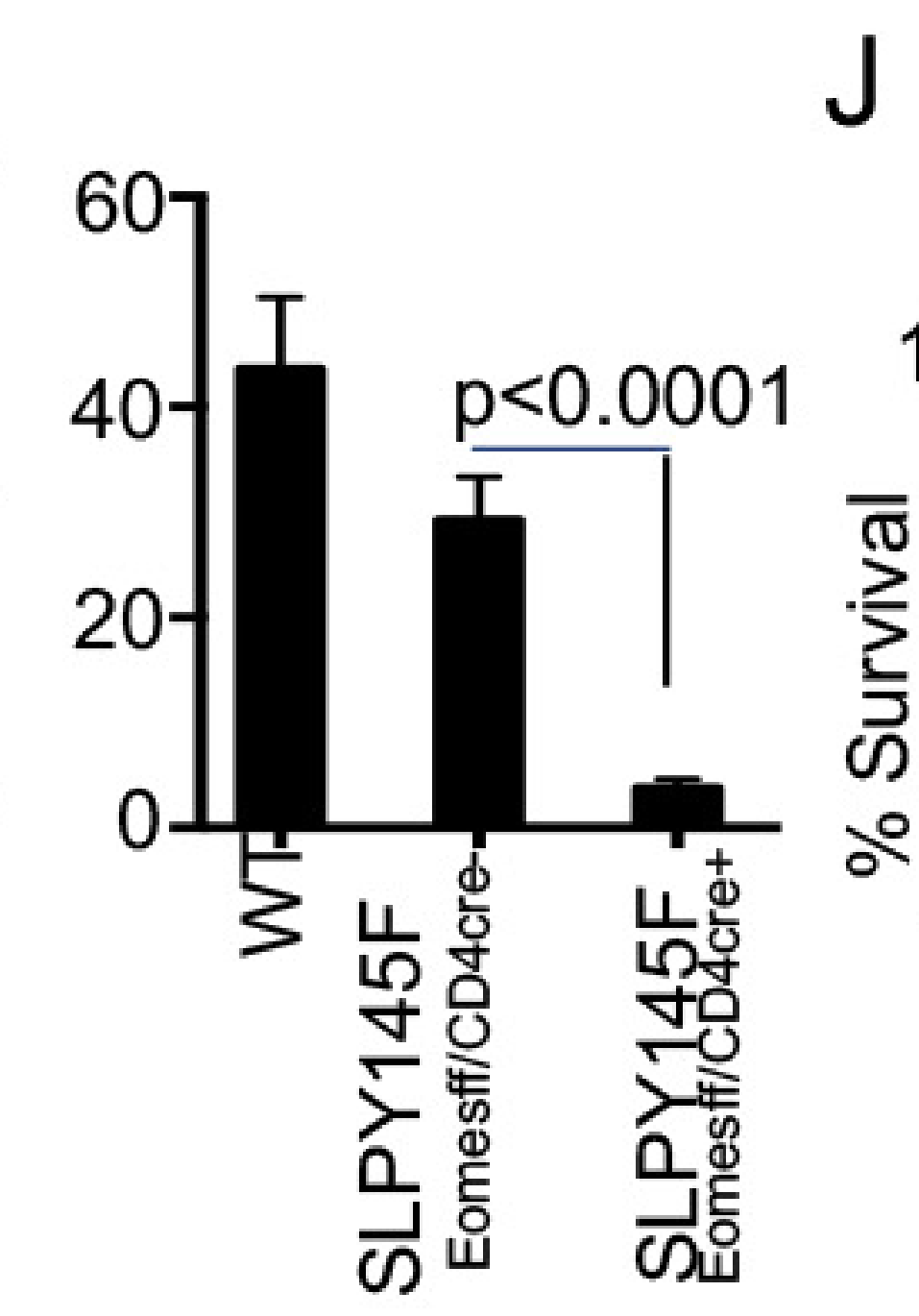

J

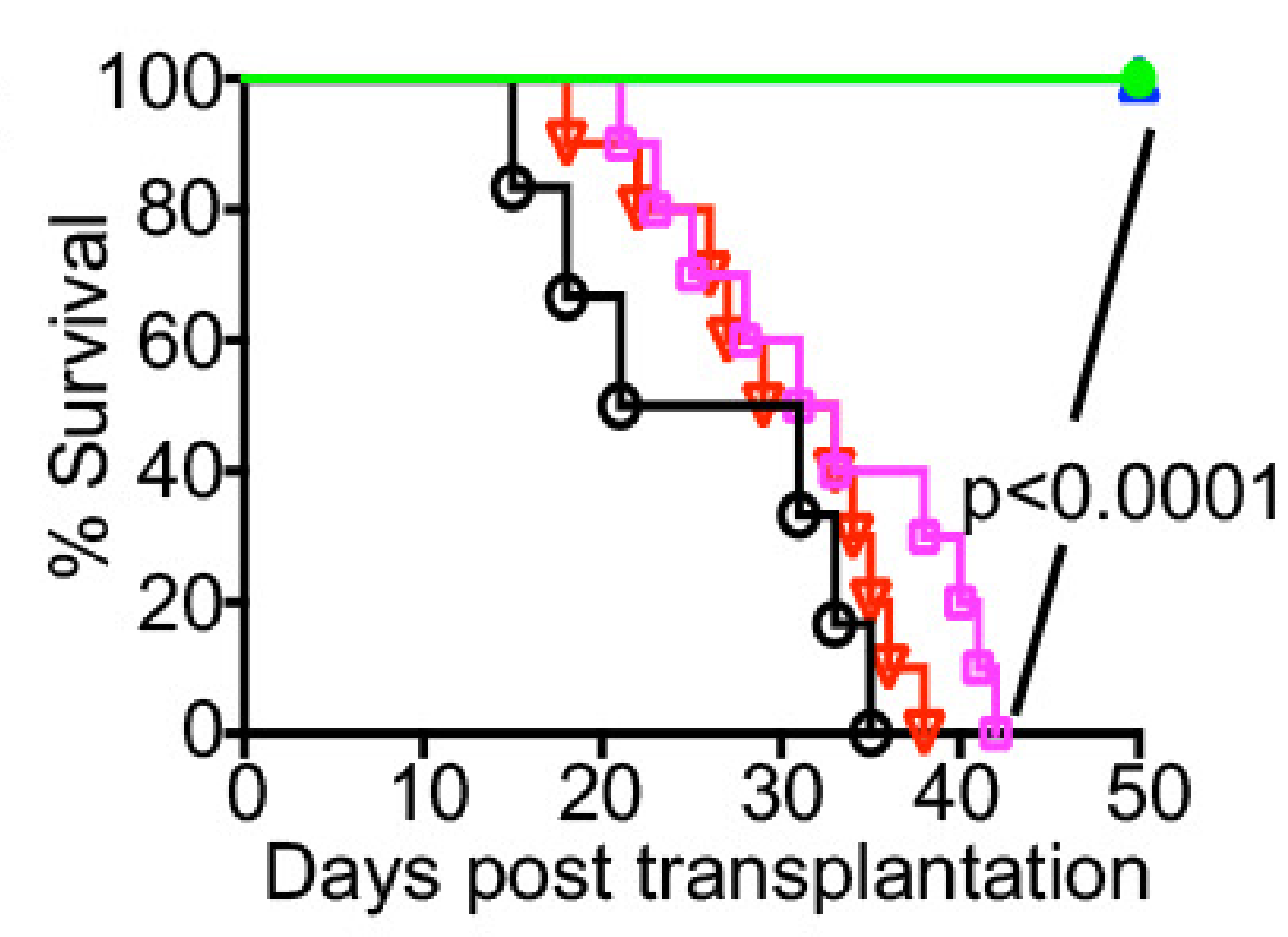

K

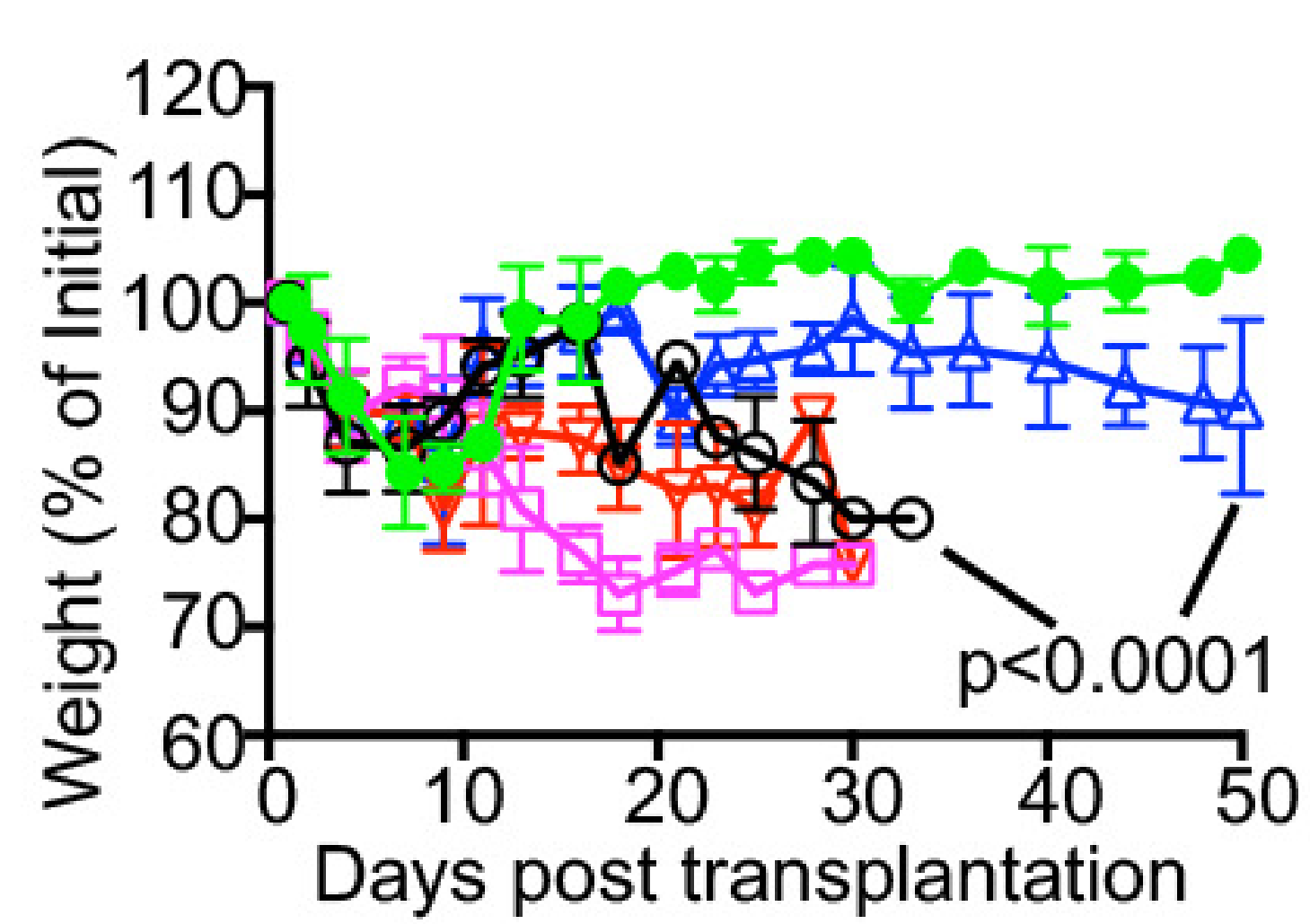

\section{L}

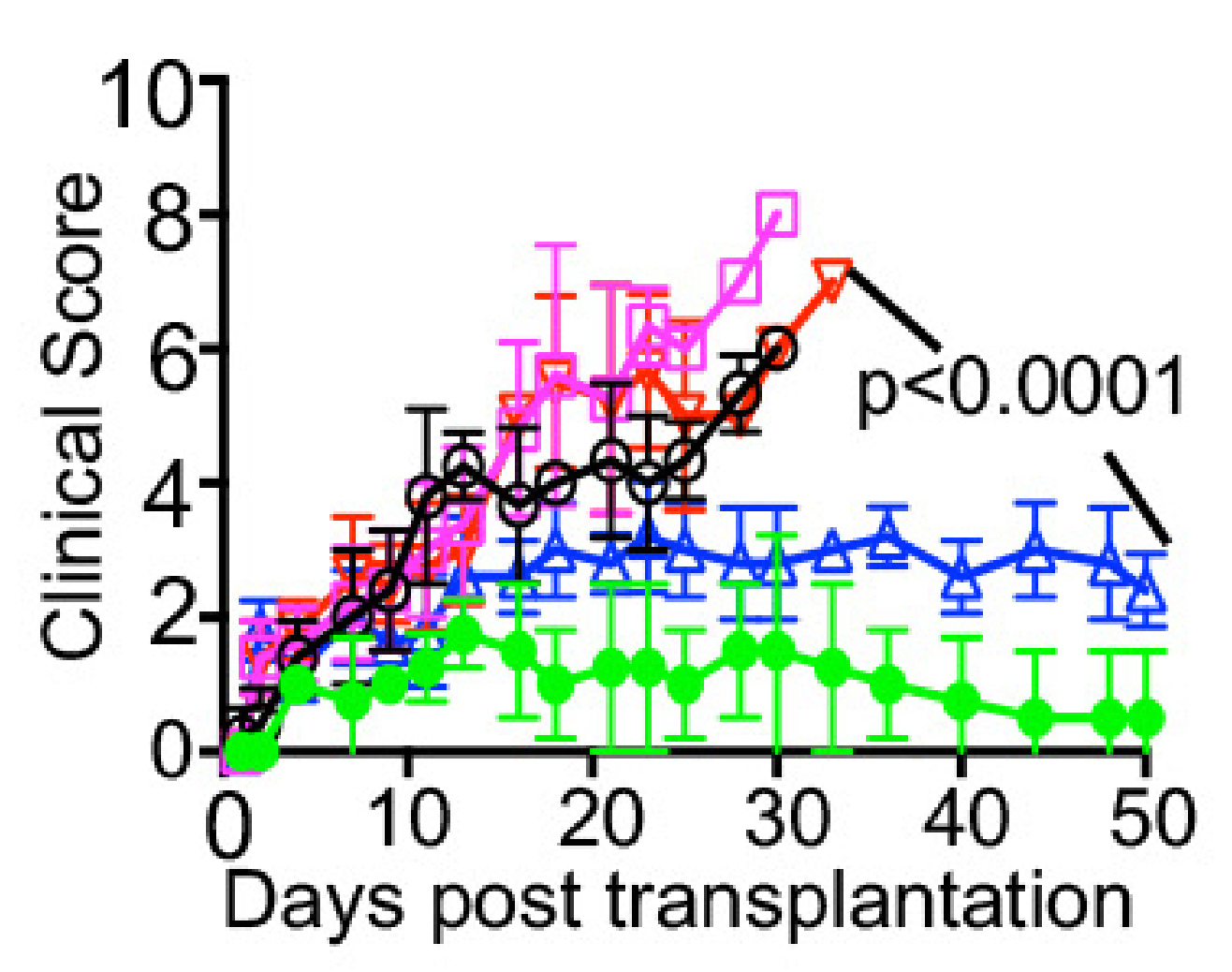

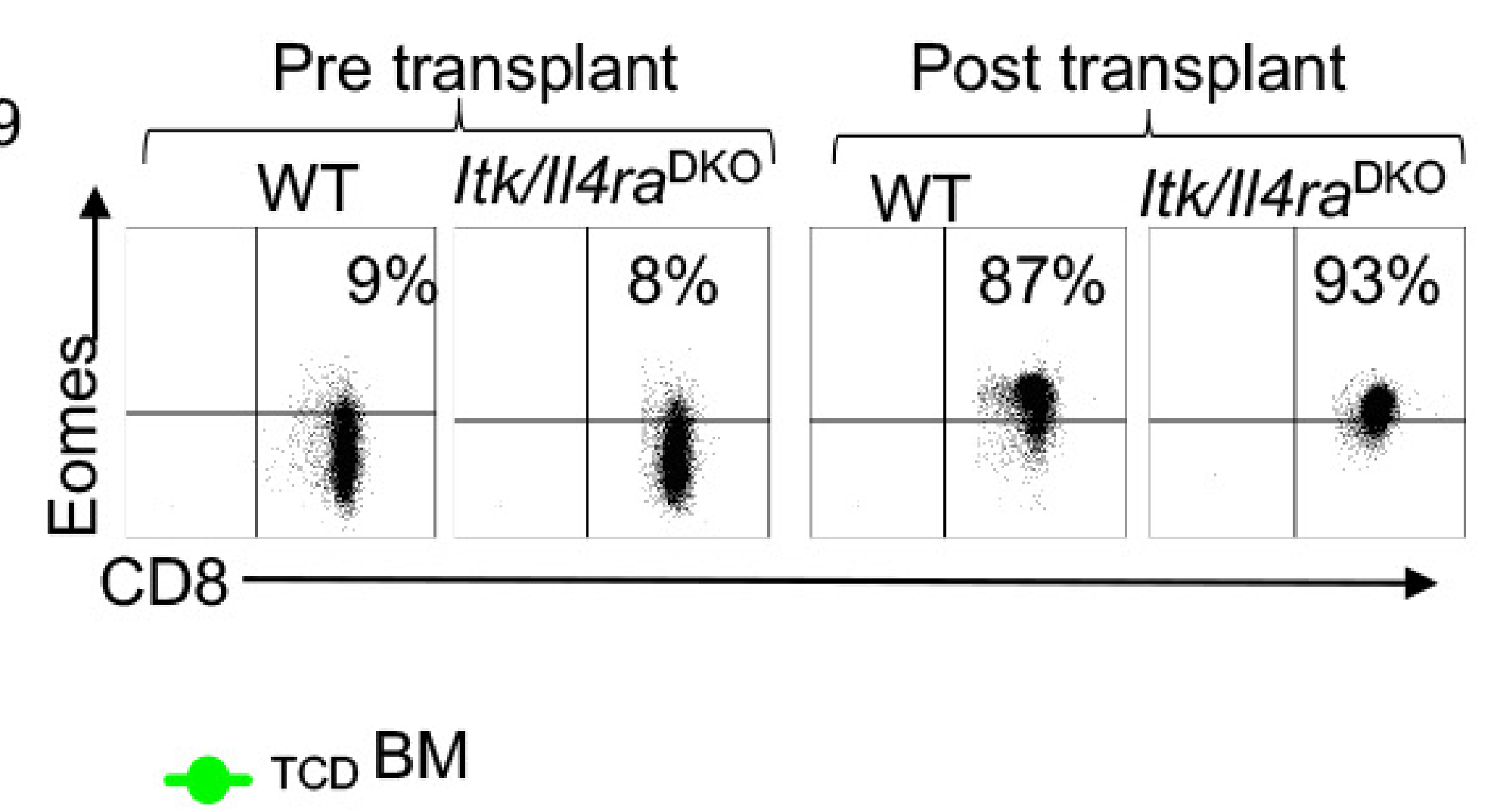

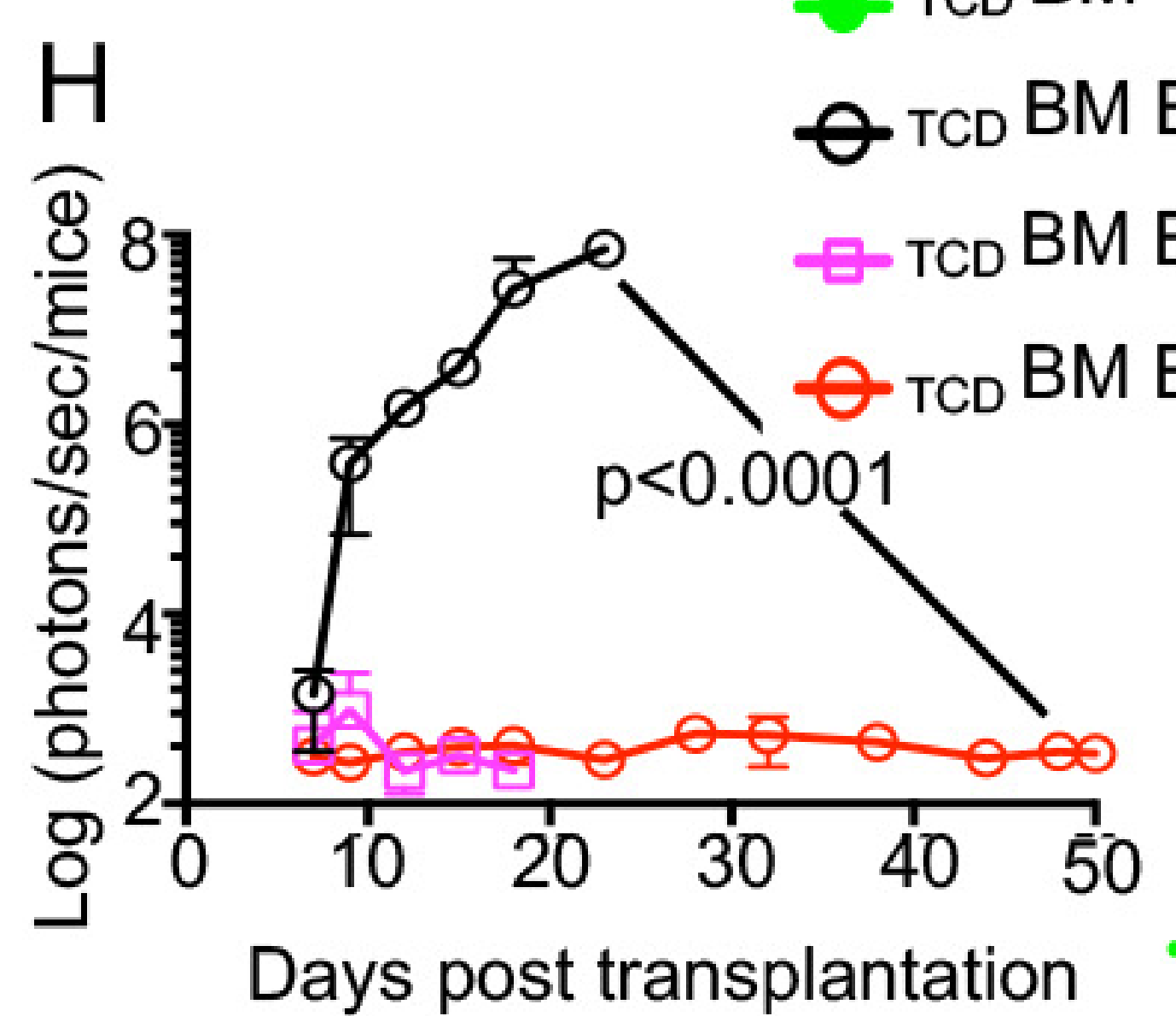

TCD BM

$\theta^{T C D} B M+B-A L L^{l u c}$

M GTCD BM B-ALL ${ }^{l u c}+$ WT CD8 ${ }_{T C D} B M+B-A l^{l / u c}+S L P Y 145 F$ 7 EomesfftcD4cre+ CD8

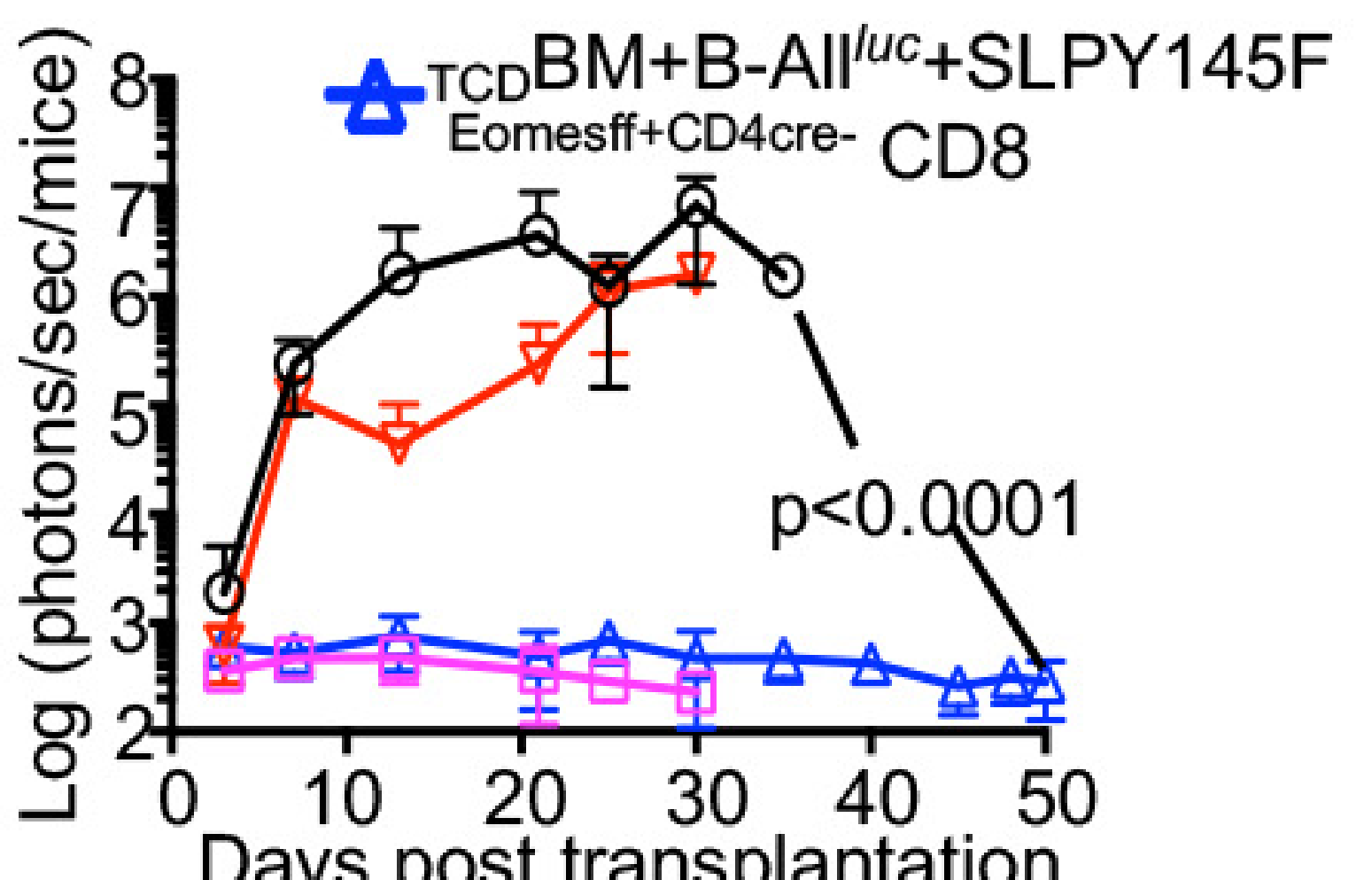




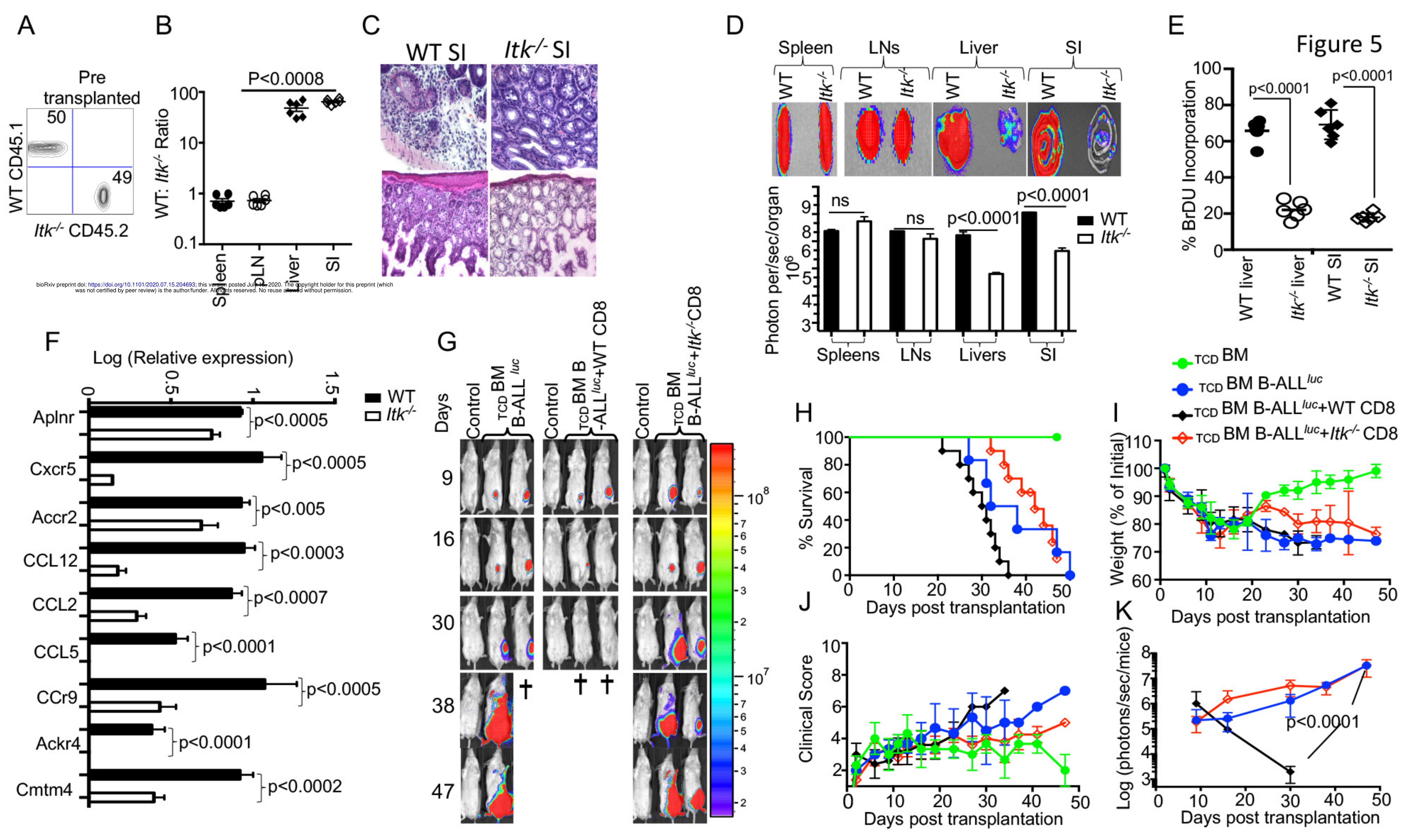


A

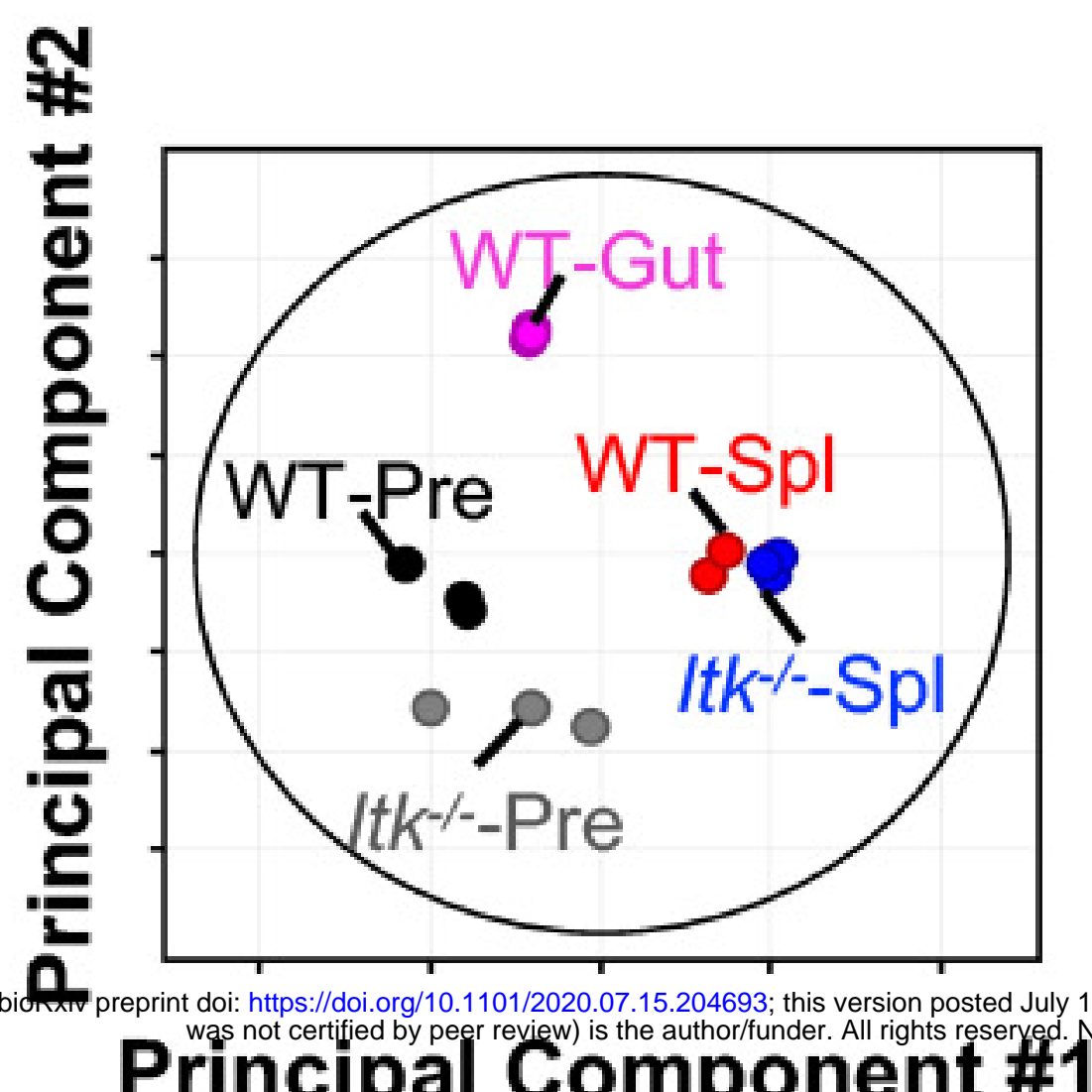

Up-FC(WT-Spl/WT-Pre) Up-FC(WT-Gut/WT-Pre)
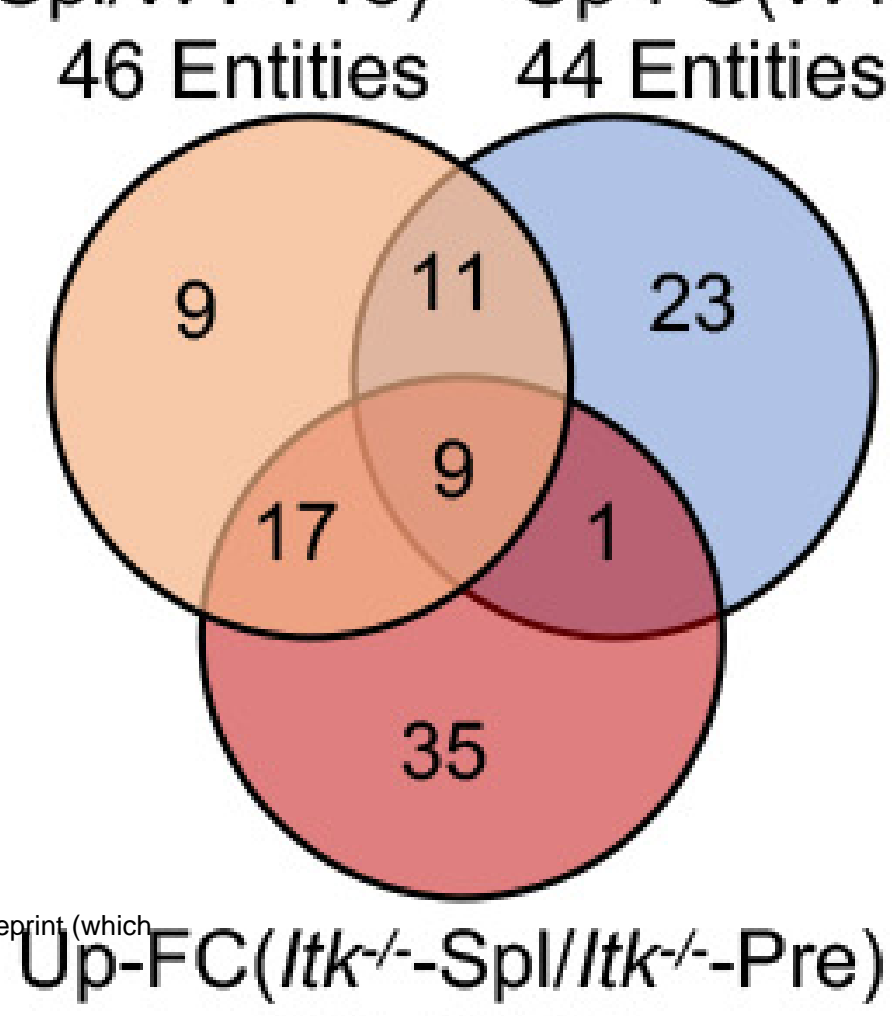

62 Entities

C

Down-FC(WT-Spl/WT-Pre) Down-FC(WT-Gut/WT-Pre)

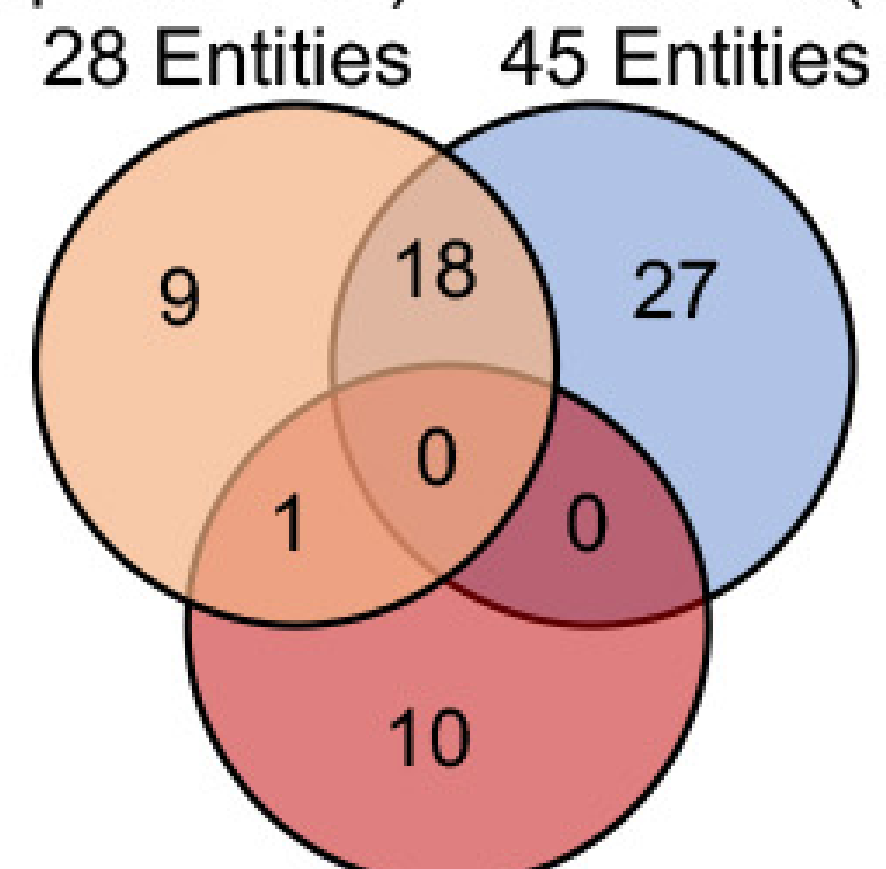

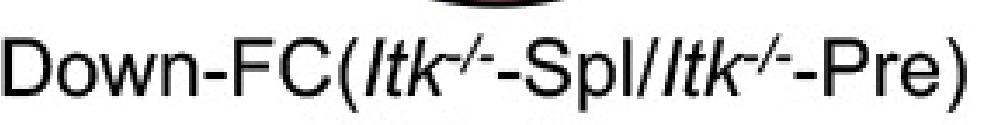
11 Entities

$\mathrm{F}$

Pathway of Differentiated Expression genes Itk $/$ to WT

$$
\text { KEGG pathways }
$$

adjusted $p$-value

Cytokine/Cytokine Receptor Interaction

$7.2 \times 10^{-8}$

Cell Adhesion Molecules

$7.7 \times 10^{-7}$

Graft-Versus-Host Disease

$9.7 \times 10^{-5}$

$3 \times 10^{-3}$
E

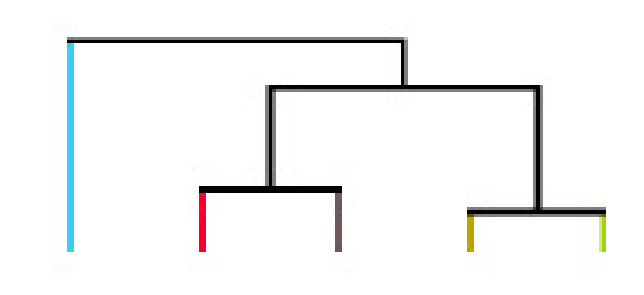

声要

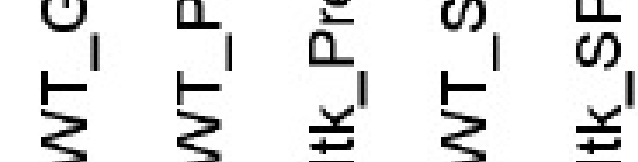

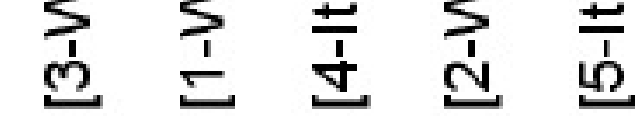

Hspa1b

Hspa1a

Osgin1

Krt8

Lypd8

Krt19

Vil1

Tnfsf9

Cdkn1a

Tigit

Tubb6

Ccl1

Csf2

B4galnt4

Grb7

Phlda1

Hilpda

Lmtk3

Col4

Bcl2a1b

Smim3

Cables 1

Corl2
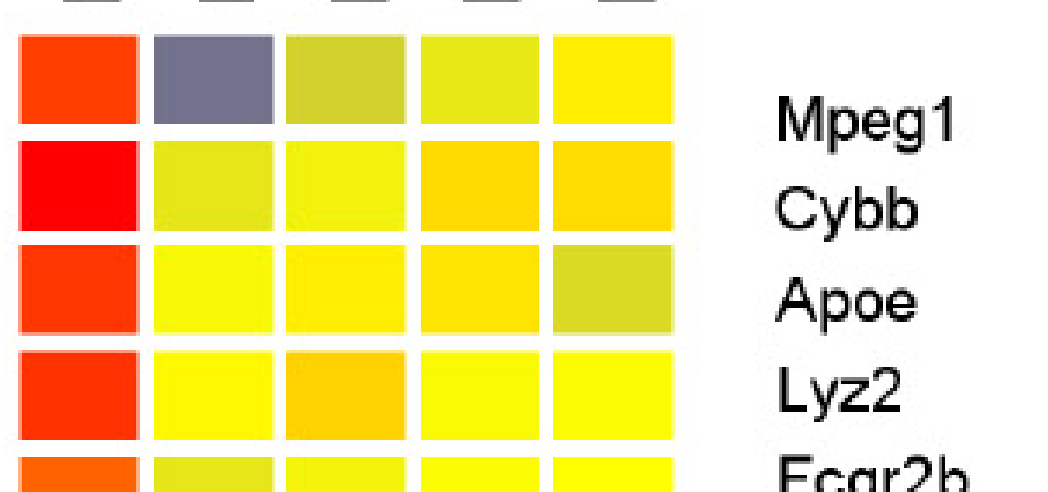

Cybb

Apoe

Fcgr2b

Dok3

Blnk

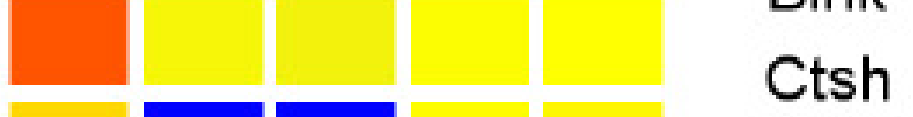

\begin{tabular}{l} 
Iffngr2 \\
\hline
\end{tabular}

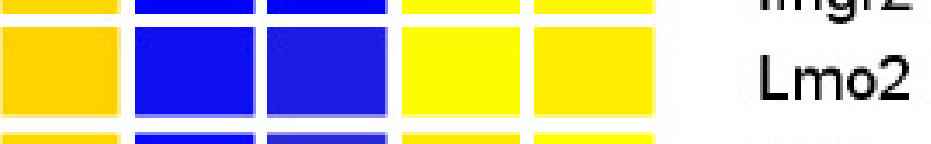

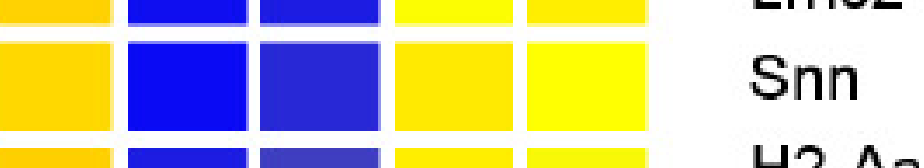

Rnas

TIr9

Cd24a

Mzb1

Dapl1

Cxxc5

Pou2af1

Cnr2

Tgtp1

Nsg2

Tmie

Cxcr5

TIr7

Ms4a4c

TIr1

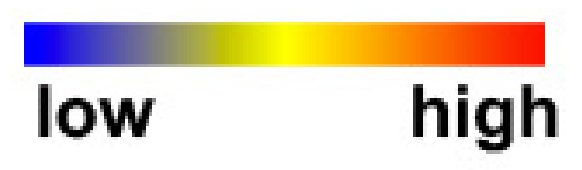

G

Figure 6

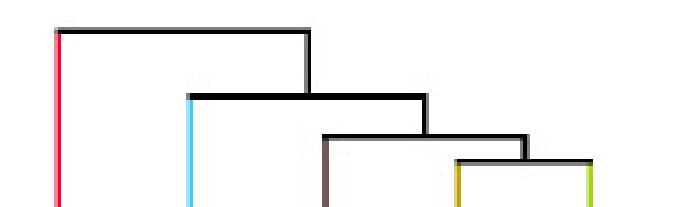

Log (Relative expression)

55

勇竞竞
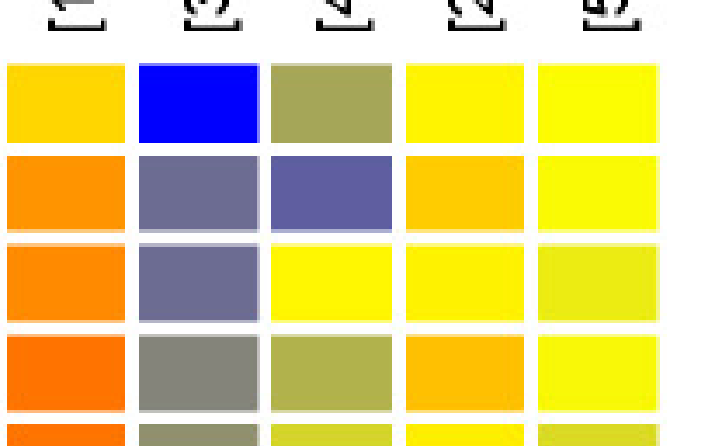

Ccr12 $\mathrm{p}<0.0002$

Hilpda

Phld1- $\mathrm{p}$ < 0.0007

Grb7]-p $<0.007$

ccr9.

Ccr4-

Apoe $]_{p<0.0003}$

Blink ש $] p<0.0003$

Ctsh - $\mathrm{p}<0.0003$

Snn? $p<0.0003$

H2Aa

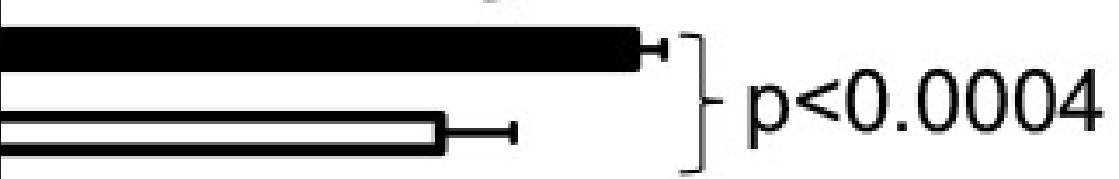

CD24a

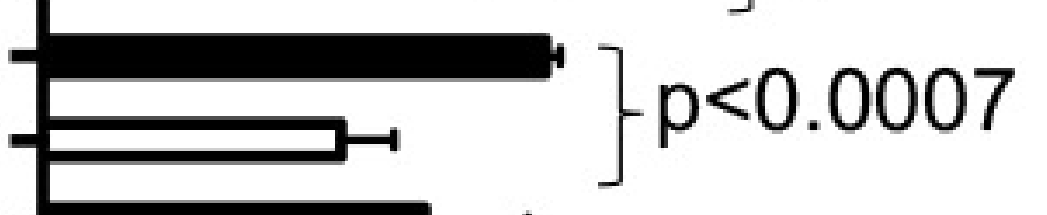

Mzb1

Dapl1-p $\mathrm{p}<0.008$

$\mathrm{CnR} 2$

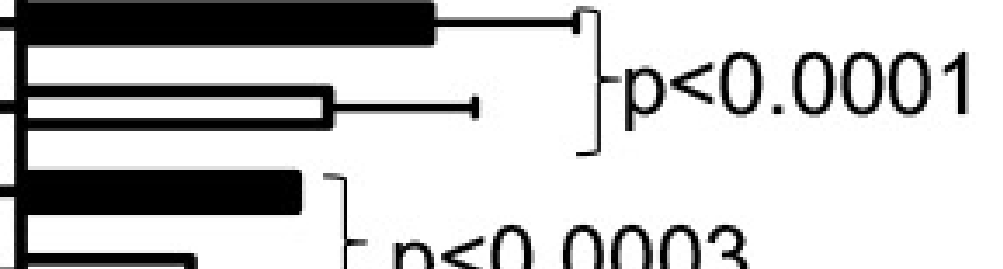

WT $\square \mathrm{Itk}^{-1 /}$

Tgtp1 


\section{A}

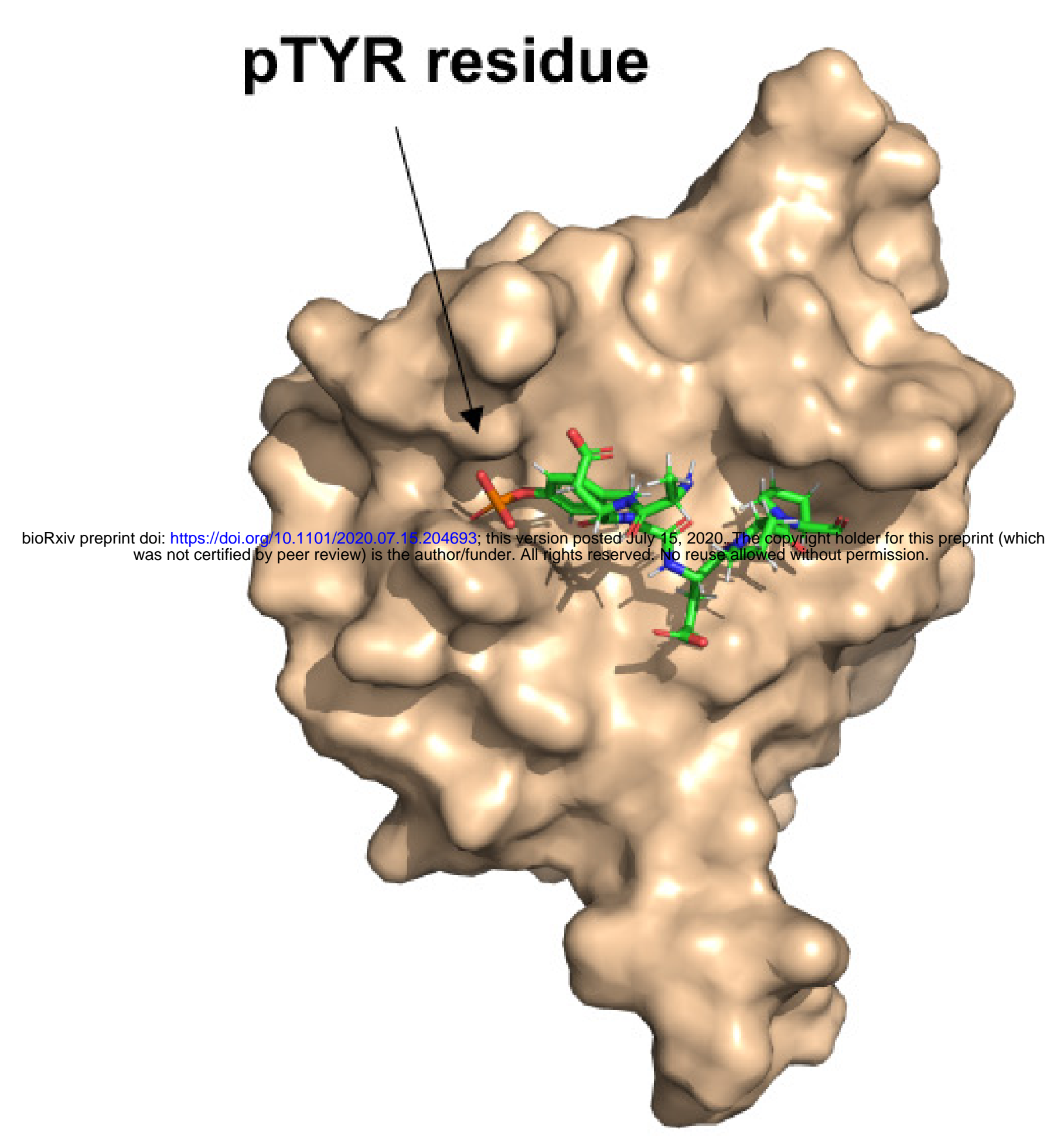

C

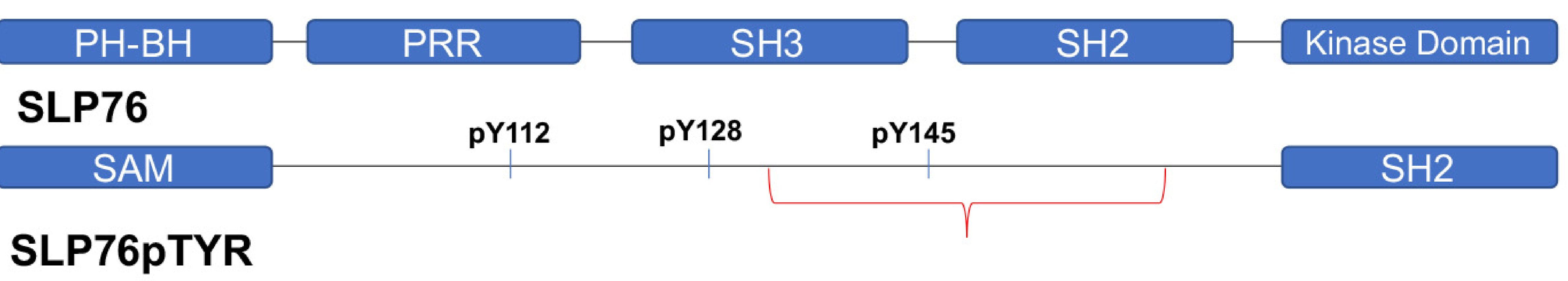

\section{pTYR binding}

pocket

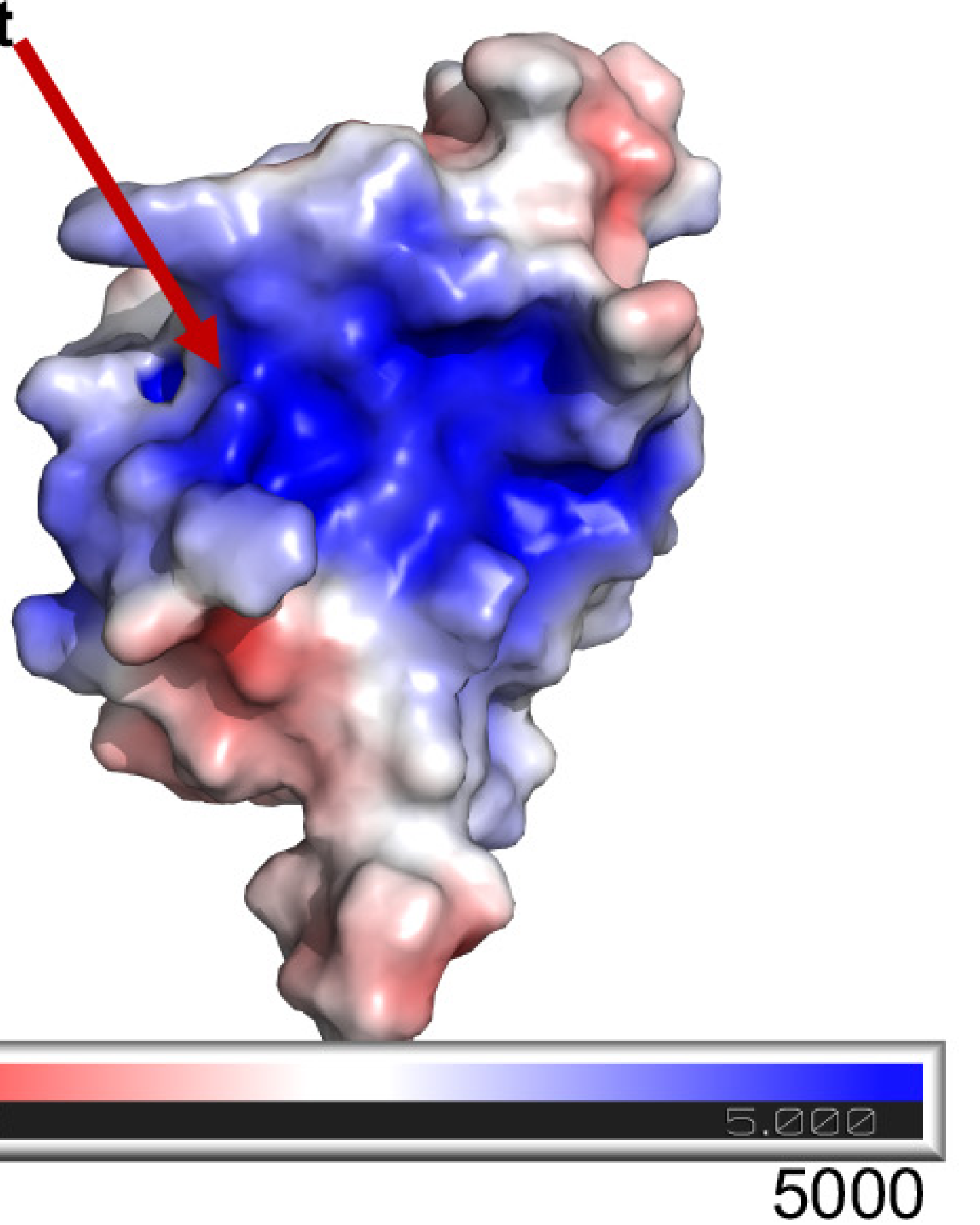

$-5000$

Red $=$ negative surface

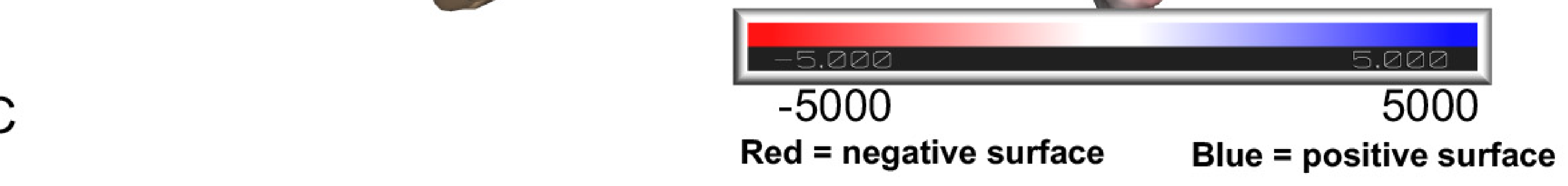

D

E

Figure 7
F

Vehicle -
Nonspecific

SLP76 pTYR ---

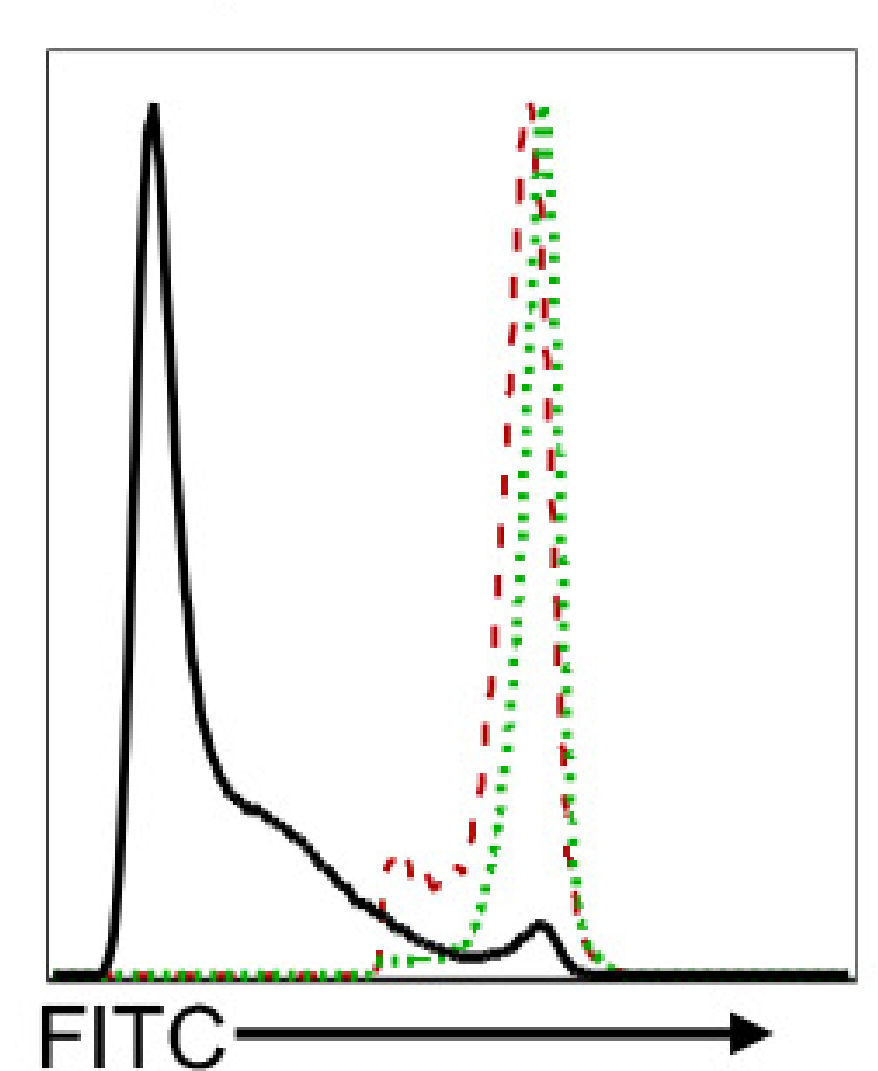

Single cell SLP76pTYR

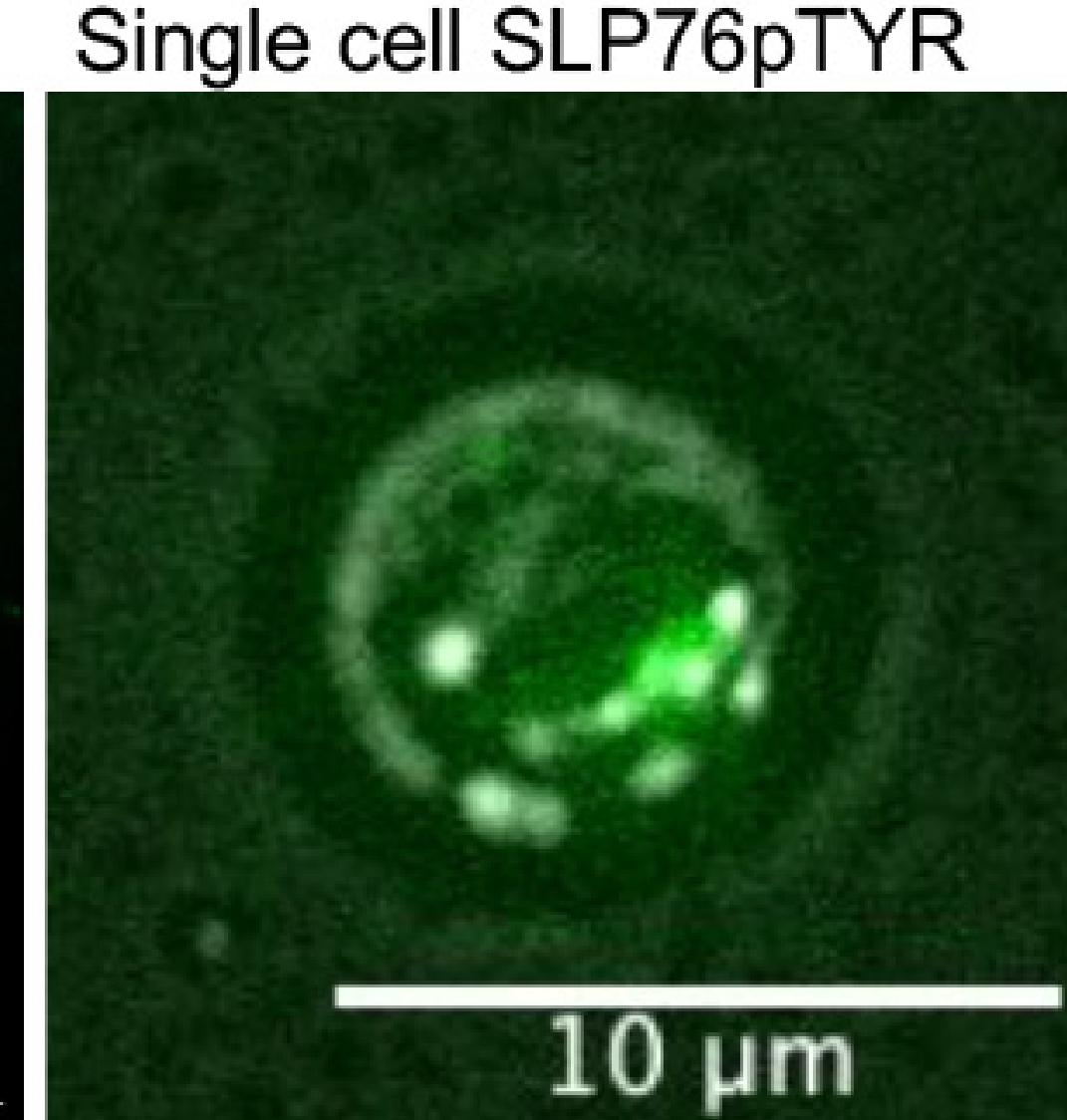

G • Vehicle

$\diamond$ Nonspecific O SLP76 pTYR $p<0.0001$

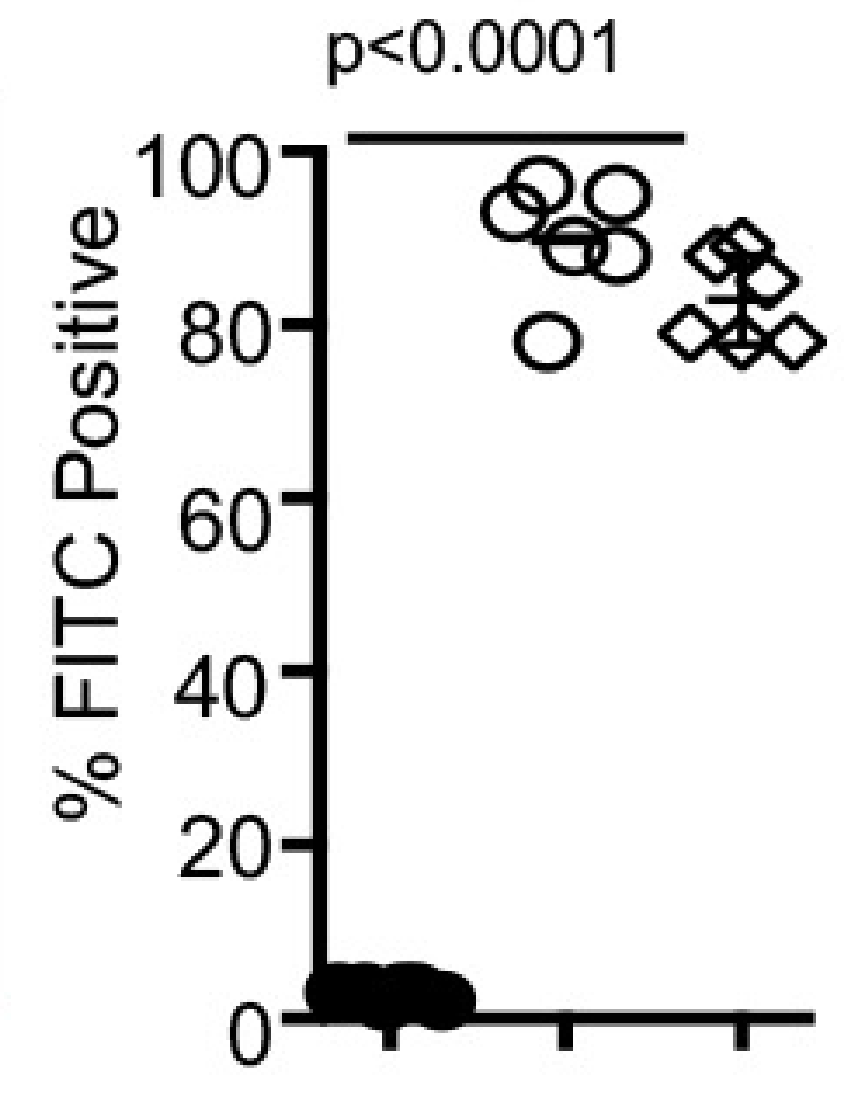

\{FITC Dye - ${ }^{132 N E E E E A P V E D D A D p Y E P P P S N D E E A ~}{ }^{155}\{\{G R K K R R Q R R R P Q\}$ 


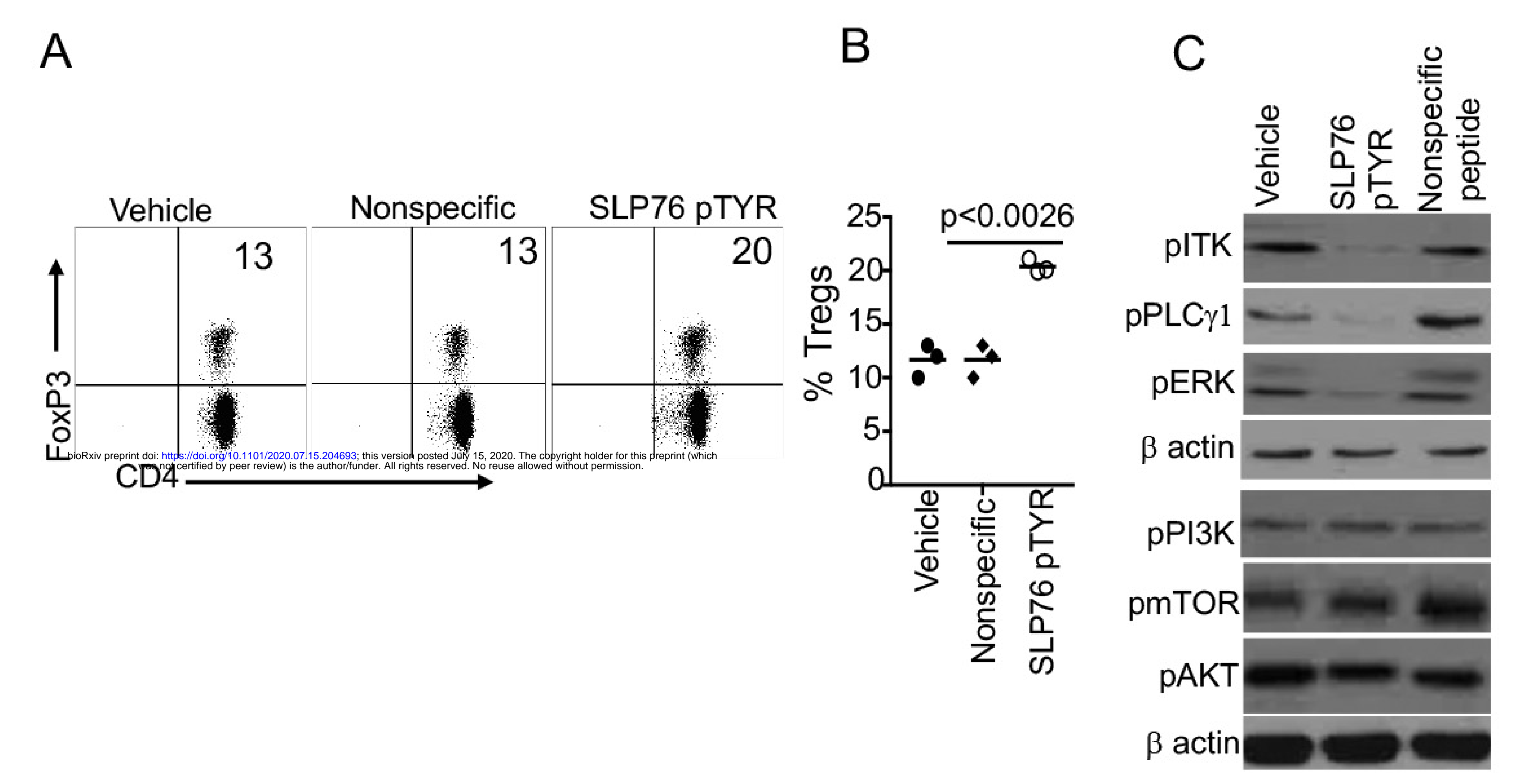

Human GVHD samples

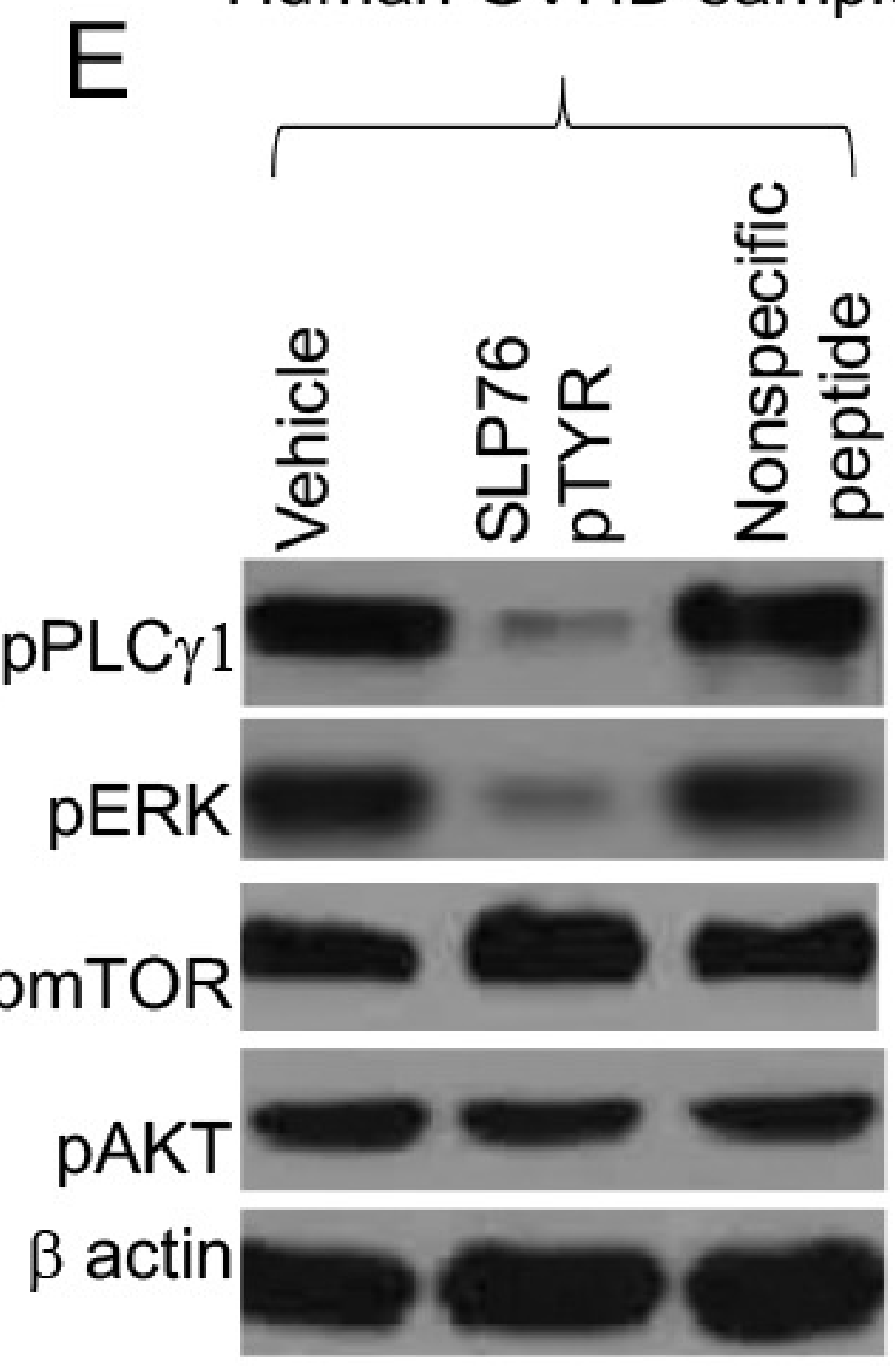

$\mathrm{F}$

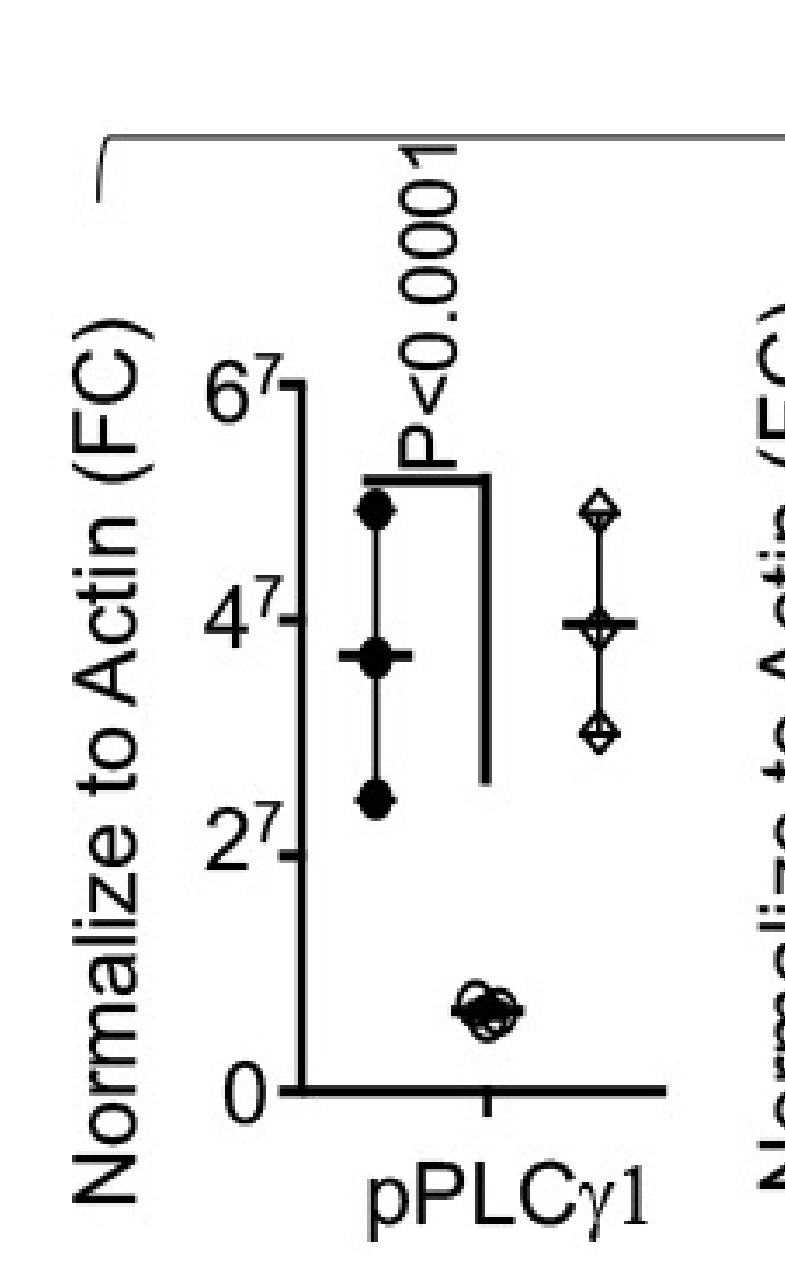

Human

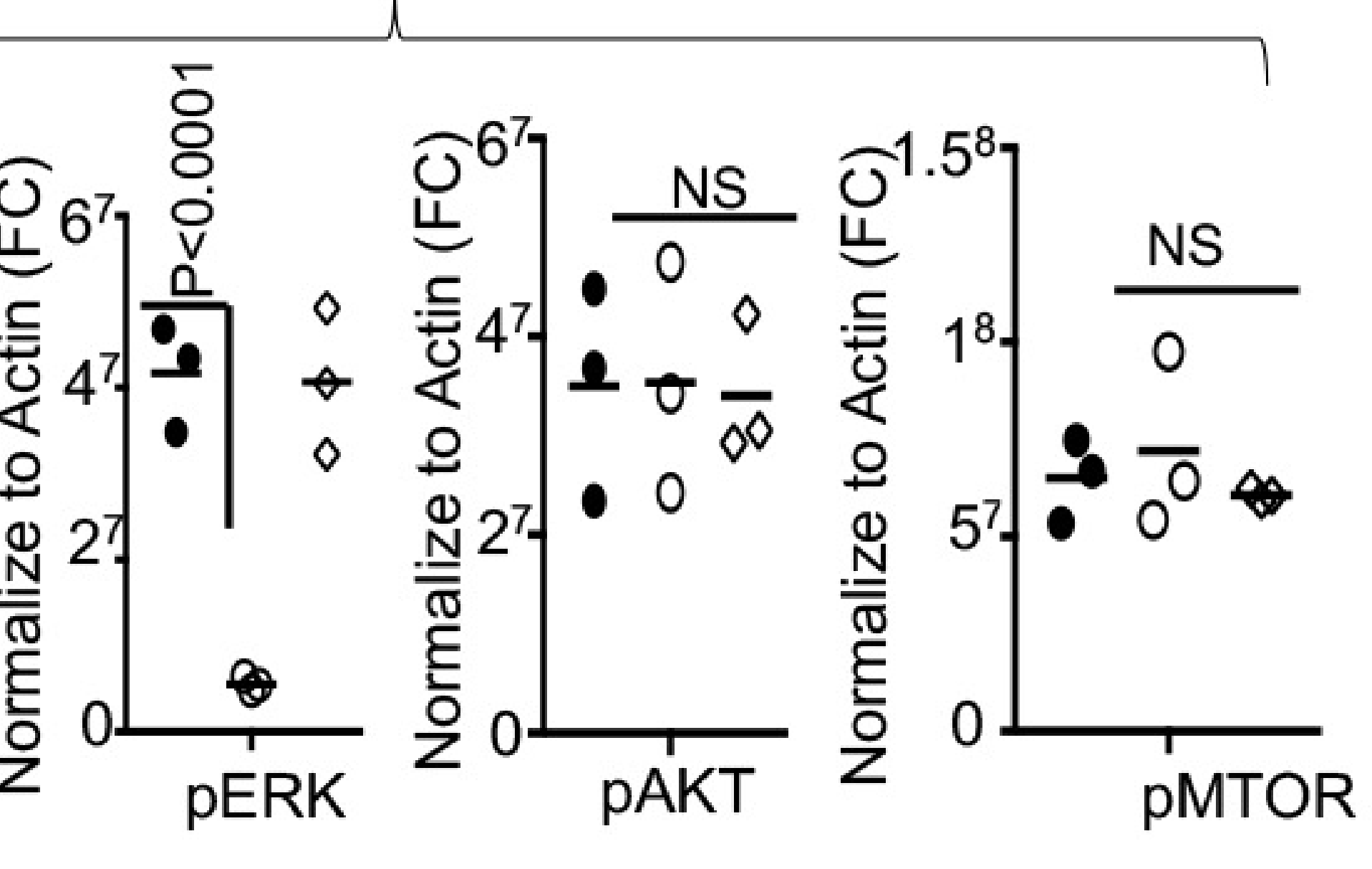

D
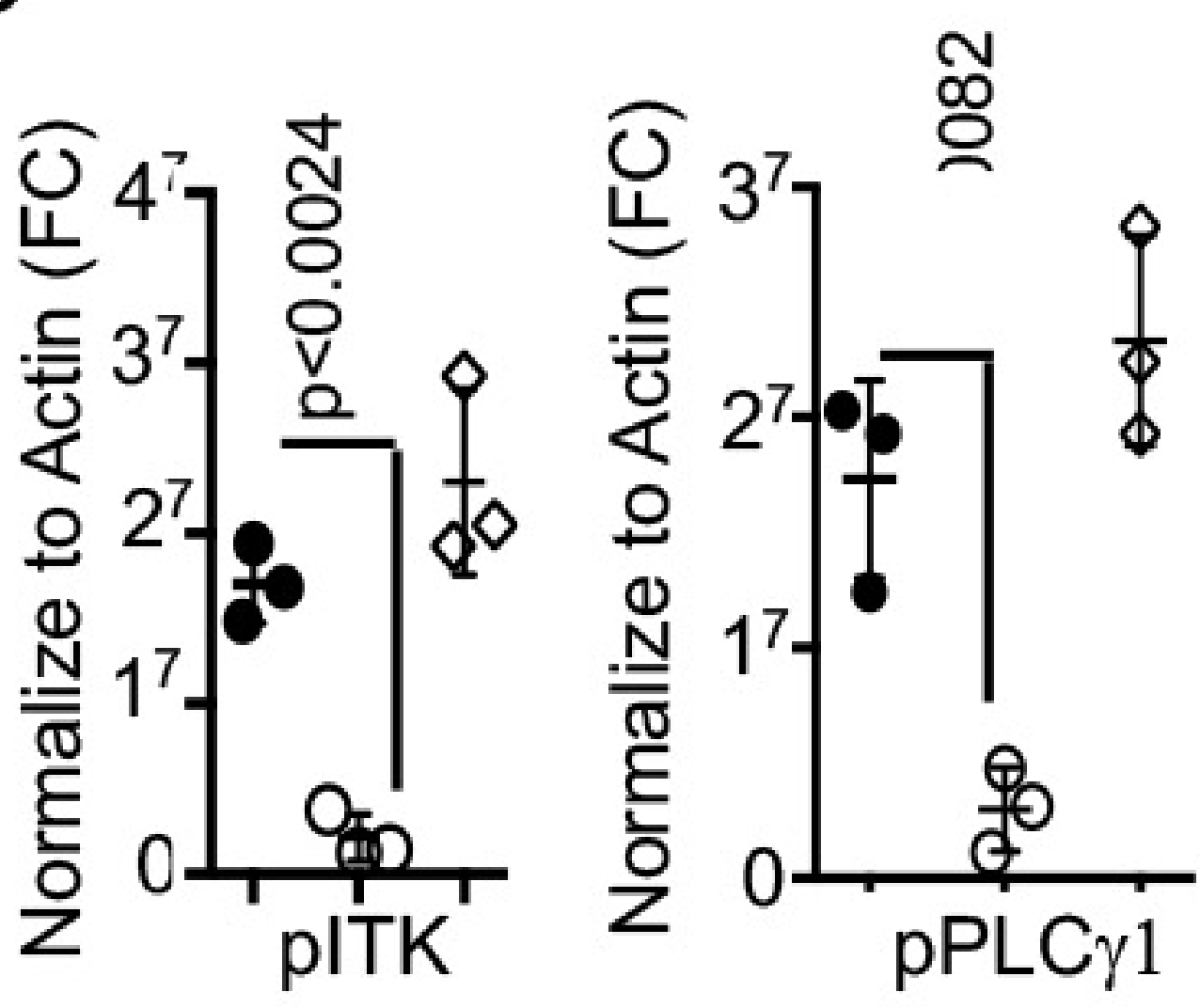

Figure 8

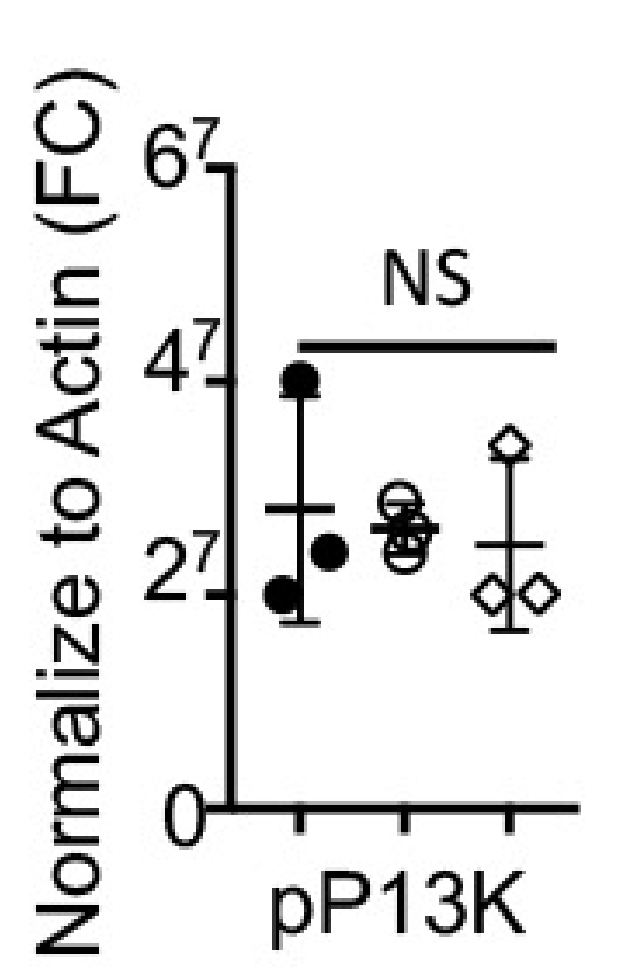

언 $4^{7} 7$ NS
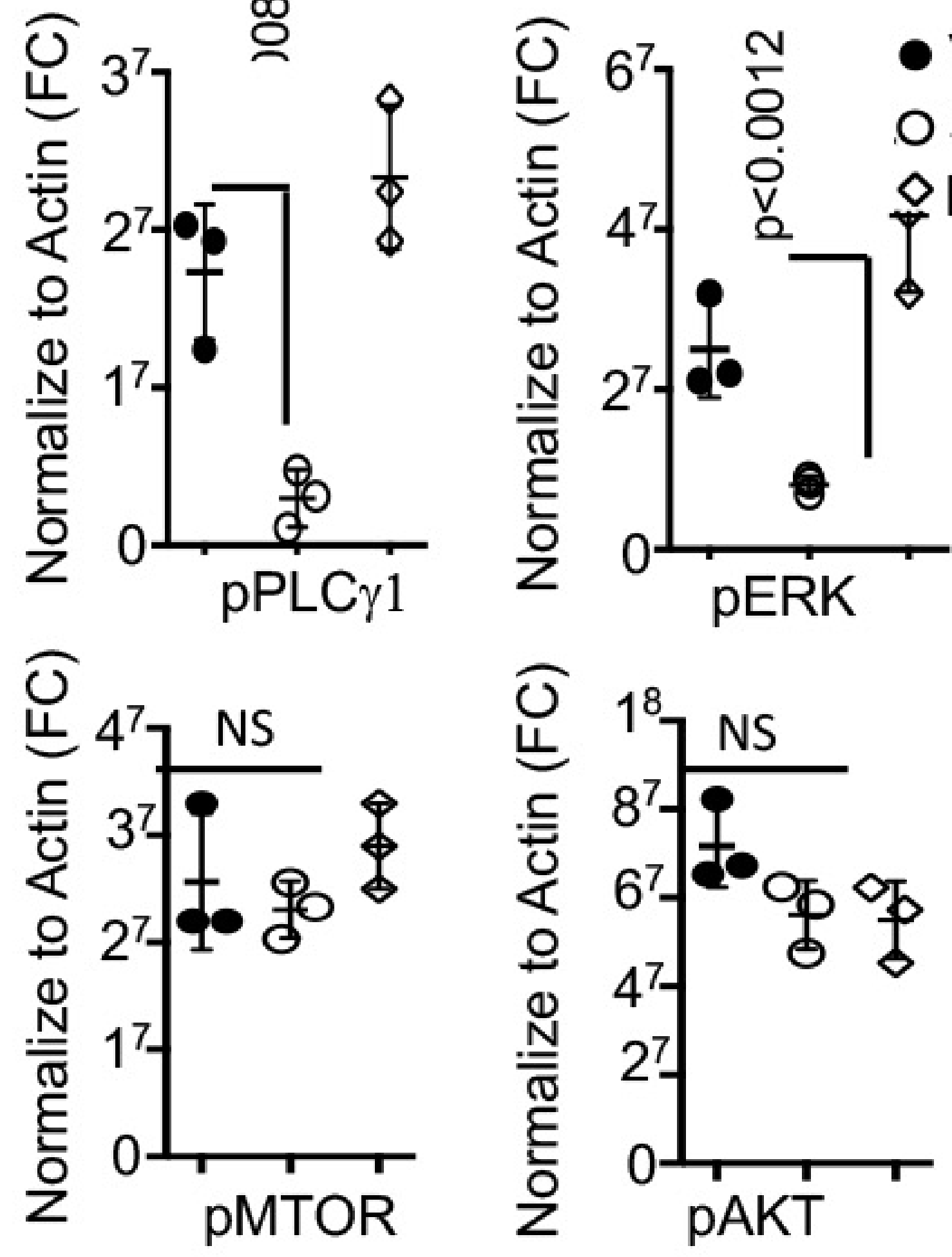

G

Human

Vehicle SLP76 pTYR PMA+I Vehicle SLP76 pTYR PMA+I

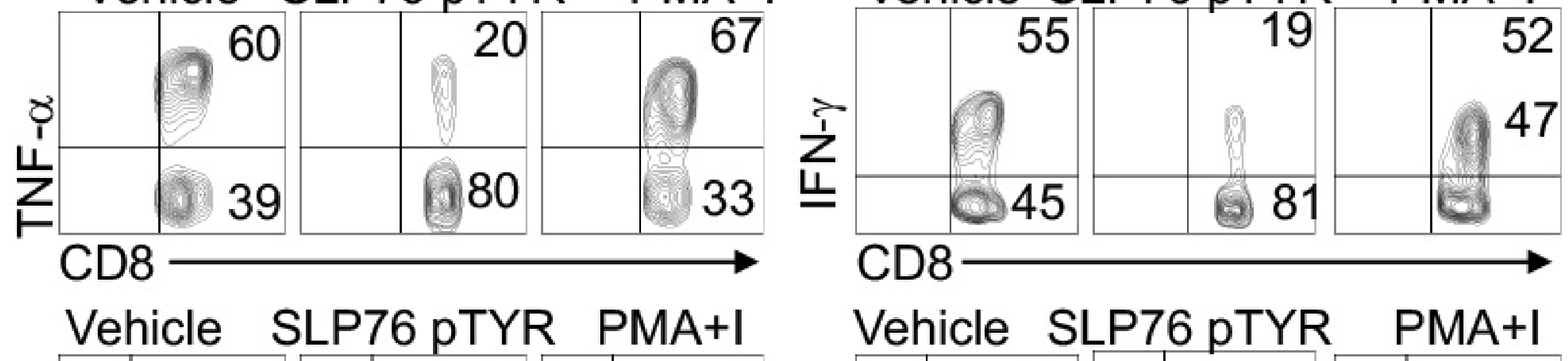

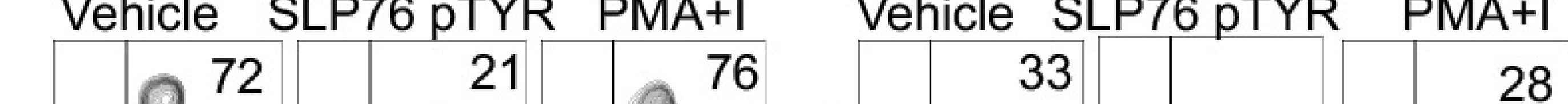

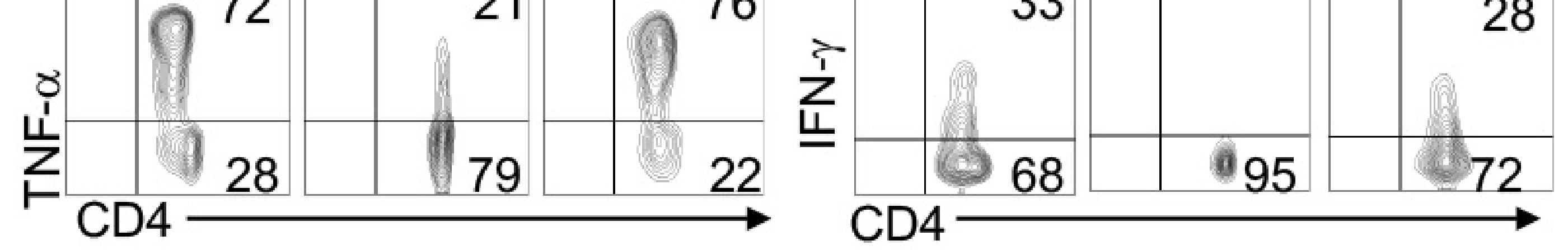


$A$

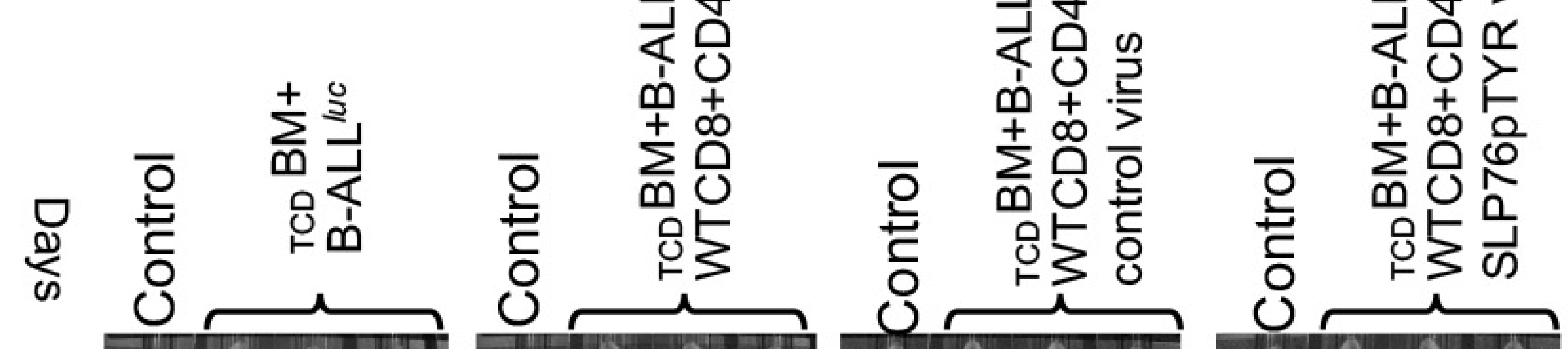

7

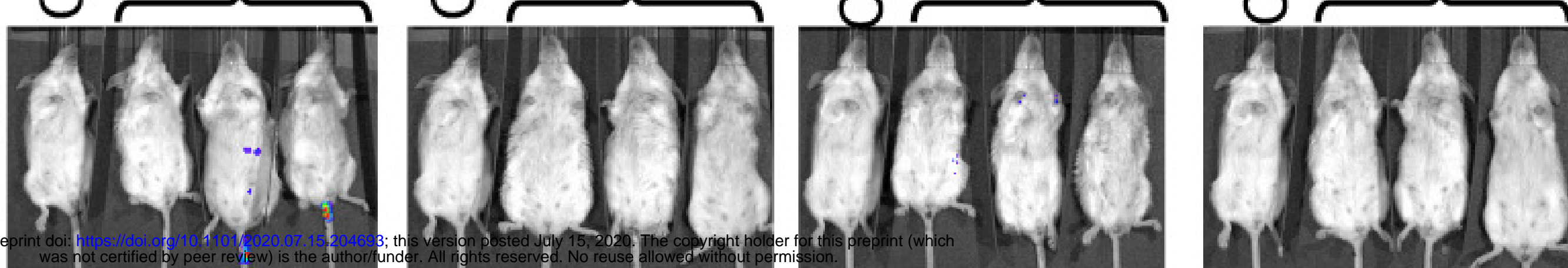

12 .

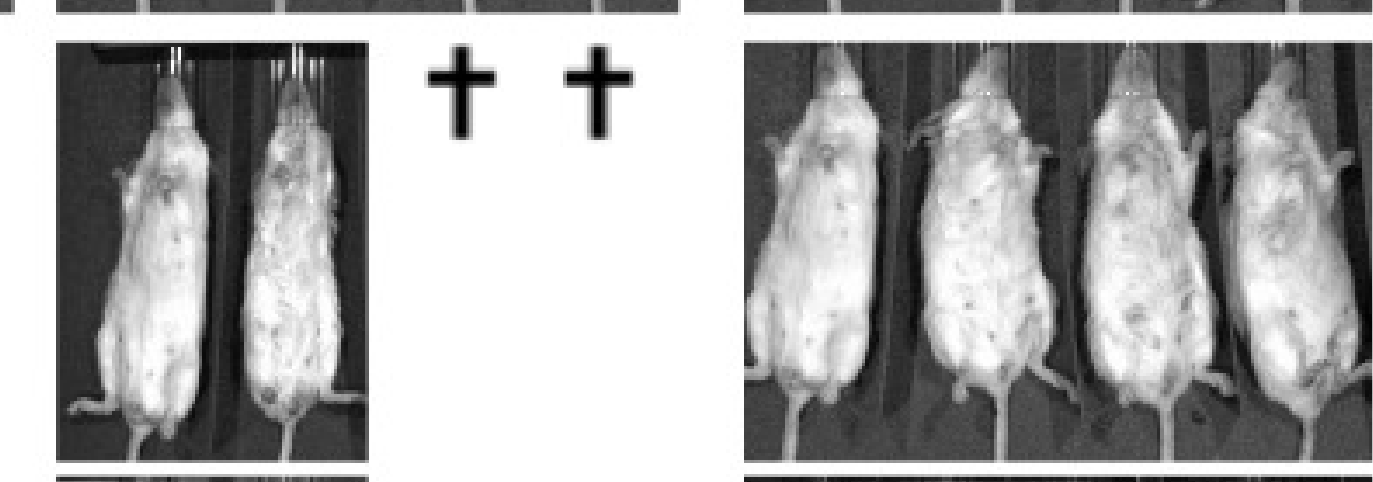

16

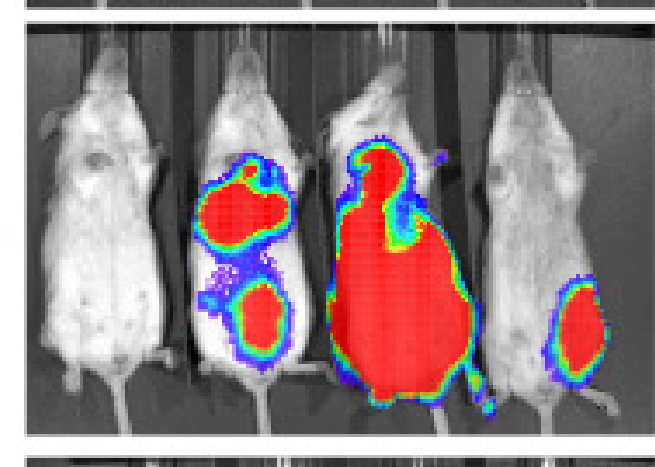

19

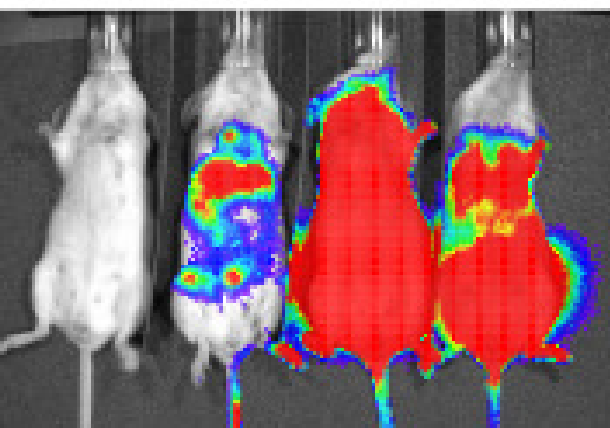

23

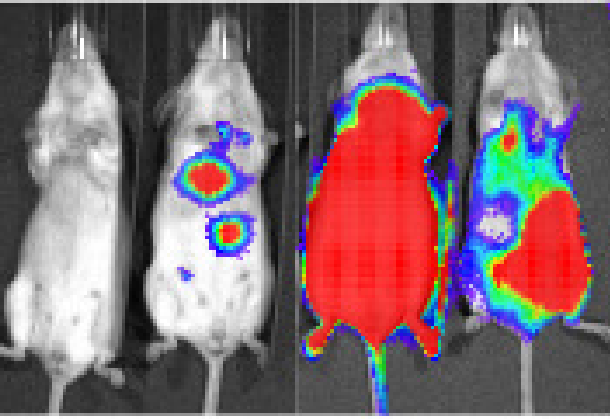

33

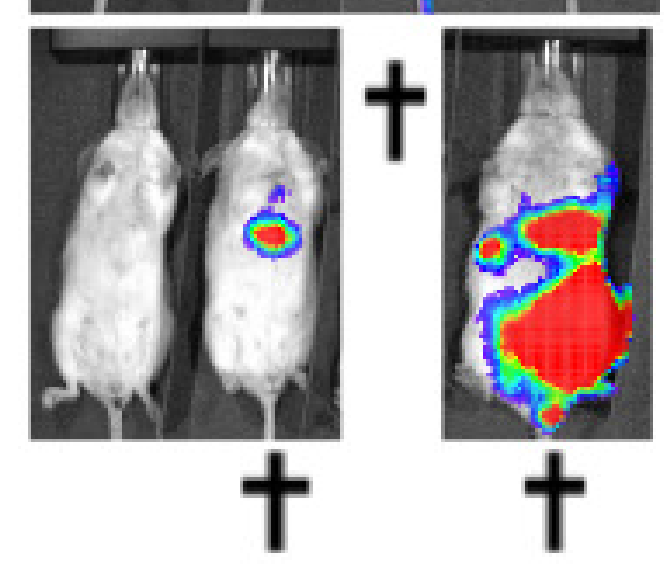

40
B

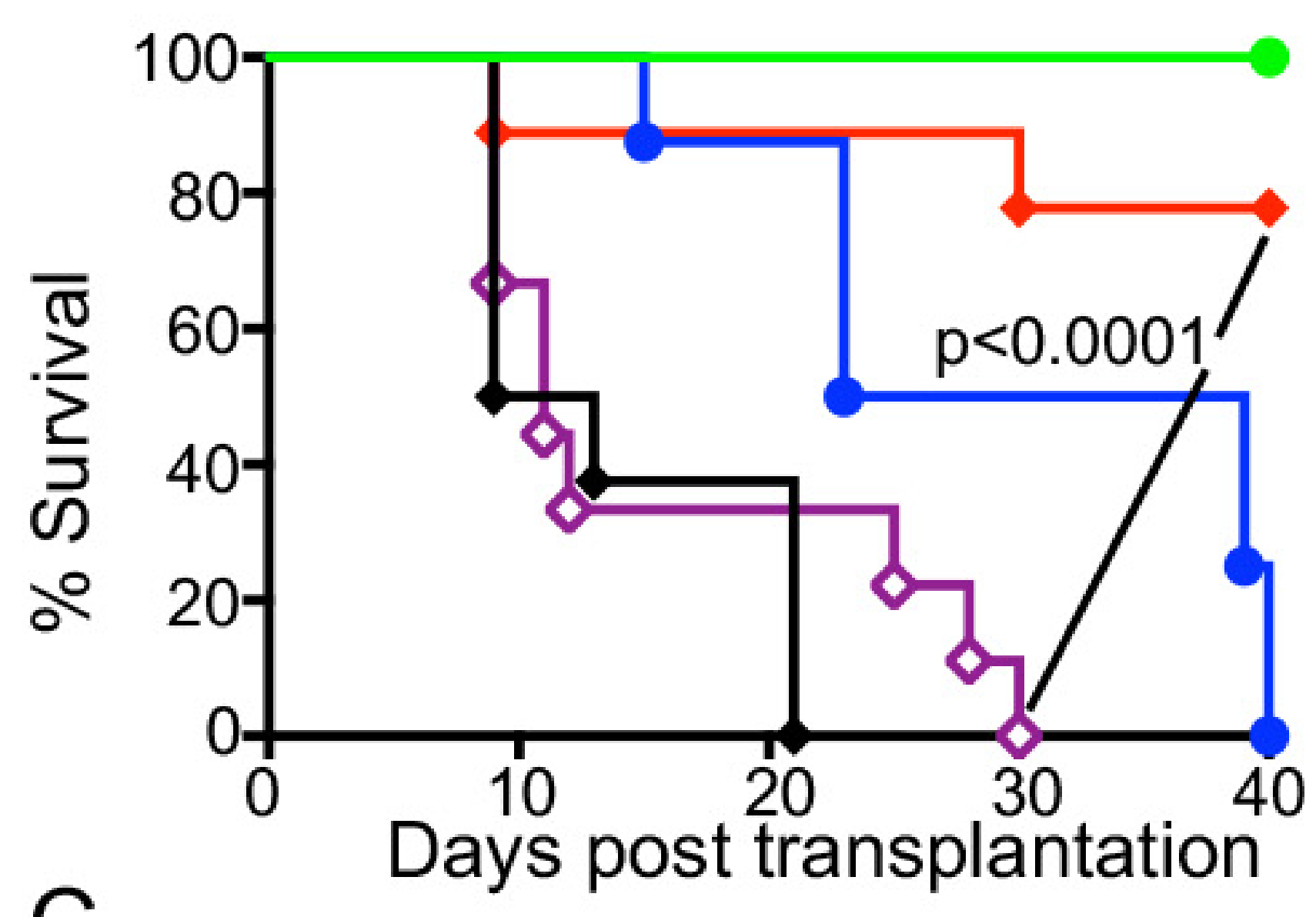

C

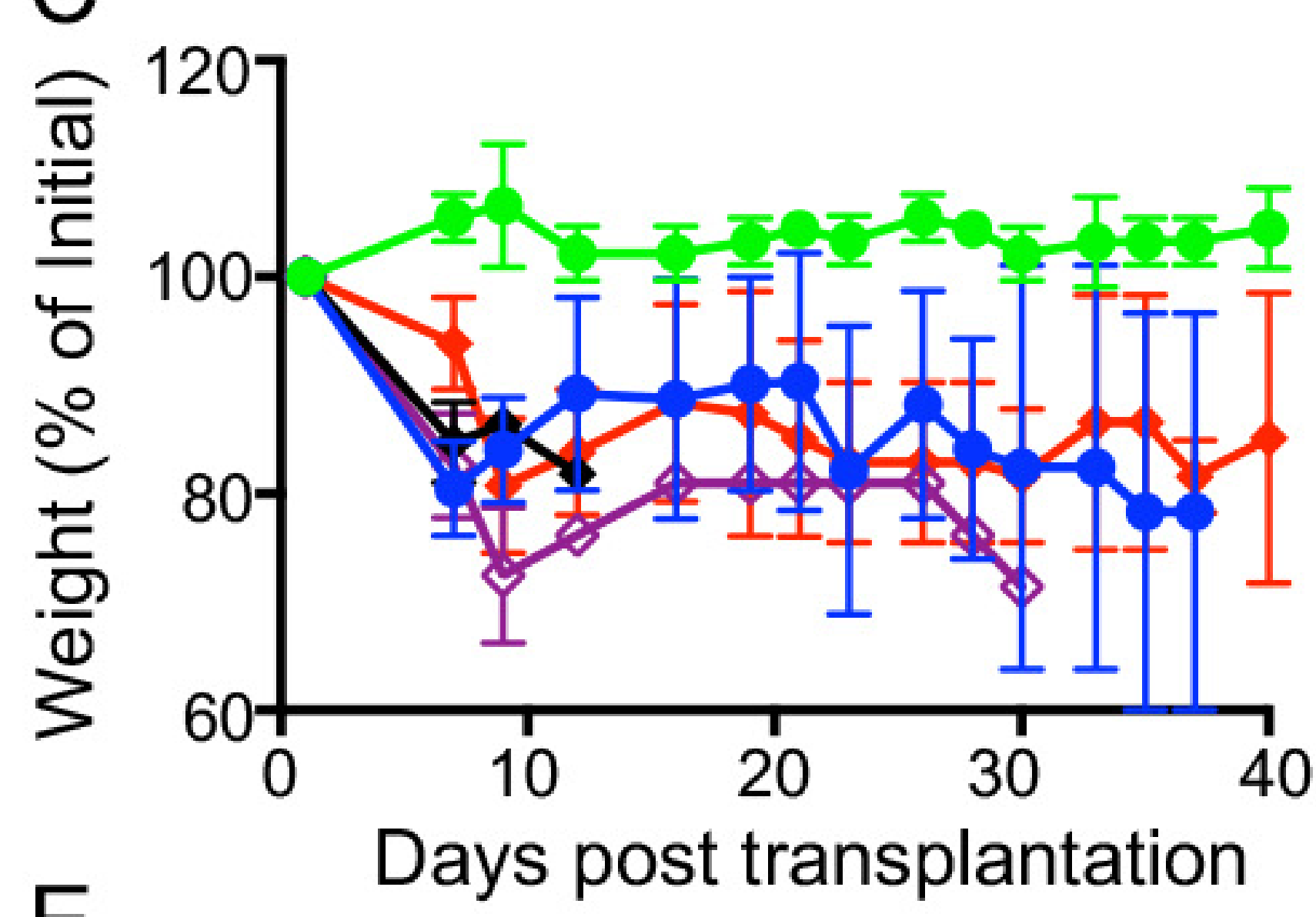

E

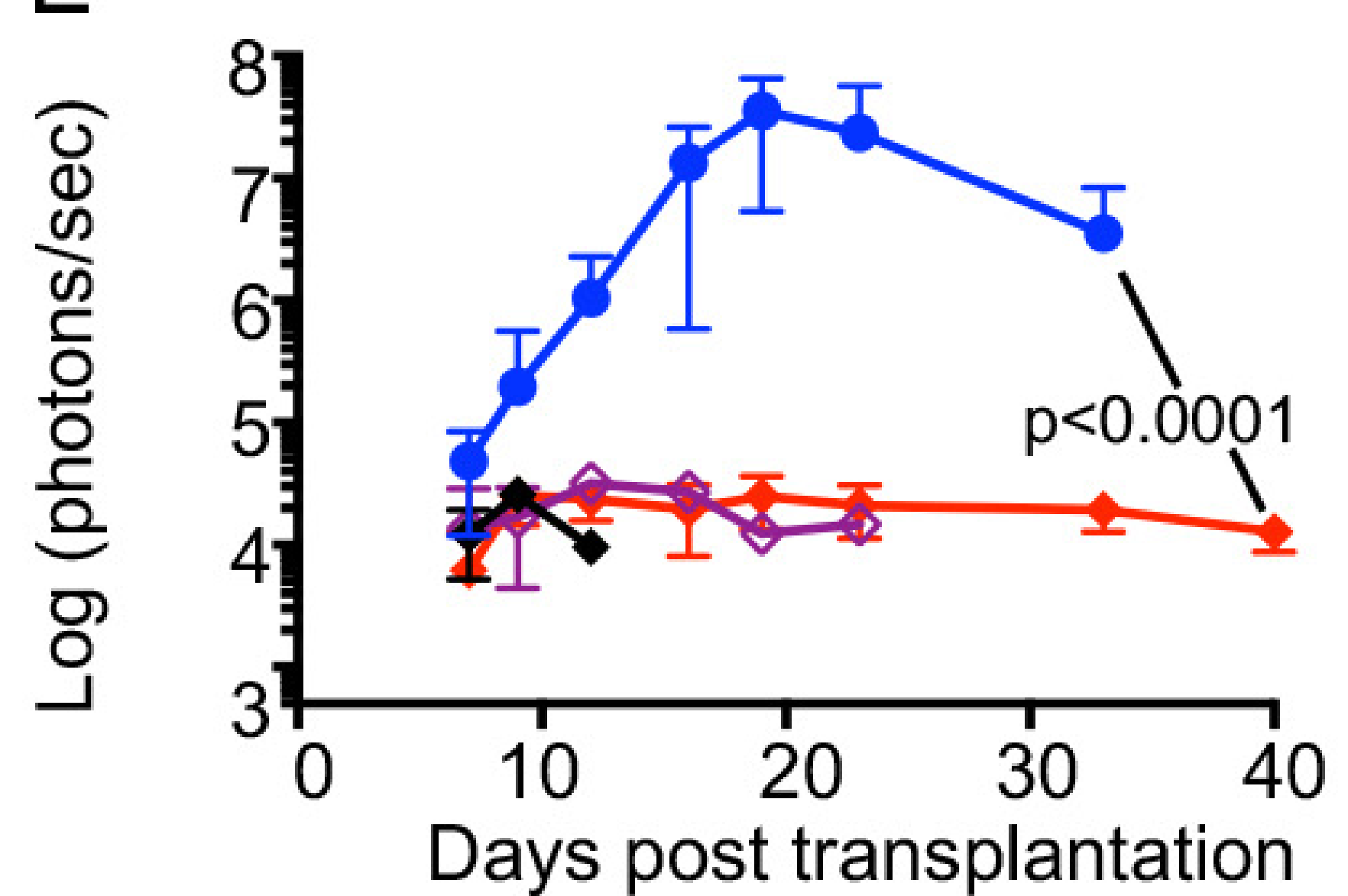

TCD BM

Figure 9

- TCD BM+ B-ALL ${ }^{l u c}$

$\rightarrow T C D$ BM+B-ALL ${ }^{l u c}+W T C D 8+C D 4$

$\checkmark T C D B M+B-A L L^{l u c}+W T C D 8+C D 4+$ control virus $\rightarrow-T C D B M+B-A L L^{l u c}+$ WTCD8+CD4+ SLP76pTYR virus

D
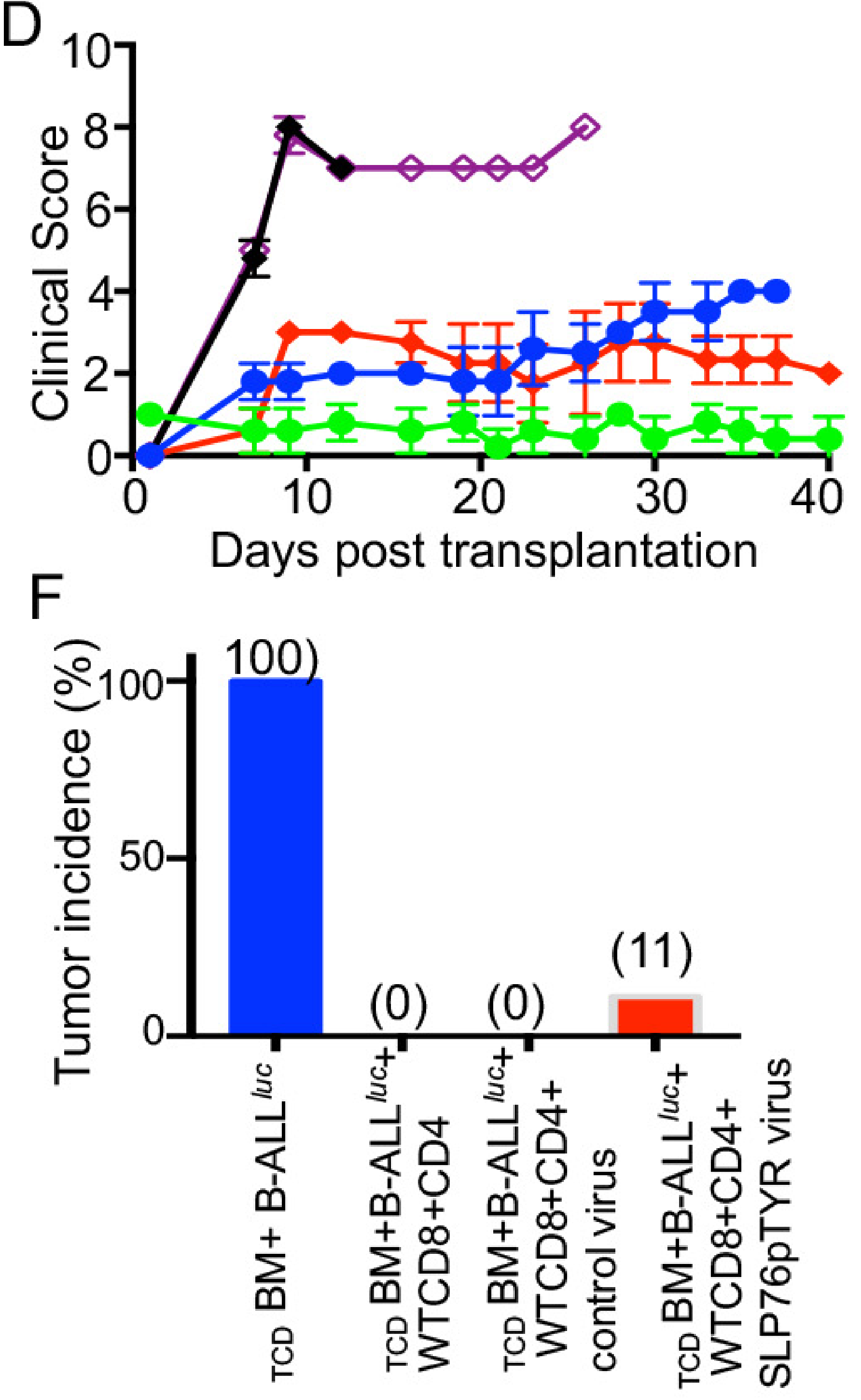